\title{
Selective contracting by health insurers
}

Citation for published version (APA):

Bes, R. E. (2018). Selective contracting by health insurers: the perspective of enrolees. [Doctoral Thesis, Maastricht University]. Maastricht University. https://doi.org/10.26481/dis.20180118rb

Document status and date:

Published: 01/01/2018

DOI:

10.26481/dis.20180118rb

Document Version:

Publisher's PDF, also known as Version of record

\section{Please check the document version of this publication:}

- A submitted manuscript is the version of the article upon submission and before peer-review. There can be important differences between the submitted version and the official published version of record.

People interested in the research are advised to contact the author for the final version of the publication, or visit the DOI to the publisher's website.

- The final author version and the galley proof are versions of the publication after peer review.

- The final published version features the final layout of the paper including the volume, issue and page numbers.

Link to publication

\footnotetext{
General rights rights.

- You may freely distribute the URL identifying the publication in the public portal. please follow below link for the End User Agreement:

www.umlib.nl/taverne-license

Take down policy

If you believe that this document breaches copyright please contact us at:

repository@maastrichtuniversity.nl

providing details and we will investigate your claim.
}

Copyright and moral rights for the publications made accessible in the public portal are retained by the authors and/or other copyright owners and it is a condition of accessing publications that users recognise and abide by the legal requirements associated with these

- Users may download and print one copy of any publication from the public portal for the purpose of private study or research.

- You may not further distribute the material or use it for any profit-making activity or commercial gain

If the publication is distributed under the terms of Article $25 \mathrm{fa}$ of the Dutch Copyright Act, indicated by the "Taverne" license above, 
Selective contracting by health insurers:

\section{the perspective of enrolees}



Selective contracting by health insurers:

the perspective of enrolees

Romy Evelien Bes 
Studies in this thesis are mainly based on information gathered in NIVEL's "Insurance Panel". This panel is financially supported by Cooperation VGZ.

The research presented in this thesis was conducted at NIVEL, Netherlands Institute for Health Services Research, Utrecht, the Netherlands. NIVEL participates in the Netherlands School of Primary Care Research (CaRe), which is acknowledged by the Royal Netherlands Academy of Arts and Sciences (KNAW).

ISBN: 978-94-6122-456-9

\section{www.nivel.nl}

nivel@nivel.nl

Telephone +31302729700

Fax +31302729729

C 2017 NIVEL, P.O. Box 1568, 3500 BN Utrecht

Cover design : Romy Bes

Lay out : : Ria Karamat Ali and Christel van Well

Printed by : GVO drukkers \& vormgevers B.V. te Ede

Data from this publication may be reproduced by mentioning NIVEL and the name of the publication. The use of numbers and / or text as explanatory or support in articles, books and theses is also permitted, provided the source is clearly stated. 


\title{
Selective contracting by health insurers: the perspective of enrolees
}

\author{
PROEFSCHRIFT \\ ter verkrijging van de graad van doctor aan de Universiteit Maastricht, \\ op gezag van de Rector Magnificus, Prof. dr. Rianne M. Letschert \\ volgens het besluit van het College van Decanen, \\ in het openbaar te verdedigen \\ op donderdag 18 januari 2018 om 12.00 uur
}

door

Romy Evelien Bes 


\section{Promotoren:}

Prof. dr. J.D. de Jong

Prof. dr. P.P. Groenewegen, Universiteit Utrecht

Prof. dr. E.C. Curfs, Open Universiteit Heerlen

\section{Beoordelingscommissie:}

Prof. dr. D. Ruwaard (Voorzitter)

Prof. dr. J.A.M. Maarse

Prof. dr. W.N.J. Groot

Prof. dr. P. Jeurissen, Radboud Universiteit Nijmegen

Prof. dr. A. Klink, Vrije Universiteit Amsterdam 


\section{Contents}

$\begin{array}{lll}\text { Chapter } 1 \text { General introduction } & 7\end{array}$

Chapter 2 Selective contracting and channelling patients to preferred providers: a scoping review 25

Chapter 3 Health plan choice in the Netherlands: restrictive health plans preferred by young and healthy individuals 53

Chapter 4 Acceptance of selective contracting: the role of trust in the health insurer

Chapter 5 Ranking sources of hospital quality information for orthopaedic surgery patients: Consequences for the system of managed competition

Chapter 6 Acceptance of selective contracting in health insurance: importance of information

Chapter 7 Advice from the health insurer as a channelling strategy: a natural experiment at a Dutch health insurance company

Chapter 8 Summary and general discussion 155

Samenvatting 173

Valorisation 191

Dankwoord

Curriculum Vitae 201 


\section{Chapter 1}

General introduction 
This thesis describes selective contracting by health insurers in the context of a health care system based on managed competition. In this research, we focus on the perspective of enrolees. This thesis aims to answer the question: How can we explain the acceptance of selective contracting and channelling enrolees to preferred care providers? It will not form any normative judgement on whether or not selective contracting or even managed competition in health care is desirable.

\section{Background}

\section{Managed competition}

Health care reforms have been implemented in several countries over the last decades in order to contain increasing health care costs and improve quality of care [1-4]. A common aspect of most of these reforms is the shift from a supply-oriented to a demand-oriented health care system. In several countries, for instance the Netherlands, Germany and Switzerland, these reforms were based on the theory of managed competition $[4,5]$. The theory of managed competition was developed by Alain Enthoven [6] (important aspects of his theory are listed in Box 1). The goal of managed competition is to improve the quality of care by stimulating competition between third-party purchasers and care providers. The idea is that the third-party purchasers, in most cases health insurers, prudently purchase care on behalf of their enrolees. Health insurers compete with each other for enrolees who have the option to switch health insurers, for instance when they are not satisfied or can get a better offer elsewhere. This is an incentive for health insurers to provide their enrolees with the best offer, i.e. good quality of care for a good price. In order to realise this, they have to negotiate with care providers on price and quality of care. Competition between care providers is stimulated, since health insurers are allowed to selectively contract care providers. When health insurers are able to channel their enrolees to contracted care providers they have a stronger bargaining position in negotiations with care providers $[7,8]$. This last aspect is where this thesis will focus on. Research will be conducted in the Netherlands, where managed competition was implemented in 2006. The Dutch health care system is unique, since it is the first country that consistently implements Enthoven's model of a health care system based on managed competition [6,9]. Findings in this thesis are relevant for all countries where a system of managed competition is implemented or where policy makers consider to implement it in the future. 
Box 1 Important aspects of managed competition (from: Enthoven, 1993)

The health plan market needs to be managed by a sponsor (e.g. employer, government, welfare trusts)

Sponsors set rules for equity:

- Every eligible person is covered or at least is offered coverage on attractive terms

- Health plans accept all eligible persons who choose them

- Every eligible person has subsidized access to the lowest-priced plan

- Coverage is continuous

- Community rating is established: the same premium is paid for the same coverage regardless of health status

- No exclusions or limitations are placed on coverage of pre-existing conditions

Sponsors select participating plans

Sponsors manage enrolment process

Sponsors create price-elastic demand:

- Employer/sponsor contributions must not exceed the lowest priced plan

- Standardized coverage contract to facilitate price comparisons and focus comparisons on price and quality

- Provide quality information on health plans

- Choice of plans at individual level

Sponsors manage risk selection:

- Single point of entry and health plan must accept al enrolees and is not allowed to drop enrolees

- Standardized coverage contract

- Compensate health plans for risks (risk equalization)

- Monitoring of enrolment patterns for evidence of risk selection

- Monitoring of specialty care and quality

\section{Managed competition in the Netherlands}

In 2006, the Health Insurance Act (HIA) and the Health Care Market Regulation Act were introduced in the Netherlands. The HIA was a major step towards implementing managed competition [10, 11]. Before 2006 in the Netherlands, low and middle income households had a mandatory social health insurance and high income households had voluntary private health insurance. Since the reform, all health insurers are private health insurers and there is standardized coverage in the form of a basic benefits package [9]. All Dutch residents are required by law to purchase a basic benefits package at a community rated premium [9, 12]. The contents of the basic benefits package are determined by the government. Contents include for instance medical care by general practitioners, medical specialists and midwives. Some care is limited to a maximum number of treatments or a certain 
price or reserved for chronic conditions, for instance physical therapy is reimbursed for people with a chronic condition, from the $21^{\text {st }}$ treatment up. All health insurers have to offer this basic benefits package. Note that contents are specified in terms of care, not providers. Health insurers are free to selectively contract care providers for the delivery of care reimbursed from the basic benefits package. The basic benefits package can differ between health insurers in price and in contracted care providers, not in terms of care. Most health insurers offer two types of health plans: in kind (selective contracting) and by refund. The refund type health plan reimburses all care providers up to the market rate. Additionally, health insurers offer voluntary insurance for supplementary benefits packages. With these, enrolees can expand their coverage [5].

Every year, enrolees are allowed to switch health plans. It is mandatory for health insurers to accept all applicants for the basic benefits package. A risk equalization scheme compensates health insurers for enrolees with predictably high medical costs and prevents risk selection. Low income households are compensated for health plan costs by income related health plan subsidies. To shift health care costs and provide an incentive for enrolees to only seek care when needed, the government implemented a yearly mandatory deductible (€385 in 2017). The deductible only applies to care that is reimbursed from the basic benefits package, not supplementary benefits. There are a few exceptions, for instance general practitioner's care, midwifery care and care for children under 18 are excluded from this deductible. It is possible for enrolees to raise their deductible with a maximum of $€ 500$ on top of their mandatory deductible, in exchange for a lower monthly premium. Furthermore, it is typical for the Dutch health care system that GPs have a gatekeeper function. This means that patients first need to go to their GP, who decides whether specialist treatment is needed $[5,13]$. Important aspects of the Dutch health care system are listed in Box 2.

In the Netherlands, the system of managed competition was introduced in steps. Before the HIA was introduced, health care prices were regulated by the government. Currently, hospital care is being deregulated, which means that health insurers can negotiate with care providers on volume, price and quality of delivered care [14]. In 2006, when the HIA was introduced, only $10 \%$ of the prices of hospital care were freely negotiable, this has increased to 70\% since 2013 [15]. 
Box 2 Important aspects of the Dutch health care system based on managed competition

The Dutch government functions as sponsor

Every Dutch citizen is required to have a basic benefits package

Every year enrolees are allowed to switch health plans

Health insurers have to accept all applicants and are not allowed to drop enrolees

Community rating

Low-incomes are given a subsidy to compensate for health insurance costs

Health insurers are compensated for elderly people and those at high risk of disease,

through a risk-equalisation system

Mandatory deductible of $€ 385$ per person per year*

Voluntary deductible up to $€ 500$ per person per year

Insurers are allowed to sell supplementary insurance

General practitioners serve as gatekeepers

Insurers are allowed to selectively contract care providers

* The government assesses the amount of the mandatory deductible every year. In 2017 it was €385.

\section{Conditions for managed competition to work}

There are a number of conditions for a system of managed competition to succeed in achieving its goals to increase health care quality and contain the costs. First, objective quality information on care providers and health insurers needs to be available for health insurers and enrolees. Without this information, health insurers are not able to prudently purchase care and enrolees cannot make informed decisions about which care provider and/or health insurer to choose [11]. Currently, more quality information is becoming available in the Netherlands, mostly on government sponsored websites. Second, it is important that enrolees use this information to consciously choose their health insurer and health plan. Ideally, enrolees base their choice for a health insurer on price and quality, i.e. quality of service provision of the health insurer and quality of the contracted care providers. Third, barriers to switch insurers and switching costs have to be low [16]. Enrolees need to be able to so-called 'vote with their feet', which means to change insurers when they are not satisfied. This is important, because if there is no mobility of enrolees, health insurers have no incentive to reduce costs and improve quality of care. In the Netherlands, guarantees are in place to enable everyone to switch health insurers if they want. Health insurers are required to accept all applicants and health insurers are not allowed to differentiate the premium of a health plan to different groups of people [15]. However, there are other barriers, for example the time and effort it takes to find and compare information on different health plans. 
In the Netherlands, the first year after the introduction of the HIA the switching rate was very high (21\%) [17]. After that, switching rates decreased to around 4-5\% every year. In 2012 and 2013, this percentage has increased again to almost 10\% and the last few years this percentage fluctuates around $8 \%[18,19]$. Another important prerequisite is that health insurers selectively contract care providers and have the ability to channel their enrolees to these contracted providers when they need care $[7,8,20,21]$. In practice, in the Netherlands, this turns out to be very difficult. Enrolees are very negative about restrictions in their care provider choice. This is where this thesis will focus on. The main question we aim to answer is: How can we explain acceptance of selective contracting and channelling enrolees to contracted care providers?

\section{Selective contracting and channelling}

In this section, the general principle of selective contracting and channelling will be explained. The situation in the Netherlands will be discussed in the following section. In general, selective contracting means that health insurers only contract a selection of available care providers. There are two forms of selective contracting. One is based on 'preferred provider networks', this means that enrolees are also allowed to use care providers that are not contracted by their health insurer, but this care will only partially be reimbursed. The other form is 'exclusive', this means that enrolees will receive no reimbursement at all when they go to a care provider that is not contracted by their insurer. Selective contracting has negative consequences for enrolees, i.e. restrictions in their freedom of provider choice and co-payments when they go to a care provider that is not contracted by their insurer. On the other hand, a positive consequence is a lower monthly premium. Usually, the more restrictive the health plan, the lower the premium.

Allowing health insurers to selectively contract care providers, means they are able to buy care in larger volumes at fewer care providers which can result in greater discounts [8]. This is supposed to lead to lower premiums, and therefore, to more enrolees. Also, selective contracting is important for the health care system to reach its goals of improving quality of care and reducing the costs, because selective contracting leads to competition between care providers, which is an incentive for care providers to improve quality and work more efficiently to reduce costs. However, competition between care providers will only happen when care providers fear to lose market share if they are not contracted by health insurers [7, 21-23]. Therefore, it is crucial that health insurers are able to channel their enrolees to 
contracted care providers. If they are successful in channelling their enrolees to contracted care providers, they will have a stronger bargaining position in negotiations with care providers [7, 8, 20, 21]. To channel enrolees to contracted providers, usually financial incentives are used whereby enrolees are not or only partially reimbursed when they go to care providers that are not contracted by their health insurer. Not much is known about the most effective ways to channel enrolees to contracted providers or why some insurers do this better than others [8]. Also, not much is known about views of enrolees on this. In the US it was found that people enrolled in managed care are less satisfied with their health plan [24, 25]. Furthermore, it was found in the US that younger and healthier people more often choose restrictive health plans, likely because they do not expect to need care in the near future and because they are more sensitive to price [26, 27].

\section{Selective contracting and channelling in the Netherlands}

Before the insurance reform in the Netherlands, selective contracting was not practised (legally it was allowed). All providers were contracted and every citizen could go to any care provider. Since the reform, selective contracting has become more important. It is allowed only in the 'preferred provider'-form, because European laws and regulations require health insurers to at least partially reimburse care that is not contracted [28]. In theory, health insurers are allowed to contract only a selection of care providers. However, they are legally bound to the duty of care, which means they have to buy in sufficient care for their enrolees [15]. In the Netherlands, a gatekeeping system is in place. This means that every citizen needs to be enrolled in a general practice and needs to visit their GP first to get referred to secondary care. Because of this, people in the Netherlands develop a strong relationship with their GP. Therefore, in practice, most selective contracting is only conducted in hospital care and physiotherapy. There were plans to change article 13 of the Health Insurance Act to allow health insurers to determine the amount of coverage for non-contracted care providers individually. However, this was blocked by the first chamber of parliament, since this impaired freedom of provider choice. Since then, the norm is a minimum coverage of $75 \%$ for non-contracted care providers. At first, health insurers started with an even milder form of selective contracting. They would select preferred providers and reward enrolees with the exemption of their deductible when they go to a preferred provider. This form could be looked at as a 'positive financial incentive' for enrolees to go to preferred or contracted care providers (a negative incentive would for instance be a co-payment) [29]. 
Selective contracting where non-contracted care providers are only partially reimbursed was later implemented by a few health insurers in the Netherlands. The most important reason that health insurers are reluctant to implement selective contracting is the fear of losing enrolees, because they expect that their enrolees will not accept it. Furthermore, health insurers believe that enrolees do not trust them to purchase good quality care on their behalf, which is also implied by literature [11, 30-32]. It is, however, not clear how the relationship between trust and acceptance of selective contracting exactly works. Furthermore, it was found that younger and healthier people are more frequently enrolled in a restrictive health plan [33]. They are also more open to advice from their health insurer [31]. It is unclear under which conditions for instance older and more unhealthy enrolees will enrol in a restrictive health plan or which mechanisms play a role in this.

\section{Goal and general research question}

The goal of this thesis is to identify mechanisms that explain enrolees' acceptance of selective contracting. One such mechanism might be price sensitivity that differs for people with different characteristics. For people with a low income, the price of the health plan may be far more important in the acceptance of selective contracting than for people with a high income. The central research question we aim to answer in this thesis is:

How can we explain acceptance of selective contracting and channelling enrolees to contracted care providers?

\section{Relevance}

\section{Scientific relevance}

Selective contracting and channelling of enrolees to contracted care providers is a crucial aspect of a health care system based on managed competition. In order to reach the intended goals of improving quality of care and controlling the costs at the same time, competition between care providers is crucial and selective contracting by health insurers is an important tool for this competition to arise. Insight in mechanisms that explain the acceptance of selective contracting and channelling are therefore very important and could lead to more efficient implementation of this 
tool. Thus far, a theory underlying the acceptance of selective contracting and channelling is lacking in the literature. This thesis will add knowledge about mechanisms that underlie the conditions under which selective contracting and channelling will be accepted by enrolees.

\section{Policy relevance}

Given there is a health care system based on managed competition in place, it is important that the key tools/incentives work as they are intended. In this thesis we focus on selective contracting and channelling by health insurers. This aspect of the health care system is proving to be a challenge in practice, since enrolees are negative about selective contracting and, therefore, health insurers are reluctant to implement this. Our results could help health insurers to more effectively implement selective contracting in a way that enrolees will accept this. Furthermore, it could provide insights for the Dutch government about the effectiveness of the health care system and whether the tool of selective contracting and channelling is working in the way it was intended. This is not only relevant for health insurers and policymakers in the Netherlands, but also for other countries in which a system of managed competition is implemented or will be implemented in the future.

\section{Specific research questions}

The goal of this theses is to identify mechanisms that explain the acceptance of selective contracting and channelling enrolees to contracted care providers. In the Netherlands, selective contracting came into play after the health insurance reform in 2006 and is therefore a relatively recent development. However, in the US, and also in other countries, selective contracting has been conducted for a long time. Therefore, this thesis starts with a review of the literature answering the research question:

RQ1: What is known about selective contracting from the enrolee's perspective; is it being done and how do enrolees feel about the role of their health insurer in their care provider choice? 


\section{Choice of care provider}

Literature shows that enrolees in the Netherlands are not always aware of which health plan they have and what selective contracting is. To find out more about the acceptance of selective contracting in the Netherlands, we will conduct a study where hypothetical choice options are given to enrolees. The research question we aim to answer is:

RQ2: What are the demographic characteristics of enrolees who are willing to choose a restrictive health plan and why are different groups of enrolees willing to choose a restrictive health plan or not?

In order to answer this research question we will study different mechanisms that may play a role in this. We specifically look at the consequences of selective contracting and having a restrictive health plan. Restrictions in care provider choice could mean a longer travelling time to the nearest care provider and/or having to change care providers. On the other hand, restrictive health plans are usually cheaper compared to free choice health plans. In other countries it was found that young and healthy enrolees more often choose restrictive health plans [27, 34, 35]. The reason for this may be that young people are more price sensitive and therefore focus more on the price of a health plan instead of having free care provider choice or a short travelling time $[36,37]$. People in poorer health are more at risk of having to change care providers, since they are more likely to already have an established relationship with a care provider. Travelling further is also more burdensome for the elderly and people in poorer health. The mechanisms that may play a role in the acceptance of selective contracting are therefore price-sensitivity, risk perception of having to change care providers, and mobility.

\section{Trust}

In the Netherlands it was found that health insurers struggle with a credible commitment problem, which means that enrolees generally distrust health insurers $[30,38]$. No research has yet been done on the role of trust in the acceptance of selective contracting, but several studies point out that this aspect could play an important role $[25,38,39]$. Also, health insurers expect their enrolees not to trust them to purchase good quality care for them, which is a reason for them not to engage in selective contracting [30]. Therefore, we aim to study more in depth the role of trust in the acceptance of selective contracting, answering the following research question: 
RQ3: What role does enrolees' trust in their health insurer play in their acceptance of selective contracting?

The mechanism we study with this research question is the relationship between trust and the acceptance of selective contracting. Trust is closely related to risk. When there is certainty, no risk has to be taken and no trust is needed. The higher the perception of risk, the more trust is needed to facilitate transactions between the trustor and the trustee [40], in this case enrolees and health insurers. In the situation of selective contracting and choosing a restrictive health plan, enrolees do not know what care they will need in the future, and therefore, they take a risk when they choose a restrictive health plan. Thus, they would need to trust their health insurer to purchase good quality care on their behalf. In addition, earlier studies on trust in relation to health insurers, state that enrolees who have more trust in their health insurer have a lower desire to switch insurers and have fewer disputes with their insurer [41-43].

Trust in the health insurer could also play a role in the acceptance of information from the health insurer. When health insurers want to channel enrolees to preferred or contracted care providers, it is important that they are seen as a source of information on care provider quality. Therefore, we study how health insurers are seen as source of information on care provider quality, compared to other sources of information, answering the following research question:

RQ4: How do enrolees rank sources of hospital quality information?

\section{Information}

Restrictions on freedom of choice are perceived as negative by enrolees. However, enrolees might understand when health insurers would not contract a certain care provider when the quality of that provider is very low. Therefore, we will study whether giving enrolees information about the selection of care providers may promote the acceptance of selective contracting. Most research on acceptance of selective contracting is not very explicit to respondents about the consequences of selective contracting. For instance, the percentage of care providers that is contracted is stated, but not specifically whether the care provider they usually go to is contracted or not. Maybe, enrolees are willing to have a restrictive health plan as long as they do not have to change care providers. The research question we aim to answer is: 
RQ5: How does providing information to enrolees about the selection of care providers influences their acceptance of selective contracting, when enrolees are informed about the specific consequences of selective contracting?

The mechanism that plays a role in this is procedural fairness. This term is from the justice literature and this theory states that people are in general more satisfied with a situation when they are properly informed about the procedures that led to the situation $[44,45]$. In the case of selective contracting, this would mean that providing information to enrolees about the selection process of care providers could be important for enrolees to accept selective contracting. Furthermore, Greenberg found that the effect of information on acceptance is even more important when the decision has negative consequences [45]. This means that when selective contracting has negative consequences for enrolees, namely having to switch care providers or a longer travelling time to the nearest care provider, information could be even more important.

\section{Channelling to preferred care providers}

Channelling enrolees to preferred care providers is hard since enrolees resent when limitations in care provider choice are imposed by their health insurer. In the US, implementation of negative financial incentives to channel enrolees to contracted care providers led to a managed care backlash, a collective resentment against managed care. Therefore, in the Netherlands health insurers are reluctant to implement selective contracting. Furthermore, because the current health care system stimulates competition between health insurers, customer service has become more important. Ideally, health insurers channel enrolees to preferred care providers in a way that does not emphasize a limitation in care provider choice and does not harm enrolees evaluation of the health insurers service quality. A large health insurer in the Netherlands plans to try out channelling enrolees to preferred care providers by offering advice on care provider choice in regular customer service calls. We will study whether this method is effective and the effect it has on service quality ratings, answering the following research question:

RQ6: Is it possible to channel enrolees to preferred care providers by giving them free advice when they call customer service and what is the effect of this service on enrolees' rating of service quality? 
Whether or not channelling enrolees to preferred providers by offering advice is possible may depend on several mechanisms. First, trust may play a role since the advice comes from the health insurer, while enrolees generally distrust health insurers [30, 38]. However, the advice is personalized and given by an employee of the health insurer. However, since interpersonal trust is usually higher than institutional trust (trust in a company) enrolees might be open to it. Furthermore, information could play a role. If the employee is able to properly explain to enrolees why a certain care provider is preferred enrolees may be more likely to accept the advice. A study on service of call centre employees found that offering personalised information and explanations to customers leads to higher evaluations of service interactions [46]. A high evaluation of service quality is found to increase trust in the company [47]. Which in turn is expected to increase the acceptance of selective contracting.

Table 1 Overview of research questions

Research question

Chapter

RQ1: What is known about selective contracting from the enrolee's perspective; is it being done and how do enrolees feel about the role of their health insurer in their care provider choice?

RQ2: What are the demographic characteristics of enrolees who are willing to choose a restrictive health plan and why are different groups of enrolees willing to choose a restrictive health plan or not?

RQ3: What role does enrolees' trust in their health insurer play in their acceptance of selective contracting?

RQ4: How do enrolees rank sources of hospital quality information?

RQ5: How does providing information to enrolees about the selection of care providers influences their acceptance of selective contracting, when enrolees are informed about the specific consequences of selective contracting?

RQ6: Is it possible to channel enrolees to preferred care providers by giving them free advice when they call customer service and what is the effect of this service on enrolees' rating of service quality? 


\section{Methods}

This thesis focuses on the perspective of the enrolees. Most data will be collected by sending questionnaires to enrolees. For three studies (Chapters 3, 4 and 6) we will send out questionnaires to members of the Insurance Panel of NIVEL (Netherlands institute for health services research). This method is suitable for testing the hypothesized mechanisms in these chapters. This panel was set up in cooperation with Dutch health insurance cooperative VGZ. All panel members are 18 years or older and insured trough this health insurance company. These panel members agreed to fill in a questionnaire three to four times a year about different subjects related to health care and health insurance. New members are recruited constantly. In May 2017, the Insurance Panel has over 9,000 members who can be approached online or by postal surveys, depending on their own preference. Every year, panel members are asked about their background data, such as health status, education, and information on their health plans to keep background information updated.

In one study (Chapter 5) a random sample of enrolees who used a preferred care provider of a Dutch health insurance company are approached with a postal questionnaire. Since we know they have recently chosen a hospital we are able to ask them how they made their choice. For the study described in Chapter 7, we will send online questionnaires to enrolees who have contact with their health insurer's customer service during the study period. Furthermore, call centre employees will log all their conversations, registering where the call was about, whether they offered advice and if they gave advice, which care provider they advised to the enrolees. In addition, claims data of the health insurer are used to determine whether enrolees follow the advice of the employee.

All analyses were conducted using STATA 14.0.

\section{Structure and content}

In order to answer the general research question a number of studies are conducted. Every study will be described in a separate chapter. Chapter 2 presents an overview of the literature on selective contracting. Questions that will be answered are: "Are selective contracting and channelling being done by health insurers, if so, how?" and "How do enrolees feel about this?". In Chapter 3 we 
research how enrolees choose a health plan type. Which enrolees choose a restrictive health plan? In Chapter 4 we look at the role of trust in the health insurer in the acceptance of selective contracting by enrolees. Chapter 5 describes if enrolees see the health insurer as a source of quality information on care providers compared to other sources of information. In Chapter 6 we further look into the acceptance of selective contracting and research whether provision of information on the care provider selection process of health insurers increases enrolees acceptance of selective contracting. In Chapter 7 a study is described which tests a new way of channelling enrolees to preferred care providers, namely through free, non-committal advice by customer service employees of the health insurer in contact moments initiated by the enrolees. These chapters are followed by a summary and discussion in Chapter 8. 


\section{References}

1. Laske-Aldershof T, Schut E, Beck K, Gress S, Shmueli A, Van de Voorde C: Consumer mobility in social health insurance markets: a five country comparison. Applied Health Economics and Health Policy 2004, 3:229-241.

2. Light DW: Comparative institutional response to economic policy: managed competition and governmentality. Social Science \& Medicine 2001, 52(1):1151-1166.

3. Saltman RB, Figueras J: Analyzing the evidence on European health care reforms. Health Affairs 1998, 17:85-108.

4. Van de Ven WPMM: Market oriented health care reforms: trends and future options. Social Science \& Medicine 1996, 43(5):655-666.

5. Enthoven AC, Van de Ven WPMM: Going Dutch - Managed-competition health insurance in the Netherlands. New England Journal of Medicine 2007, 357(24):2421 2423.

6. Enthoven AC: The history and principles of managed competition. Health Affairs 1993, 12(1):24-48.

7. Sorensen AT: Insurer-hospital bargaining: negotiated discounts in post-deregulation Conneticut. Journal of Industrial Economics 2003, 51(4):469-490.

8. Wu VY: Managed care's price bargaining with hospitals. Journal of Health Economics 2009, 28:350-360.

9. Van de Ven WPMM, Schut FT: Universal mandatory health insurance in the Netherlands: a model for the United States? Health Affairs 2008, 27(3):771-781.

10. Boonen LHHM: Consumer channeling in health care: (im)possible?: Erasmus Universiteit Rotterdam; 2009.

11. Van de Ven WPMM, Schut FT: Managed competition in the Netherlands: still work-inprogress. Health Economics 2009, 18:253-255.

12. Schut FT, Van de Ven WPMM: Effects of purchaser competition in the Dutch health system: is the glass half full of half empty? Health Economics, Policy and Law 2011, 6:109-123.

13. Ministerie van VWS [Dutch Ministry of Health Welfare and Sports]: Explenatory notes to the Health Insurance Act (HIA). In. Den Haag [The Hague, the Netherlands]; 2004.

14. Enthoven AC: A living model of managed competition: a conversation with Dutch health minister Ab Klink. Health Affairs 2008, 27(3):w196-w203

15. Kroneman M, Boerma W, van den Berg M, Groenewegen PP, de Jong JD, van Ginneken E: The Netherlands: health systems review. Health Systems in Transition 2016, 18(2):1239.

16. Reitsma-van Rooijen $\mathrm{M}$, de Jong JD, Rijken $\mathrm{M}$ : Regulated competition in health care: switching and barriers to switching in the Dutch health insurance system. BMC Health Services Research 2011, 11:95. 
17. De Jong JD, Delnoij DMJ, Groenewegen PP: Verzekerdenmobiliteit is hoog. Ook ouderen zijn overgestapt [Switching rates are high. Even the elderly have switched]. Utrecht: NIVEL; 2006.

18. Reitsma-van Rooijen M, Brabers AEM: Verzekerden bezuinigen op hun zorgverzekering, het aantal overstappers neemt nog steeds toe [Enrollees cut down on their health insurance, the number of switchers is still increasing]. Utrecht, The Netherlands: NIVEL; 2013.

19. Barometer wisselen van zorgverzekeraar [Barometer for switching health insurers]

20. Melnick GA, Zwanziger J, Bamezai A, Pattison R: The effects of market structure and bargaining position on hospital prices. Journal of Health Economics 1992, 11:217-233.

21. Pauly MV: Monopsony power in health insurance: thinking straight while standing on your head. Journal of Health Economics 1987, 6:73-81.

22. Boonen LHHM, Schut FT: Sturing op de zorgmarkt. Economisch Statische Berichten 2006, 91(4486):226-228.

23. Varkevisser M, Polman N, Van der Geest SA: Zorgverzekeraars moeten patiënten kunnen sturen. Economisch Statische Berichten 2006, 91(4478):38-40.

24. Blendon RJ, Brodie M, Benson JM, Altman DE, Levitt L, Hoff T, Hugick L: Understanding the managed care backlash. Health Affairs 1998, 17(4):80-94.

25. Gawande AA, Blendon RJ, Brodie M, Benson JM, Levitt L, Hugick L: Does dissatisfaction with health plans stem from having no choices? Health Affairs 1998, 17(5):184-194.

26. Block LE: Evolution, growth, and status of managed care in the United States. Public Health Reviews 1997, 25(3/4):193-244.

27. Hellinger FJ: Selection bias in HMOs and PPOs: A review of the evidence. Inquiry 1995, 32(4):135-142.

28. Van de Ven WPMM, Schut FT, Hermans HEGM, de Jong JD, van der Maat M, Coppen R, Groenewegen PP, Friele RD: Evaluatie Zorgverzekeringswet en Wet op de zorgtoeslag. ZonMw, Den Haag; 2009.

29. Boonen LHHM, Donkers B, Schut FT: Channeling consumers to preferred providers and the impact of status quo bias: does type of provider matter? Health Services Research 2011.

30. Boonen LHHM, Schut FT: Preferred providers and the credible commitment problem in health insurance: first experiences with the implementation of managed competition in the Dutch health care system. Health Economics, Policy and Law 2011, 6:219-235.

31. Bes RE, Wendel S, De Jong JD: Het vertrouwensprobleem van zorgverzekeraars [The trust issue of health insurers]. Economisch Statistische Berichten 2012, 97(4647):676677.

32. Boonen LHHM, Schut FT: Zorgverzekeraars kampen met vertrouwensprobleem (Health insurers face problems with trust). Economisch Statistische Berichten 2009, 94(4572):678-681. 
33. Monitor Zorgverzekeringsmarkt 2009. [Monitor Health Insurance Market 2009.] Utrecht: NZa [Dutch Healthcare Authority]; 2009

34. Hellinger FJ, Wong HS: Selection bias in HMOs: A review of the evidence. Medical Care Research and Review 2000, 57(4):405-439.

35. Lehman H, Zweifel P: Innovation and risk selection in deregulated social health insurance. Journal of Health Economics 2004, 23:997-1012.

36. Hoch SJ, Kim BD, Montgomery AL, Rossi PE: Determinants of store-level price elasticity. Journal of Marketing Research 1995, 32:17-29.

37. Marquis SM, Long SH: Worker demand for health insurance in the non-group market. Journal of Health Economics 1995, 14:47-63.

38. Miller $\mathrm{NH}$ : Insurer-provider integration, credible commitment, and managed-care backlash. Journal of Health Economics 2006, 25:861-876.

39. Heinemann S, Leiber S, Gress S: Managed competition in the Netherlands - A qualitative study. Health Policy 2013, 109:113-121.

40. Pavlou PA: Consumer acceptance of electronic commerce: integrating trust and risk with the technology acceptance model. International Journal of Electronic Commerce 2003, 7(3):69-103.

41. Balkrishnan R, Dugan E, Camacho FT, Hall MA: Trust and satisfaction with physicians, nsurers, and the medical profession. Medical Care 2003, 41(9):1058-1064.

42. Hall MA, Dugan E, Zheng B, Mishra AK: Trust in physicians and medical institutions: what is it, can it be measured, and does it matter? The Milbank Quarterly 2001, 79(4):613639.

43. Zheng B, Hall MA, Dugan E, Kidd KE, Levine D: Development of a scale to measure patients' trust in health insurers. Health Services Research 2002, 37(1):185-200.

44. Folger R, Bies RJ: Managerial responsibilities ans procedural justice. Employee Responsibilities and Rights Journal 1989, 2(2):79-90.

45. Greenberg J: Employee theft as a reaction to underpayment inequity: the hidden cost of pay cuts. Journal of Applied Psychology 1990, 75(5):561-568.

46. Rafaeli A, Ziklik L, Doucet $L$ : The inpact of call center employees' customer orientation behaviours on service quality. Journal of Service Research 2008, 10(3):239-255.

47. Wendel S, de Jong JD, Curfs EC: Consumer evaluation of complaint handling in the Dutch health insurance market. BMC Health Services Research 2011, 1 (doi:10.1186/1472-6963-11-310). 


\section{Chapter 2}

Selective contracting and channelling patients to preferred providers: a scoping review

Published as:

Bes RE, Curfs EC, Groenewegen PP, de Jong JD. Selective contracting and channelling patients to preferred providers: a scoping review. Health Policy 2017, 121(5): 504-514 


\section{Abstract}

Selective contracting by health insurers and channelling patients to contracted providers is crucial in a health care system based on managed competition, as this should lead to better value for money delivery of healthcare. However, an important consequence for enrolees is that health insurers interfere with their choice of care provider. This scoping review aims to find out what is known about selective contracting from the enrolee's perspective. Is it being done and how do enrolees feel about the role of their health insurer in their care provider choice? A literature search was conducted, and, in addition, experts were consulted for extra information and documents. Results show that selective contracting and channelling is practised in several countries. This is mostly through negative financial incentives, which are also found to be the most effective strategy. However, enrolees are very negative about restrictions on provider choice introduced by their insurer. This results in enrolees feeling less satisfaction with, and trust in, care providers and health insurers. Choice is crucial in this respect since enrolees are more satisfied with their health plans and care providers when they have chosen them themselves. Future research should focus on the role of trust and how people weigh different attributes of health plans if selective contracting and channelling is to be implemented in a manner acceptable to enrolees. 


\section{Introduction}

Health care reforms have been implemented in several European countries over the last decades in order to improve quality and contain costs in the health care system [1-3]. Most of these reforms involved a shift from a supply to a demand-oriented health care system. In several countries these reforms were based on introducing managed competition. In such a system the health care market is a competitive market in which three important players interact; enrolees, care providers and health insurers (Figure 1). The idea is that health insurers compete with each other for enrolees, based on the price and quality of their health plans. Therefore, health insurers have to negotiate with care providers about the price and quality of delivered care. Health insurers are allowed to contract care providers selectively, which means they do not have to contract with all care providers. There are two forms of selective contracting, one in an exclusive network of providers and one in a preferred provider network. In an exclusive provider network, enrolees will not be reimbursed if they choose to go to a non-contracted care provider - except in emergencies. In a preferred provider network, enrolees are allowed to go to any care provider they like, however, if they go to a provider that is not contracted by their insurer, they have to pay a co-payment. This role of health insurers as a prudent purchaser of care is supposed to lead to competition between care providers which, in turn, should lead to better value for money delivery of health care [4].

Health insurers function as an intermediary between the enrolees -the potential patients- and care providers. To attract enrolees, health insurers need to offer health plans with an attractive network of care providers for a good price. Therefore, health insurers need to negotiate with care providers about the price and quality of the care they deliver. In these negotiations, health insurers need to have a strong bargaining position in order to negotiate discounts. For care providers, it is important that they get something in return for these discounts, namely more patients. Logically, health insurers with the largest market shares would be in the best positions to negotiate. However, Wu and Sorensen have found that health insurers' ability to channel enrolees to preferred or contracted care providers, is even more important. This is because when health insurers are successful in channelling their enrolees to preferred providers, the threat of care providers losing business when they are not contracted by the insurer becomes a credible one $[5,6]$. 
Figure 1 Model of health care market in a system of managed competition

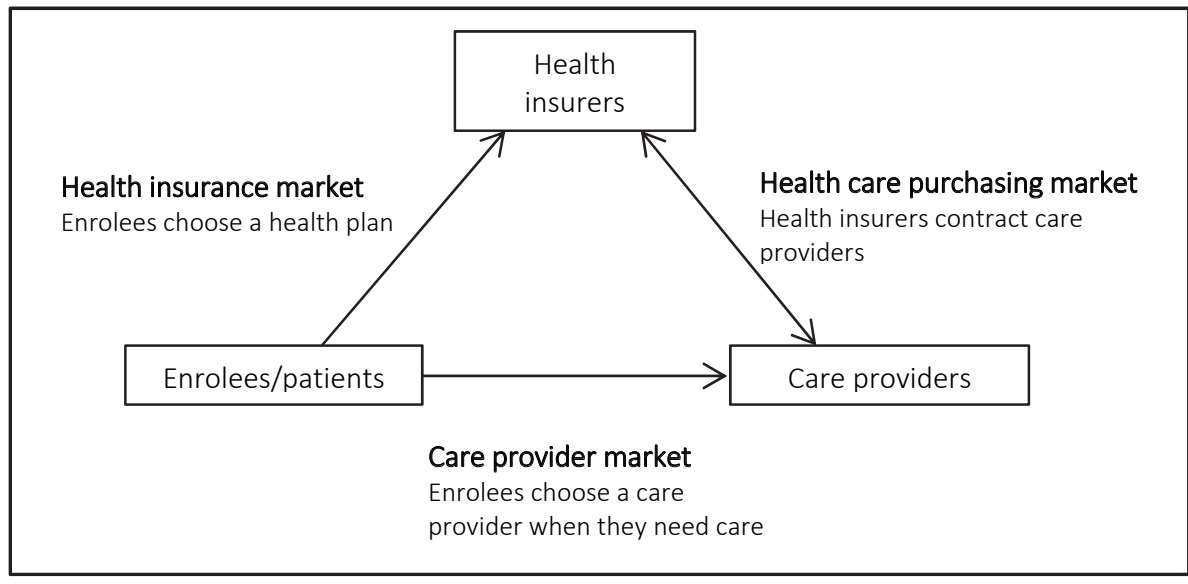

There are several ways to channel enrolees to preferred or contracted care providers. Health insurers can use negative financial incentives when enrolees go to a not contracted care provider, for instance by having enrolees pay a co-payment or by not reimbursing them at all. This last option, however, is not always allowed. In the Netherlands, regulated competition was introduced in 2006 with the introduction of the Health Insurance Act. In Europe this country is seen as an important example for the implementation of a managed competition health care system. Here, a part of the Health Insurance Act that gave health insurers autonomy to determine the reimbursement levels for non-contracted care providers was rejected by the Dutch parliament because free choice of care provider was threatened. Health insurers are now obligated to reimburse at least $75 \%$ of the costs of non-contracted care providers [7]. This made selective contracting and channelling enrolees to preferred care providers harder in the Netherlands. Other options to channel enrolees to preferred providers are positive financial incentives, for instance by giving discounts on co-payments when enrolees visit a contracted provider. Or to use quality incentives, for instance offering extra services or better quality of care when enrolees go to contracted providers. All these incentives require the involvement of the health insurer in their enrolees' choice of care provider. But these pose several questions: Are these incentives used by health insurers and do they work? And how do enrolees feel about the role of their health insurer in their care provider choice? We believe that little research has been done on this subject and no knowledge syntheses were conducted. Therefore, we aim to conduct an exploratory scoping review to find out what is known about selective 
contracting from the enrolee's perspective. Is it being done and how do enrolees feel about the role of their health insurer in their care provider choice? With this, we aim to contribute to the policy and research agenda on this subject.

\section{Methods}

A scoping review is a type of literature review that is used when: (1) it is difficult to identify a narrow research question; (2) studies in the reviewed sources are likely to have employed a range of data collection and analysis techniques; (3) no prior synthesis has been undertaken on the topic; and (4) a quality assessment of reviewed sources is not going to be conducted $[8,9]$. The scoping review method is an appropriate method to use for this knowledge synthesis since our aim to find out what is known about channelling enrolees to contracted care providers by health insurers is quite broad, we are not aware of any prior synthesis on this topic and a quality assessment of reviewed sources is not going to be conducted. However, it is possible that selective contracting and channelling is present in a particular country, but that there have been no scientific articles published about this. Therefore, in addition to the literature search, we approached experts from several European countries, where health care reforms were introduced in the last decades, in order to collect information on selective contracting in their countries.

\section{Scoping review search strategy and selection}

The databases Pubmed and Embase were searched for the scoping review. Before determining the search strategy, an initial broad search of the literature was conducted and a librarian was consulted. Since channelling or selective contracting is about the influence of health insurers on enrolees' choices for a care provider we decided to search for the four main topics: enrolees, choice, providers and health insurers. These, and their synonyms combined with OR, were combined with AND in the search strategy. See Table 1 for the search strategy in Pubmed. A similar search strategy was conducted in Embase. After the literature search all duplicates were removed. Then, all articles were judged firstly on the title alone. Then on the title, the abstract and the full text (Figure 2), following the inclusion criteria listed in Table 2. Additionally, relevant references and reports that we were already aware of were added. This resulted in a total of 42 references. 


\section{Table 1 Search strategy in Pubmed}

\section{Enrolees}

1 enrolees[tiab] OR enrolee[tiab] OR enrollees[tiab] OR enrollee[tiab]

2 patients[mesh]

3 patient[tiab] OR patients[tiab]

4 consumer[tiab] OR consumers[tiab]

5 insured[tiab]

$6 \quad \# 1$ OR \#2 OR \#3 OR \#4 OR \#5

\section{Choice}

7 choice[tiab] OR choosing[tiab]

8 patient preference[mesh]

9 choice behaviour[mesh]

10 \#7 OR \#8 OR \#9

\section{Provider}

11 provider[tiab] OR providers[tiab]

12 hospitals[mesh]

13 hospital[tiab] OR hospitals[tiab]

14 doctor[tiab] OR doctors[tiab]

15 physicians[mesh]

16 physician[tiab] OR physicians[tiab]

17 general practitioner[tiab] OR general practitioners[tiab] OR GP[tiab] OR GPs[tiab]

18 pharmacies[mesh]

19 pharmacy[tiab] OR pharmacies[tiab]

20 health personnel[mesh]

21 \#11 OR \#12 OR \#13 OR \#14 OR \#15 OR \#16 OR \#17 OR \#18 OR \#19 OR \#20

\section{Health insurer}

22 insurance, health[mesh]

23 health insurance[tiab]

24 health insurer[tiab] OR health insurers[tiab]

25 health plan[tiab] OR health plans[tiab]

26 purchaser[tiab] OR purchasers[tiab]

27 \#22 OR \#23 OR \#24 OR \#25 OR \#26

28 \#6 AND \#10 AND \#21 AND \#27 
Figure 2 Flow diagram of review process

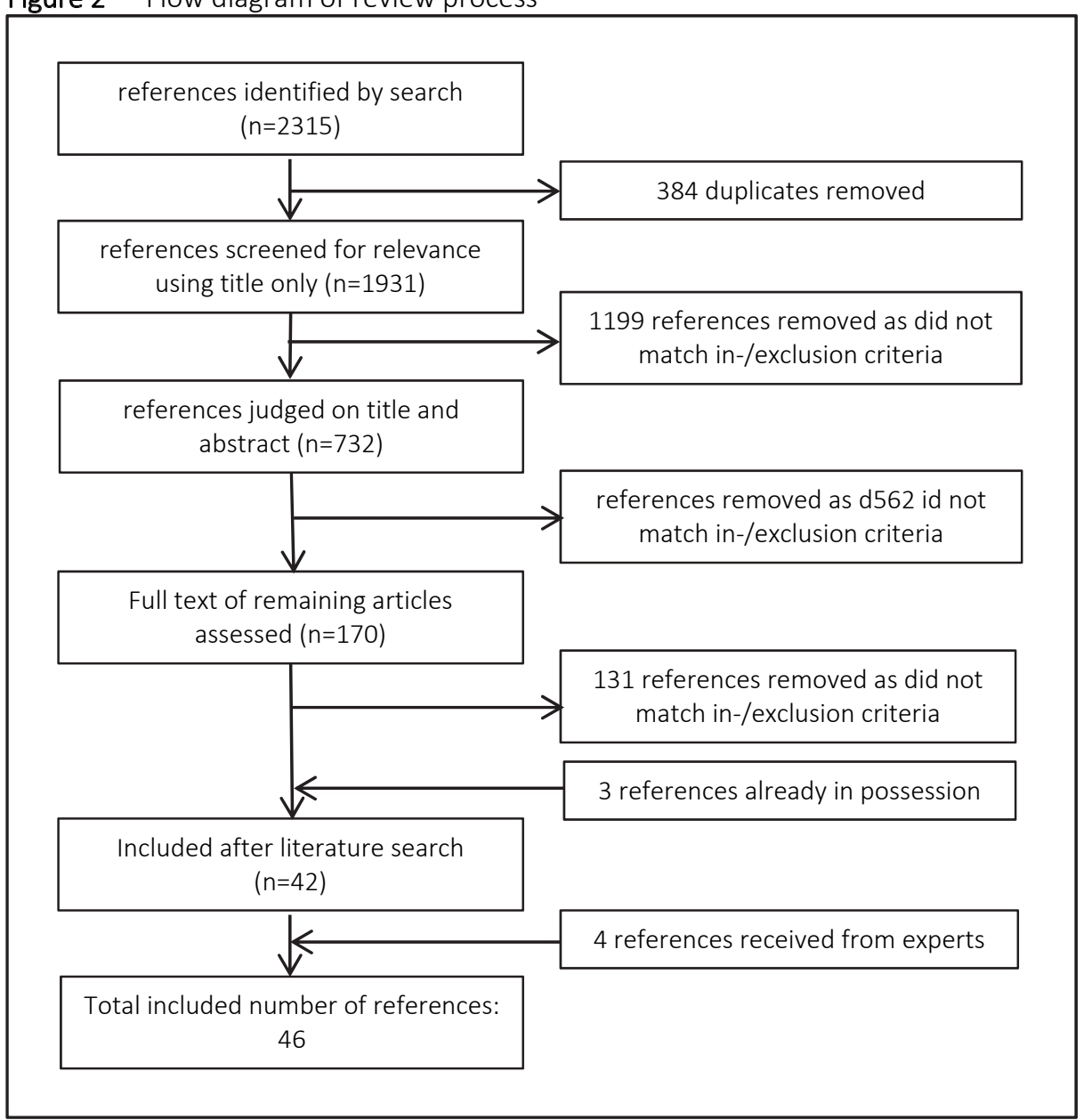

Table 2 Inclusion criteria for literature search

1 The article is written in English, Dutch, German or French

2 It is empirical, scientific research

3 It is about choice of a care provider, not choice of treatment or health insurer/health plan

4 It is about factors that influence the choice of enrolees in general OR about factors that have to do with the influence of the health insurer on enrolees $O R$ factors that influence enrolees' acceptance of their health insurers' influence on them. 


\section{Expert approach}

Almost all the studies we found in the literature search were conducted in the US or the Netherlands. However, we wanted to collect information too from a number of European countries who have also undergone health reforms. Therefore, in addition to the literature search, experts on health care system research in Belgium, Germany and Switzerland were asked for information on selective contracting and channelling of enrolees by health insurers. Experts were chosen based on their scientific expertise or where they work, for instance in a national knowledge centre for health care. The experts were asked specifically to provide information about selective contracting and channelling enrolees to contracted/preferred care providers in their countries. Do health insurers channel enrolees to contracted care providers? If so, how? And what are the consequences of channelling for enrolees? Furthermore, they were asked to provide documents or reports that could be helpful in answering these questions.

\section{Results}

The flow diagram (Figure 2) shows the process of excluding papers. In the end, 46 papers were included in this scoping review, including the papers that were sent by the experts in the field (Table 3). Some experts sent documents, but most gave only a written response to our questions. The findings are discussed in four sections. First, we will discuss whether selective contracting and channelling is conducted in different countries, the second part is about how channelling of enrolees is being done in different countries, thirdly, we will discuss enrolees perspectives on selective contracting, and lastly, consequences of selective contracting for enrolees will be addressed. 
Table 3 Included studies ( $\mathrm{N}=46$ )

\begin{tabular}{|c|c|c|}
\hline First author, year & Country & Methods/participants/data \\
\hline Abraham J, $2011[10]$ & US & $\begin{array}{l}\text { Survey of } 467 \text { patients at four clinics in } \\
\text { Minnesota }\end{array}$ \\
\hline Allen HM Jr, 1984 [35] & US & $\begin{array}{l}\text { Telephone interviews on } 365 \text { adults from Los } \\
\text { Angeles }\end{array}$ \\
\hline Bes RE, 2012 [46] & Netherlands & Survey of 2679 enrolees of a health insurer \\
\hline Bin Saeed KS,1998 [21] & Saudi Arabia & $\begin{array}{l}\text { Survey of } 541 \text { patients in } 2 \text { government and } 2 \\
\text { private hospitals }\end{array}$ \\
\hline $\begin{array}{l}\text { Boonen LHHM, } 2008 \\
\text { [27] }\end{array}$ & Netherlands & $\begin{array}{l}\text { Analysis of registration data from two health } \\
\text { insurers }\end{array}$ \\
\hline $\begin{array}{l}\text { Boonen LHHM, } 2009 \\
{[26]}\end{array}$ & Netherlands & $\begin{array}{l}\text { Discrete Choice Experiment (DCE) Survey on } \\
1.875 \text { respondents from representative } \\
\text { household panel }\end{array}$ \\
\hline $\begin{array}{l}\text { Boonen LHHM, } 2011 \\
{[11]}\end{array}$ & Netherlands & $\begin{array}{l}\text { Review of available data, interviews with four } \\
\text { directors of health insurance companies and } \\
\text { annual surveys on a representative panel of } \\
\text { Dutch adult population covering the years } \\
\text { 2005-2009 (N=803-2234) }\end{array}$ \\
\hline $\begin{array}{l}\text { Boonen LHHM, } 2011 \\
\text { [25] }\end{array}$ & Netherlands & $\begin{array}{l}\text { Discrete Choice Experiment (DCE) survey of } \\
1.907 \text { and } 1.857 \text { respondents of representative } \\
\text { household panel }\end{array}$ \\
\hline Chernew M, 1998 [16] & US & Analysis of discharge data from hospitals \\
\hline $\begin{array}{l}\text { Chu-Weininger MYL, } \\
2006 \text { [49] }\end{array}$ & US & Telephone survey on 564 households \\
\hline Cooper PF, 1996 [17] & US & $\begin{array}{l}13.336 \text { interviews with individuals who visited a } \\
\text { care provider }\end{array}$ \\
\hline Curbow B, $1986[36]$ & US & $\begin{array}{l}\text { Interviews with } 180 \text { women who visited an } \\
\text { urban welfare office }\end{array}$ \\
\hline Davis K, 1995 [37] & US & $\begin{array}{l}\text { Telephone interviews with } 3.000 \text { enrolees of } \\
\text { fee-for-service and managed care organizations }\end{array}$ \\
\hline Donelan K, 2010 [28] & US & $\begin{array}{l}\text { Survey on } 3.490 \text { employees of large national } \\
\text { firm }\end{array}$ \\
\hline Draper DA, 2002 [38] & US & $\begin{array}{l}\text { Interviews with } 895 \text { key participants in the local } \\
\text { healthcare markets }\end{array}$ \\
\hline
\end{tabular}




\begin{tabular}{|c|c|c|}
\hline First author, year & Country & Methods/participants/data \\
\hline $\begin{array}{l}\text { Duijmelinck DMID, } 2016 \\
\text { [45] }\end{array}$ & Netherlands & Literature review \\
\hline $\begin{array}{l}\text { Dutch Health care } \\
\text { Authority, } 2007 \text { [23] }\end{array}$ & Netherlands & $\begin{array}{l}\text { Surveys among GPs end patients, interviews } \\
\text { with health insurers, trade organizations, civil } \\
\text { society organizations and consumer and } \\
\text { patient organizations }\end{array}$ \\
\hline Fitzgerald JD, 2012 [53] & US & $\begin{array}{l}\text { Analysis on data of Medicare Provider Analysis } \\
\text { and Review (MEDPAR) administrative records }\end{array}$ \\
\hline Forrest CB, 2002 [39] & US & $\begin{array}{l}\text { Telephone survey of } 19.415 \text { 18- to } 64 \text { year-old } \\
\text { adults whose most recent visit in the past } 12 \\
\text { months was their primary care provider }\end{array}$ \\
\hline $\begin{array}{l}\text { Freedman RA, } 2015 \\
\text { [13] }\end{array}$ & US & Survey interviews of 500 women \\
\hline Harris KM, 2002 [48] & US & $\begin{array}{l}\text { Discrete Choice Experiment (DCE) survey of } \\
206 \text { adults aged 25-64 in Los Angeles } \\
\text { metropolitan area }\end{array}$ \\
\hline Howard DH, 2008 [54] & US & Analysis on outcome data of transplant centres \\
\hline Kemper P, $1999[40]$ & US & $\begin{array}{l}\text { Analysis on nationally representative data from } \\
\text { the Community Tracking Study }\end{array}$ \\
\hline Kemper P, $2002[41]$ & US & $\begin{array}{l}\text { Survey of } 25.560 \text { individuals who have private } \\
\text { health insurance }\end{array}$ \\
\hline Kreier R, 2010 [19] & Switzerland & $\begin{array}{l}\text { Results are based on literature review and } \\
\text { knowledge of the authors }\end{array}$ \\
\hline Kyanko KA, 2013 [18] & US & Survey of 7.812 privately insured adults \\
\hline Leu RE, 2009 [20] & $\begin{array}{l}\text { Switzerland, } \\
\text { Netherlands }\end{array}$ & $\begin{array}{l}\text { Results are based on literature and knowledge } \\
\text { of the authors from the different countries }\end{array}$ \\
\hline Linton A, 2007 [29] & US & $\begin{array}{l}\text { Analysis on prescription fill records of } 300.084 \\
\text { beneficiaries }\end{array}$ \\
\hline Maarse H, 2016 [24] & Netherlands & Literature review \\
\hline Manning BT, 2016 [14] & US & $\begin{array}{l}\text { Questionnaires to } 231 \text { patients who sought } \\
\text { treatment by one spine surgeon }\end{array}$ \\
\hline McGlone TA, 2002 [15] & US & Survey of 222 adults who have a PCP \\
\hline Sakowski JA, 2004 [42] & US & $\begin{array}{l}\text { Survey of } 1.22418 \text { to } 64 \text { year-old adults with } \\
\text { private health insurance }\end{array}$ \\
\hline
\end{tabular}




\begin{tabular}{|c|c|c|}
\hline First author, year & Country & Methods/participants/data \\
\hline Scanlon DP, 2008 [30] & US & $\begin{array}{l}\text { Analysis on claims and enrolment data, hospital } \\
\text { level data, discharge data and hospital admissions } \\
\text { and discount data }\end{array}$ \\
\hline Schmittdiel J, 1997 [51] & US & Survey of 11.494 adults enrolled in an $\mathrm{HMO}$ \\
\hline Schur CL, 1998 [43] & US & $\begin{array}{l}\text { Telephone and in-person follow up survey of } \\
2.498 \text { adults }\end{array}$ \\
\hline Sinaiko AD, 2011 [31] & US & Survey of 4.200 Massachusetts state employees \\
\hline Sinaiko AD, 2014 [34] & US & $\begin{array}{l}\text { Analysis of claims and enrollment data of six } \\
\text { health plans over July } 2004 \text { to June } 2010\end{array}$ \\
\hline Sofaer S, 1993 [32] & US & Interviews with 811 members of an HMO \\
\hline Stevens GD, 2002 [44] & US & $\begin{array}{l}\text { Telephone survey of } 413 \text { parents of a random } \\
\text { sample of children attending elementary school } \\
\text { in southern California }\end{array}$ \\
\hline Tai-Seale M, 2003 [50] & US & $\begin{array}{l}\text { Survey of } 1.172 \text { respondent who indicated they } \\
\text { could switch health plans }\end{array}$ \\
\hline Thomson S, 2013 [12] & $\begin{array}{l}\text { Belgium, } \\
\text { Germany, } \\
\text { Netherlands, } \\
\text { Switzerland }\end{array}$ & $\begin{array}{l}\text { Results are based on literature and knowledge of } \\
\text { the authors from the different countries }\end{array}$ \\
\hline Tu HT, 2005 [47] & US & $\begin{array}{l}\text { Yearly telephone survey data of adults aged 18- } \\
64, N=39.000 \text { in } 2001 \text { and 2002, N=30.000 in } \\
2003\end{array}$ \\
\hline $\begin{array}{l}\text { Van de Ven WPMM, } \\
2013[3]\end{array}$ & $\begin{array}{l}\text { Belgium, } \\
\text { Germany, } \\
\text { Israel, } \\
\text { Netherlands, } \\
\text { Switzerland }\end{array}$ & $\begin{array}{l}\text { Results are based on literature and the } \\
\text { knowledge of the authors from the different } \\
\text { countries }\end{array}$ \\
\hline $\begin{array}{l}\text { Van der Geest SA, } 2015 \\
\text { [33] }\end{array}$ & Netherlands & $\begin{array}{l}\text { Analysis of claims data from a health insurer from } \\
\text { January } 2007 \text { to December } 2009\end{array}$ \\
\hline Williams DR, 2003 [52] & US & $\begin{array}{l}\text { Telephone survey of } 2.427 \text { households enrolled in } \\
\text { HMO }\end{array}$ \\
\hline Yip WC, 1998 [22] & China & Survey of 1.877 households in Beijing \\
\hline
\end{tabular}




\section{Do health insurers channel enrolees to contracted care providers?}

Selective contracting and channelling seem to be carried out mainly in the US, but they are also present in Switzerland, Israel and the Netherlands e.g. [3, 10-12]. In the US, different types of health plans are available and they differ in how far they restrict freedom of provider choice. Health Maintenance Organisations (HMOs) are managed care organisations that impose the most restrictions in care provider choice, while Fee-For-Service (FFS) is not managed, offering a free choice. HMOs seem to be able to channel enrolees to contracted care providers, since enrolees take the list of contracted providers into account when they choose a care provider $[10,13,14]$. McGlone et al. also emphasize that the reimbursement policy of the health insurer plays an important role in the selection of a primary care provider (PCP) [15]. Other studies from the US found that enrolees who chose an HMO that limits provider choice, use different care providers than other enrolees [16, 17]. A study by Kyanko et al. showed that most patients visit in-network providers. Only $8 \%$ of enrolees who went to a care provider had visited an out-of-network provider. The majority $(72,6 \%)$ of these did so on purpose, because, for instance, they wanted to continue treatment with a previously known physician or because this physician was recommended by friends or family [18]. In the US, literature on managed care organisations often describe broader issues than specifically channelling enrolees to contracted care providers. Those papers were not included in this study. We find that the overall reason why enrolees are channelled to contracted care providers successfully is that they want to avoid considerable out-of-pocket payments, since out-of-network providers are usually not reimbursed by their health plans.

According to both an expert's opinion and two papers, channelling enrolees to contracted providers is also common in Switzerland $[19,20]$. There, health insurance is mandatory and enrolees can choose between different health insurers. In addition to regular health plans offering a free choice of provider, health insurers also offer some sort of managed care plans. Enrolment in these managed care plans is growing (1,7\% in 1996 to 12,1\% in 2005 [19, 20] and 60\% in 2013 (expert)). However, not all forms of these managed care plans involve selective contracting, two-thirds of the managed care enrolees have fee-for-service plans with gatekeeping provisions [20]. In Israel, all health insurers offer only managed care contracts and offer a panel of care providers that differ between health insurers. Enrolees are not reimbursed when they go to a non-contracted care provider [3]. Experts from the other two European countries that reformed their health care in the last decades, Germany and Belgium, say selective contracting and channelling patients to preferred, 
contracted care providers is rare. This view was supported by two papers that compare the health care markets of European countries that have reformed health care in the last decades $[3,12]$. We found two studies from other countries, Saudi Arabia and China. In these papers, the involvement of health insurers in enrolees' choice of care provider was solely that enrolees take into account the reimbursement of their health insurer when they choose a care provider [21, 22]. We expect this to be the case in every country where health insurers are allowed to select care providers and determine their own levels of reimbursement.

In the Netherlands, where health insurers are supposed to contract care providers selectively in order to take up their role as prudent buyers of care, insurers are reluctant to implement selective contracting. The Dutch Health Care Authority drew the same conclusion one year after the implementation of the Health Insurance Act in the Netherlands in 2006 [23]. The reasons for this are that there is still uncertainty about the minimal level of reimbursement for enrolees who visit non-contracted care providers, there is a lack of transparency in the health insurance market and a lack of reliable quality indicators for health care. In addition many enrolees still value the advice of their GP above all when they choose a care provider [23]. Even by 2011, Boonen et al. found that health insurers are still reluctant to implement selective contracting [11]. They argue that the most important reason for this is a credible commitment problem; health insurers believe that their enrolees do not trust them to purchase good quality care on their behalf. They also found that enrolees are unwilling to listen to their health insurers' advice on the choice of care provider. However, this differs according to the type of provider. Enrolees are more willing to listen to their health insurer in relation to pharmacy or hospital choice and less when it comes to choosing a GP or a dentist. Maarse et al. reviewed the results of the Dutch health care reform and found that selective contracting is mainly done in pharmaceutical care. He also stated that enrolees do not trust health insurers to purchase good quality care on their behalf [24]. However, the take-up of selective contracting and the implementation of incentives to channel enrolees to preferred or contracted providers has been growing strongly in the last years [12]. We see a growth in the number of health plans in which selective contracting is practiced. This is especially true for health plans where care providers are selected for specific treatments, such as cancer treatments and hip or knee replacement surgery. Enrolees are given an incentive such as offering only partial reimbursement of healthcare costs when they go to a non-contracted care provider or a positive 
financial incentive, such as a financial bonus when a preferred provider is chosen [11].

\section{Summary}

There are differences between countries in the implementation of selective contracting and channelling. In the US, Switzerland and Israel selective contracting is practised, mostly by using negative financial incentives, such as by refusing reimbursement or introducing co-payments when enrolees visit out-of-network providers. In the Netherlands, the uptake of selective contracting is growing, although health insurers are still reluctant to implement this, since they fear their enrolees will not accept this and change insurers.

\section{How do, or how can, health insurers channel enrolees to contracted care providers?}

We found nine studies that investigated ways to channel patients to preferred or contracted providers [11, 25-33]. Five of these were conducted in the Netherlands $[11,25-27,33]$. The other studies were conducted in the US [28-32].

\section{Channelling incentives and status quo bias}

One study used a natural experiment to investigate a small financial incentive ( $\$ 6$ (generic) / \$18 (brand) out-of-pocket cost savings per supply) to channel enrolees of 65 years and older to an online pharmacy. This incentive was found to be ineffective. However, it did not reveal why. The incentive could have been too low, but it could also be that enrolees did not know about the incentive or were not able, or did not want to, use the online pharmacy. Age and distance to the pharmacy were the most important predictors of using the online pharmacy [29]. An article by Donelan and colleagues reports from a natural experiment where enrolees were offered a telephone service to help them choose a care provider. This service channelled enrolees towards choosing high quality care providers. The service was offered by the employer. Enrolees were very positive about this service and most enrolees who used it also followed the recommendations. However, many enrolees were not aware the service existed. Furthermore, it is very important that the information comes from a trusted source [28]. Research from the Netherlands shows that enrolees are unwilling to accept advice from their health insurer about which care provider to choose $[11,26]$. Willingness to accept advice from the health insurer is lowest for the choice of a GP and dentist, followed by physiotherapist, pharmacy and hospital [11]. Boonen et al. studied channelling strategies on the choice of a pharmacy by conducting a discrete choice experiment and found that 
both negative and positive financial incentives could work to channel enrolees to preferred providers. However, enrolees react much more strongly to negative financial incentives (co-payments) than to positive financial incentives (discounts). Quality incentives, namely customer satisfaction ratings, extended opening hours and the availability of a quality certificate, also have an effect on provider choice. Additionally, they found that status quo bias plays an important role in the ability to channel enrolees to preferred providers. Even though there are better options available, enrolees are reluctant to leave their current care provider [26]. A natural experiment showed that even small and temporary incentives have an effect on pharmacy choice [27]. However, the larger the incentive, the more likely that enrolees choose the preferred pharmacy and more enrolees stayed with the preferred pharmacy when the incentive was permanent [27]. Another natural experiment studied the effectiveness of channelling to specific hospitals for cataract surgery and varicose veins treatment. The incentive was exemption of paying the deductible when visiting a preferred provider. It was found to be effective for varicose veins treatment, not for cataract surgery. Reason for this was probably that enrolees who need cataract surgery are usually older and more likely to need care for other complaints as well. Therefore they would use up their deductible anyway and would not benefit from this incentive. Varicose veins patients are usually younger and therefore more likely to benefit from the incentive [33]. A discrete choice experiment by Boonen et al. shows that the impact of channelling incentives differs between different types of provider. For GPs, channelling incentives was less effective compared to pharmacies, most probably because enrolees have a more personal relationship with their GP than with their pharmacy. Status quo bias is much stronger for GPs than for pharmacies. This means that channelling enrolees to preferred GPs will be more costly, but if it succeeds, it is also more likely that the enrolee will stay with that GP [25]. However, it is also likely that enrolees will not accept this, since, according to Sofaer and Hurwicz, loyalty to the care provider (GP) is likely to be higher than loyalty to the health insurer. In this study, conducted in the US, authors conclude from a natural experiment that most enrolees switched health plans when their HMO cancelled the contract with their current care provider. They chose instead a health plan that does contract with their current provider [32].

\section{Tiered networks}

Sinaiko researched channelling enrolees to preferred providers in the context of a tiered network [31]. In a tiered network, enrolees have freedom of provider choice. The care providers are ranked by the health insurer on their level of preference, 
based on their performance on cost-effectiveness and quality. The most preferred providers are ranked in Tier 1 . When enrolees choose a provider in Tier 1 , they pay less or no out-of-pocket payments compared to when they choose a provider in a lower tier. The lower the tier, the higher the co-payments. In a hypothetical setting, Sinaiko shows that most enrolees (90\%) would choose a Tier 1 provider when the Tier 2 provider costs $\$ 10-35$ more than the Tier 1 provider. However, when a Tier 2 provider is recommended by a friend or family member, half of the enrolees would choose the Tier 2 provider. Even more enrolees would choose the Tier 2 provider when this provider is recommended by another physician. Channelling enrolees to the Tier 1 provider then would only succeed when the co-payment of a Tier 2 provider is much higher (\$290-440). The medical condition for which enrolees needed to choose a physician also mattered. Co-payments were less important to people when they had to choose a cardiologist for a heart condition, than when they had to choose a dermatologist for a routine skin check [31]. Scanlon et al. also researched channelling enrolees in a tiered hospital network, only they reported from a natural experiment. The subjects were employees, engineers and machinists of a large manufacturing company [30]. The tiers were based on a quality indicator, safety, with the safest hospitals in Tier 1 . When enrolees use a Tier 1 hospital they did not need to pay any co-insurance and their co-payment was lower. The results showed that this incentive worked, since enrolees who were exposed to the incentive were more likely to choose a safer hospital compared to the group that was not. However, this was only true for the engineers, not the machinists. The engineers are higher educated and, therefore, they may have found it easier to learn how to take advantage of this incentive. It is possible that the incentive will also work for the machinists, for instance if they are better informed about the incentive and how to benefit from it, but this is not clear [30]. A study on claims and enrolment data of a health plan that included a tiered physician network found that physicians in the lowest tier had the lowest market share of new patient visits compared to higher tiered physicians. Furthermore, tiering has the most effect when enrolees are looking for a new physician. The effect is absent when enrolees already have a relationship with a physician [34].

\section{Summary}

Channelling enrolees to preferred or contracted providers by using financial incentives seems to be most effective. Negative financial incentives are more effective than positive financial incentives. Other options are incentives related to quality. Furthermore, there is a strong status quo bias, which means that enrolees 
tend to prefer their current provider even if a better alternative is available. It is also possible in a tiered network to channel enrolees to preferred providers. Here, enrolees have freedom of choice, but their health insurer ranks care providers on quality and price and when they choose a provider in the highest tier (preferred) they have to pay lower out-of-pocket payments or co-insurance. This is also a negative financial incentive. The type of provider, the condition or the health status of the enrolees, recommendations from others and also the ability of enrolees to understand the preconditions of the health plan, may influence in how far enrolees can be channelled to preferred or contracted care providers.

\section{Enrolees' attitudes towards channelling by health insurers}

Enrolees are negative about choice restrictions

We found research showing that in general enrolees think negatively about restrictions in provider choice [24, 35-45]. Allen researched, through telephone interviews, customers' responses to three cost containment strategies for health care provision. Among these strategies was the use of preferred provider networks. Results showed that customers are negative about this strategy. Younger people, people with lower social economic status and non-white people were least negative about preferred provider arrangements [35]. Schur and Dorosh (1998) also conducted a survey to study the acceptance of cost containment strategies, among which was 'to choose a physician from a list'. They also showed that enrolees were negative about this. Older people, people with ischaemic heart disease, people with poor health status and enrolees of a FFS health plan were most negative, and the uninsured, poorer people and enrolees already in managed care, were least negative [43]. Results from a survey conducted by Sakowski et al. showed that, together with dissatisfaction with the coverage of preventive services, dissatisfaction with choice of providers is the largest predictor of enrolees' unwillingness to recommend their health plan to others [42]. In the Netherlands, it was found that health insurers are reluctant to implement restrictions in provider choice, because they fear losing enrolees, since they believe that their enrolees will not trust them to purchase good quality care on their behalf $[11,24]$. In previous research we conducted in the Netherlands we found that most enrolees (60\%) are positive that their health insurer would not contract low quality care providers. However, most enrolees (55\%) also indicate they would not want advice from their health insurer on care provider choice, let alone have their health insurer restrict their choice. Many enrolees say they would rather choose a care provider themselves and they question the intentions of the health insurer [46]. 
How to overcome this negative attitude?

In the US negativity about restrictions in provider choice has led to the so-called 'managed care backlash', a collective resentment against managed care [45]. Because of this, HMOs started to increase their freedom of provider choice, which resulted in an increase in co-payments and higher premiums in order to keep health care affordable [38, 45, 47]. A study from the US shows that $59 \%$ of insured employees are now willing to give up some freedom of provider choice in exchange for lower costs [47]. Enrolees with a low income (67\%) were more likely to be willing to give up some freedom of choice compared to enrolees with a high income (54\%). Among chronically ill enrolees, the percentage was 56\%. However, a large number of enrolees was not willing to give up freedom of provider choice for lower costs and the conclusion was that preferences differ substantially amongst enrolees. Therefore, it is important that choice options are given [47]. In a report on selective contracting by the Dutch Health Care Authority, authors state that satisfaction with a restrictive health plan is higher when enrolees have consciously chosen this health plan themselves, rather than it being assigned to them, for instance when health insurers readily implement it or, in the case of the US, when their employer only offers a restrictive health plan [23]. Duijmelink et al. studied the managed care backlash of the US to find lessons for Europe. One of these lessons includes giving enrolees a choice between types of health plans. Other things they recommend are providing enrolees with information about the quality of care of providers and about managed care and the effects of it [45]. Harris studied whether high quality of care could overcome the resistance of enrolees to restrictions in provider choice. Results show that a high quality of care increases the willingness of enrolees to accept restrictions in provider choice. However, for enrolees to accept this, the level of quality of care needs to be very high. It is most likely to be too high to be attainable [48].

\section{Summary}

Enrolees are very negative about restrictions in provider choice. However, since the out-of-pocket costs in the US were rising with the implementation of more freedom of choice, more and more enrolees are willing to give up some freedom of choice for lower co-payments. Also, enrolees who chose a restrictive health plan, for instance to save costs, seem to be more positive about their health plan. 


\section{Consequences of selective contracting for enrolees} Negative consequences

It was found that not having a choice, or having restrictions in provider choice, has negative effects upon the patient-provider relationship. This is because enrolees with restricted choice of primary care provider (PCP) report lower trust in their PCP $[37,40,41,44,49,50]$ and lower satisfaction with their PCP $[39,51]$. Even when the physician was not very popular in general, enrolees who chose their own physician were always more satisfied than enrolees who were assigned one [51]. HMO enrolees also report lower satisfaction with their health care in general [40]. Selective contracting also affects the way enrolees look at their health insurer. Enrolees' trust in their health plan is lower when there are restrictions in provider choice [44]. Furthermore, enrolees are more likely to recommend their health plan to others when they are satisfied with their PCP and when they have a choice of PCP [52]. Sinaiko found that when patients already have a relationship with a physician and their health plan places their physician in the lowest tier, they are $75 \%$ more likely to switch health plans [34]. Patients also experience more out-of-pocket costs, because they have to pay a co-payment when they use an out-of-network provider, and endure more administrative barriers in when they are enrolled in a managed care organisation. Fitzgerald et al. studied the impact on patients to see if they would be channelled to high-volume hospitals and found that for most enrolees this would not result in unmanageable travel distances. Except for patients in rural areas, who would sometimes have to travel further. In urban areas, the choice of a lowvolume hospital is associated with lower socioeconomic status. Channelling to high volume hospitals could limit access to care for this group [53].

\section{Positive consequences}

We found a few papers that review the impact of selective contracting on the quality of care that enrolees receive. Selective contracting seems to lead to better health care quality even though enrolees covered through $\mathrm{HMO}$ insurance assess their care as worse than those not insured with an HMO. Howard compared differences in quality between in-network and out-of-network providers, and found that in-network providers have better outcomes. A reason for health plans to contract high quality care providers is that patients will be more likely to enrol when the provider network includes such providers. He also found that patients insured privately with restrictive provider networks are more likely to register at hospitals with higher survival rates [54]. Chernew et al. found that enrolees of HMOs travel farther to hospitals, but also that they receive better quality of care [16]. Kemper et 
al. compare different types of insurance with regard to patients' use of services, access to care, and assessment of care. Looking at the whole range of managed care from completely unmanaged to highly managed, they found no proof of differences in unmet need or delayed care, the use of hospitals, and in the use of surgery and emergency rooms [41]. To be more sure of the effects of selective contracting on quality of care in general, a more specific literature search on this subject needs to be conducted.

\section{Summary}

The consequences of restrictions in choice are that enrolees have less trust in their care providers and in their health insurer. Furthermore, enrolees in managed care need to travel farther for their care providers. It is however positive that in-network providers seem to deliver better quality of care compared to out-of-network providers, which means that restrictive health plans contract good quality care providers for their enrolees. On the other hand, the finding that enrolees in HMOs assess their care as worse than those not insured with an $\mathrm{HMO}$, shows that the negative impact of restricting choice has a heavy impact on enrolees.

\section{Discussion}

In the theory of managed competition, selective contracting by health insurers is important. Health insurers are supposed to negotiate with care providers, both to promote improvement in the quality of health care and to control the costs. In order to have a strong bargaining position in negotiations with care providers, health insurers need to be able to channel their enrolees to contracted care providers. This scoping review was conducted to find out what is known about health insurers channelling enrolees to contracted care providers. Overall, the results of this scoping review show that selective contracting is mainly practised in the US, but also in Switzerland and Israel. In the Netherlands, it is increasingly being implemented. Enrolees are mostly channelled to preferred or contracted care providers through negative financial incentives such as co-payments. We also found that this is the most effective strategy for channelling patients to preferred or contracted providers. There are other options too, such as quality incentives or advice from the health insurer. However, trust in their health insurer seems to be too low to accept advice about the choice of care provider. Furthermore, enrolees are very negative about restrictions in provider choice. The consequences of restricting choice are 
that satisfaction with, and trust in, care providers and the health insurer diminish. Choice seems to be crucial in this respect. Enrolees are more satisfied with their health plans and care providers when they have chosen them themselves instead of them being assigned by their employer and health plan, respectively.

\section{Strengths and limitations}

A strength of this scoping review is the very broad search strategy developed together with a librarian. This resulted in over 2000 references that were all assessed, in part, by two reviewers. Therefore, it is likely that few references were missed. In addition, we asked experts in the field for their knowledge on the subject and for documents to add to our results. A limitation of this study is that we only searched for scientific papers, which could mean that we missed grey literature such as reports. However, we also added references from our own possession and experts to our search results, which were reports and not scientific papers.

\section{Knowledge gaps and future research}

According to the theory of managed competition, selective contracting and channelling enrolees to contracted care providers is very important if a health care system based on managed competition is to achieve its goals of improving the quality of care and containing costs. Since the results of this knowledge synthesis showed that channelling enrolees is possible, but that enrolees are very negative about this, the question that remains is: How can selective contracting and channelling be implemented in a way that is acceptable to enrolees? It was shown in this paper that choice is very important to enrolees and that enrolees are more satisfied with their health plan when they have chosen it themselves. This can be explained by the Self Determination Theory (SDT), which states that autonomy is one of the basic human needs $[55,56]$. But, under which conditions will enrolees choose a restrictive health plan over a health plan with more freedom of choice? According to economic theory and the assumptions which underpin health care systems based on managed competition, enrolees are critical consumers who make rational choices $[4,57]$. The idea is that enrolees would want to maximize their utility according to their preferences with the means they have available. Lancasters' theory states that, instead of the good itself, utility is derived from the properties or characteristics, named attributes, of the good [58]. Thus, enrolees need to weigh different attributes of health plans, such as coverage, freedom of choice and whether their preferred care provider is contracted against price and other "costs", such as the time and effort that it takes to change insurers. Research questions that 
need to be answered would be: How much cheaper does a restrictive health plan need to be for enrolees to choose it? And, what role do other important attributes such as quality, freedom of choice and travel distance to the nearest contracted hospital, play in this? For example, are enrolees willing to travel further for a care provider in exchange for a lower premium? Furthermore, it is expected that preferences for different attributes differ between enrolees with different characteristics. For instance, the reviewed literature showed that compared to enrolees with a lower income, enrolees with a higher income are more willing to give up some freedom of provider choice in exchange for a lower premium or copayments, while enrolees with a chronic condition are less willing to give up freedom of choice in exchange for lower costs, compared to healthier enrolees. It would be interesting to look further into enrolees' characteristics in combination with their preferences for types of health plans and the effectiveness of channelling incentives. Research questions could be: Under which conditions will different types of enrolees choose a restrictive health plan? And, for which enrolees will different types of incentives be more effective? Determan et al., from the Netherlands, recently conducted a DCE and found that young and healthy enrolees are willing to accept selective contracting when prices of such health plans are lower than they are now. Also, older enrolees and enrolees in poorer health are not likely to choose a restrictive health plan at all [59]. However, this is only one study, and travel distance to the nearest care provider, which is very important to enrolees $[60,61]$, was not included in the analyses. Therefore more research is needed to find out how enrolees weigh different attributes of health plans against each other. Furthermore, we found that trust in the health insurer may be an important factor in the acceptance of selective contracting. Enrolees supposedly do not trust their health insurer to purchase good quality health care. A lack of trust may thus be a factor that adds to the "costs" of a restrictive health plan. It is likely that enrolees with greater trust in their health insurer will accept selective contracting more readily. This is confirmed by the findings of Bes et al. [62]. Therefore, it is important that health insurers focus on ways to restore or gain the trust of their enrolees.

\section{Policy implications}

The results of this scoping review are relevant to consider if selective contracting is going to be implemented. It is important to look further into how selective contracting and channelling can be implemented in such a way that enrolees will accept it. Since this paper showed there are many negative aspects to selective contracting for enrolees, it is important too to consider other ways to improve 
quality and reduce costs in health care systems based on managed competition. Because of the resentment towards choice restrictions, it may be better if health insurers use soft incentives, such as providing only advice to enrolees on choosing a care provider. While trust in health insurers is quite low, soft incentives are less likely to be effective as a channelling method. However, trust may be built up over time, while financial incentives may lower trust even further. Furthermore, policy that is effective in one country will not necessarily be successful in another. When looking at other countries in order to find solutions to common problems, it is important to note that the degree to which policy can be transferred between countries may be hampered by contextual differences within the different health care systems. This often makes direct copying of policy impossible, since policy needs to be adjusted to the specific situation in a country $[63,64]$. For example, in the Netherlands before the insurance reform, enrolees were used to free choice of care provider. This may make the switch to restrictive health plans in the current health care system more negative for them compared to enrolees in countries where free choice was never de norm.

\section{Conclusions}

This scoping review shows that channelling enrolees to preferred or contracted providers is possible. In channelling enrolees, negative financial incentives are most effective. However, these also have the most negative consequences for enrolees. There are other options to channel patients to preferred or contracted providers such as quality incentives or advice from the health insurer. However, these are less effective and for these options to succeed enrolees must first trust their health insurer. Currently, trust in health insurers seems to be too low to accept advice on care provider choice. Enrolees are very negative about restrictions in provider choice introduced by the health insurer. Restrictions in provider choice also have negative consequences for satisfaction with, and trust in, care providers and the health insurer. In order to implement selective contracting and channelling in a way acceptable to enrolees, research should focus on how health insurers can gain or restore trust enrolees have in them and how people weigh different attributes of health plans. The results of this study provide a good starting point for further research as it sheds light on several knowledge gaps. 


\section{References}

1. Laske-Aldershof T, Schut E, Beck K, Gress S, Shmueli A, Van de Voorde C: Consumer mobility in social health insurance markets: a five country comparison. Applied Health Economics and Health Policy 2004, 3:229-241.

2. Saltman RB, Figueras J: Analyzing the evidence on European health care reforms. Health Affairs 1998, 17:85-108.

3. Van de Ven WPMM, Beck K, Buchner F, Schokkaert E, Schut FT, Shmueli A, Wasem J: Preconditions for efficiency and affordability in competitive healthcare markets: are they fulfilled in Belgium, Germany, Isreal, the Netherlands and Switzerland? Health Policy 2013, 109:226-245.

4. Enthoven AC: The history and principles of managed competition. Health Affairs 1993, 12(1):24-48.

5. Sorensen AT: Insurer-hospital bargaining: negotiated discounts in post-deregulation Conneticut. Journal of Industrial Economics 2003, 51(4):469-490.

6. Wu VY: Managed care's price bargaining with hospitals. Journal of Health Economics 2009, 28:350-360.

7. Kroneman M, Boerma W, Van den Berg M, Groenewegen PP, De Jong JD, Van Ginneken E: The Netherlands: health systems review. Health Systems in Transition 2016, 18(2):1239.

8. Arksey H, O'Mally L: Scoping studies: towards a methodological framework. International Journal of Social Research Methodology 2005, 8(1):19-32.

9. Crooks VA, Kingsbury P, Snyder J, Johnston R: What is known about the patient's experience of medical tourism? A scoping review. BMC Health Services Research 2010, 10:266.

10. Abraham J, Sick B, Anderson J, Berg A, Dehmer C, Tufano A: Selecting a provider: What factors influence patients' decision making? Journal of Healthcare Management 2011, 56(2):99-114.

11. Boonen LHHM, Schut FT: Preferred providers and the credible commitment problem in health insurance: first experiences with the implementation of managed competition in the Dutch health care system. Health Economics, Policy and Law 2011, 6:219-235.

12. Thomson S, Busse R, Crivelli L, Van de Ven WPMM, Van de Voorde C: Statutory health insurance competition in Europe: a four country comparison. Health Policy 2013, 109:209-225.

13. Freedman RA, Kouri EM, West DW, Keating NL: Racial/Ethnic differences in patients selection of surgeons and hospitals for breast cancer surgery. JAMA Oncology 2015, 1(2):222-230. 
14. Manning BT, Ahn J, Bohl DD, Mayo BC, Louie PK, Singh K: Spine sugeon selection criteria: factors influencing patient choice. SPINE 2016, 41(13):814-819.

15. McGlone TA, Butler ES, McGlone VL: Factors influencing consumers' selection of a primary care physician. Health Marketing Quarterly 2002, 19(3):21-37.

16. Chernew M, Scanlon DP, Hayward R: Insurance type and choice of hospital for coronary artery bypass graft surgery. Health Services Research 1998, 33(3):447-466.

17. Cooper PF, Nichols LM, Taylor AK: Patient choice of physician: Do health insurance and physician characteristics matter? Inquiry 1996, 33:237-246.

18. Kyanko KA, Curry LA, Busch SH: Out-of-network physicians: How prevalent are involuntary use and cost transparency? Health Services Research 2013, 48(3):11541172.

19. Kreier R, Zweifel P: Health insurance in Switzerland: a closer look at a system often offered as a model for the United States. Hofstra Law Review 2010, 39(1):89-110.

20. Leu RE, Rutten FFH, Brouwer W, Matter P, Rütschi C: The Swiss and Dutch health insurance systems: universal coverage and regulated competetive insurance markets. In.: The Common Wealth Fund; 2009.

21. Bin Saeed KS: Factors affecting patients' choice of hospitals. Annals of Saudi Medicine 1998, 18(5):420-424.

22. Yip WC, Wang H, Liu Y: Determinants of patient choice of medical provider: A case study in rural China. Health Policy and Planning 1998, 13(3):311-322.

23. Dutch Health Care Authority: Richting geven aan keuzes. Kunnen verzekeraars consumenten stimuleren naar gecontracteerde voorkeursaanbieders te gaan? [Directions to choices. Can health insurers stimulate consumers to visit contracted preferred providers?]. Utrecht, The Netherlands: Dutch Health Care Authority [NZa]; 2007.

24. Maarse $H$, Jeurissen $P$, Ruwaard $D$ : Results of the market-oriented reform in the Netherlands: a review. Health Economics Policy and Law 2016, 11(2):161-178.

25. Boonen LHHM, Donkers B, Schut FT: Channeling consumers to preferred providers and the impact of status quo bias: does type of provider matter? Health Services Research 2011.

26. Boonen LHHM, Schut FT, Donkers B, Koolman X: Which preferred providers are really preferred? Effectiveness of insurers' channeling incentives on pharmacy choice. International Journal of Health Care Finance Economics 2009, 9:347-366.

27. Boonen LHHM, Schut FT, Koolman X: Consumer channeling by health insurers: natural experiments with preferred providers in the Dutch pharmacy market. Health Economics 2008, 17:299-316. 
28. Donelan K, Rao SR, Rogers RS, Mailhot JR, Galvin R: Experience with health coachmediated physician referral in an employed insured population. Journal of General Internal Medicine 2010, 25(10):1071-1077.

29. Linton A, Garber M, Fagan NK, Peterson M: Factors associated with choice of pharmacy setting among DoD health care beneficiaries aged 65 years or older. Journal of Managed Care Pharmacy 2007, 13(8):677-686.

30. Scanlon DP, Lindrooth RC, Christianson JB: Steering patients to safer hospitals? The effect of a tiered hospital network on hospital admissions. Health Services Research 2008, 43(5, Part II):1849-1868.

31. Sinaiko AD: How do quality information and cost affect patient choice of provider in a tiered network setting? Results from a survey. Health Services Research 2011, 46(2):437-456.

32. Sofaer $\mathrm{S}$, Hurwicz ML: When medical group and HMO part company: disenrollment decisions in Medicare HMOs. Medical Care 1993, 31(9):808-821.

33. Van der Geest SA, Varkevisser M: Using the deductible for patient channeling: did preferred providers gain patient volume? European Journal of Health Economics 2016, 17(5):645-652.

34. Sinaiko AD, Rosenthal MB: The impact of tiered physician networks on patient choices. Health Services Research 2014, 49(4):1348-1363.

35. Allen HM: Consumers and choice: costcontainment strategies for health care provision. Health Psychology 1984, 3(5):411-430.

36. Curbow B: Health care and the poor: psychological implications of restrictive policies. Health Psychology 1986, 5(4):375-391.

37. Davis K, Collins KS, Schoen C, Morris C: Choice matters: enrollees' views of their health plans. Health Affairs 1995, 14(2):99-112.

38. Draper DA, Hurley RE, Lesser CS, Strunk BC: The changing face of managed care. Health Affairs 2002, 21(1):11-23.

39. Forrest. C B, Shi L, Von Schrader S, Ng J: Managed care, primary care, and the patientpractitioner relationship. Journal of General Internal Medicine 2002, 17:270-277.

40. Kemper P, Reschovsky JD, Tu HT: Do HMOs make a difference? Summary and implications. Inquiry 1999, 36:419-425.

41. Kemper P, Tu HT, Reschovsky JD, Schaefer E: Insurance product design and its effects: trade-offs along the managed care continuum. Inquiry 2002, 39:101-117.

42. Sakowski JA, Phillips KA, Liang SY, Haas JS: Willingness to recommend a health plan: Who is dissatisfied and what don't they like? The American Journal of Managed Care 2004, 10(6):393-400. 
43. Schur $\mathrm{CL}$, Dorosh E: Attitudes toward cost-containment features of managed care: differences among patient subgroups. The American Journal of Managed Care1998, 4(10):1385-1391.

44. Stevens GD, Shi L: Effect of managed care on children's relationships with their primary care physicians: Differences by race. Archives of Pediatrics \& Adolescent Medicine 2002, 156:369-377.

45. Duijmelinck DMID, Van de Ven WPMM: What can Europe learn from the managed care backlash in the United States? Health Policy 2016, 120(5):509-518.

46. Bes RE, Wendel S, de Jong JD: Het vertrouwensprobleem van zorgverzekeraars [The trust issue of health insurers]. Economisch Statistische Berichten 2012, 97(4647):676677.

47. Tu HT: More Americans willing to limit physician-hospital choice for lower medical costs. Center for Studying Health System Change 2005, 94:1-5.

48. Harris KM: Can high quality overcome consumer resistance to restricted provider access? Evidence from a health plan choice experiment. Health Services Research 2002, 37(2):551-571.

49. Chu-Weininger MYL, Balkrishnan R: Consumer satisfaction with primary care provider choice and associated trust. BMC Health Services Research 2006, 6:139.

50. Tai-Seale M, Pescosolido B: The public's opinions of physicians: Do perceived choice and exercised choice matter? The American Journal of Managed Care 2003, 9(9):631-638.

51. Schmittdiel J, Selby JV, Grumbach K, Quesenberry CP: Choice of a personal physician and patient satisfaction in a health maintenance organization. Journal of the American Medical Association 1997, 278(19):1596-1599.

52. Williams DR, O'Connor SJ, Shewchuk RM: Upstream or downstream: Determinants of consumer willingness to recommend an HMO. The Journal of Ambulatory Care Management 2003, 26(2):175-180.

53. Fitzgerald JD, Soohoo NF, Losina E, Katz JN: Potential impact on patient residence to hospital travel distance and access to care under a policy of preferential referral to highvolume knee replacement hospitals. Arthritis Care \& Research 2012, 64(6):890-897.

54. Howard DH: Hospital Quality and Selective Contracting: Evidence from Kidney Transplantation. Forum for Health Economics and Policy 2008, 11(2):Article 2.

55. Deci EL, Ryan RM: Intrinsic motivation and self-determination in human behaviour. New York, NY: Plenum Press; 1985.

56. Deci EL, Ryan RM: Self Deternination Theory: a macrotheary of human motivation, development and health. Canadian Psychology 2008, 49(3):182-185.

57. Victoor A, Delnoij DMJ, Friele RD, Rademakers JJDJM: Determinants of patient choice of healthcare providers: a scoping review. BMC Health Services Research2012, 12(272). 
58. Lancaster KJ: A new appraoch to consumer theory. Journal of Political Economy 1966, 74(2):132-157.

59. Determan D, Lambooij MS, de Bekker-Grob EW, Hayen AP, Varkevisser M, Schut FT, de Wit GA: What health plans do people prefer? The trade off between premium and provider choice. Social Science \& Medicine 2016, 165:10-18.

60. Varkevisser M, Van der Geest SA: Why do patients bypass the nearest hospital? An empirical analysis for orthopaedics care and neurosurgery in the Netherlands. European Journal of Health Economics 2007, 8(3):287-295.

61. Varkevisser M, Van der Geest SA, Schut FT: Assessing hospital competition when prices don't matter to patients: the use of time-elasticities. International Journal of Health Care Finance Economy 2009, 10(1):43-60.

62. Bes RE, Wendel S, Curfs EC, Groenewegen PP, de Jong JD: Acceptance of selective contracting: the role of trust in the health insurer. BMC Health Services Research 2013, 13:375.

63. Hansen J, De Jong JD, Groenewegen PP, Ricciardi W: Building sustainable and resilient health care systems, how ERA-NETs in Horizon 2020 can help Eurohealth (forthcoming) 2015.

64. Rose R: Lesson drawing in public policy: a guide to learning across time and space: Chatham House; 1993 


\section{Chapter 3}

Health plan choice in the Netherlands: restrictive health plans preferred by young and healthy individuals

Published as:

Bes RE, Curfs EC, Groenewegen PP, de Jong JD. Health plan choice in the Netherlands: restrictive health plans preferred by young and healthy individuals. Health Economics, Policy and Law 2017, 1-18. 


\section{Abstract}

In a health care system based on managed competition, health insurers negotiate on quality and price with care providers and are allowed to offer restrictive health plans. It is crucial that enrolees who need care choose restrictive health plans, since otherwise health insurers cannot channel patients to contracted providers and they will lose their bargaining power in negotiations with providers. We aim here to explain enrolees' choice of a restrictive health plan in exchange for a lower premium. In 2014 an online survey with an experimental design was conducted on members of an access panel (response 78 per cent; $n=3,417$ ). This showed 37.4 per cent of respondents willing to choose a restrictive health plan in exchange for a lower premium. This fell to 22 per cent when the restrictive health plan also included a longer travelling time. Enrolees who choose a restrictive health plan are younger and healthier, or on lower incomes, than those preferring a non-restrictive one. This means that enrolees who use care will be unlikely to choose a restrictive health plan and, therefore, health insurers will not be able to channel them to contracted care providers. This undermines the goals of the health care system based on managed competition. 


\section{Introduction}

Several countries have implemented health care systems based on managed competition, for instance Germany, Switzerland and the Netherlands [1, 2]. In a health care system based on managed competition, the idea is that third party payers prudently purchase care based on price and quality on behalf of their clients, the patients [3]. These third party payers are usually health insurers, but they can also be employers or government bodies. Enrolees are allowed to switch health plans and, therefore, health insurers are supposed to compete with each other for enrolees by trying to offer the best health plans in terms of quality and price. Health insurers are allowed to contract care providers selectively, which means that they do not have to contract all care providers. In order to keep their revenue, care providers will compete with each other to be contracted by health insurers. This competition between care providers should lead to increased quality of care, while costs are contained. The idea is that health insurers will have a better bargaining position in negotiations with care providers if they can successfully channel their enrolees to contracted care providers, since this will imply a loss of business for noncontracted care providers $[4,5]$. Selective contracting, which means that the choice of care providers is more restrictive, can be conducted in preferred provider networks and in exclusive networks. In a preferred provider network, costs are only partially reimbursed if enrolees go to a non-contracted care provider. In an exclusive network, care providers who are not contracted are not reimbursed at all. The idea of a system of managed competition is that health insurers select care providers based on price and quality. Care providers are supposed to compete with each other to be included in a health plan's network, since that will increase their number of patients and thus their revenues. This should lead to better quality of care and a reduction in health care costs.

Channelling enrolees to contracted care providers is important for the health care system to reach its goals of improving the quality of care and reducing costs $[5,6]$. It was shown that financial incentives in restrictive health plans are effective in channelling patients to contracted care providers [7-9]. However, restrictive health plans are not favoured by enrolees [10]. Enrolees are sensitive to negative aspects of restrictions in their choice of care provider. E.g., the fact that their health insurer is involved in the choice of care provider and that enrolees may have to travel further to the nearest care provider. A positive aspect, however, is that restrictive 
health plans are usually cheaper for enrolees compared to health plans with a free choice of provider.

However, research from the US shows that enrolees who have a restrictive health plan are less satisfied with their health plan and their care providers [11-14]. This was the case even though it was shown that the quality of care providers in restrictive health plans is equal or even better than care in non-restrictive health plans $[15,16]$. However, when enrolees have chosen a restrictive health plan themselves, rather then it being appointed to them (e.g. by their employer which is common in the US), enrolees are more positive about their health plan and their care providers. Therefore, it seems to be important that enrolees have a choice between different types of health plans $[12,17]$. An important question is, who would choose a restrictive health plan and, thus, accept restrictions in provider choice, and maybe a longer distance to travel as well, for a lower premium? If the health care system is to reach its intended goals of improving quality and reducing health care costs, it is important that not only young and healthy enrolees, but also enrolees who actually use care, choose a restrictive health plan. Because, when only healthy enrolees, who rarely use care, choose a restrictive health plan, care providers will not notice a loss of business when they are not contracted, since enrolees who use care do not have a restrictive health plan and keep visiting the same care providers. Thus, there will be no incentive for competition between care providers and, according to Enthoven's theory, no incentive to improve health care quality while costs are controlled. Restrictive health plans could still be cheaper compared to non-restrictive health plans, because of favourable selection bias, but this would mean that the health care system does not work as intended. Some research on who chooses a restrictive health plan has been carried out in the US, but not yet in the Netherlands, and there are significant differences in health care systems between the two countries, for instance in the Netherlands people are obliged to have health insurance and historically, they are used to having free choice of care provider [18]. Therefore, this study will focus on the Dutch situation. It will also be relevant for other countries implementing a system of managed competition, especially where, like in the Netherlands, a transfer from a supplyoriented, social health insurance system, to a managed competition system with a free choice of health plan is intended. The research question that will be answered in this paper is: What are the demographic characteristics of people who are willing to choose a restrictive health plan? Furthermore, we aim to explain why different groups of enrolees would choose a restrictive health plan or not. 


\section{Context}

Research in the US has been conducted on who chooses Health Maintenance Organisation (HMO) plans, i.e. health plans which restrict provider choice. This was mainly in order to find out whether HMO plans are experiencing favourable selection bias, where younger and healthier enrolees enrol more often in these type of health plans e.g. [19-21]. Literature reviews by Hellinger show that healthier enrolees are more likely to enrol in an HMO plan. People who actually need to use care are less willing to choose a restrictive health plan, probably because they do not want to change care providers since they already have an established relationship with their current care provider $[19,20]$. In Switzerland too, HMO plans experience favourable selection bias since enrolees of $\mathrm{HMO}$ plans are on average seven years younger than enrolees of conventional health plans [22].

Ever since health plans in the US increased freedom of choice in response to a collective resentment against managed care, out-of-pocket payments have grown rapidly in order to keep health care affordable [23]. Research, therefore, now shows an increasing willingness of enrolees to give up freedom of provider choice in exchange for lower out-of-pocket payments (from 55 to 59 per cent ) [23]. It was found that adults on a low income are more willing to accept restrictions on their freedom of choice in exchange for lower costs compared to adults earning a higher income. But the difference is not large. Additionally, it was found that adults suffering from a chronic illness are less willing to accept restrictions on their freedom of choice in exchange for lower costs compared to adults enjoying better health. This is likely because they do not want to risk having to switch care providers. However, the difference in willingness to accept restrictions on their freedom of choice in exchange for lower costs, between the two groups is small. The effect is likely cancelled out by a higher price-sensitivity of patients with chronic health conditions compared to enrolees who hardly use care. Patients with chronic conditions are more price sensitive because, in the US, enrolees have a high burden of out-of-pocket costs [23]. Although the chronically ill in the Netherlands probably pay somewhat more compared to people in better health, the difference is not very large [24]. Therefore, it is likely that in the Netherlands people with chronic conditions will be less willing to accept a restrictive health plan in exchange for a lower premium.

Basic health plans are all the same, since the government determines the content in terms of care; but the freedom of provider choice and the premiums differ between 
different health insurers or health plans. For instance, midwifery care is included in the basic health plan, so all health insurers have to offer this type of care. However, health insurers are free to contract only a certain number of care providers that offer midwifery care. In general, more freedom of choice means a more expensive premium. If enrolees use providers with whom the insurers do not have a contract then enrolees will have to pay part of the costs themselves.

Typical of the Dutch health care system is that before the introduction of managed competition in 2006, there was a social health insurance system in which people experienced freedom of provider choice. Therefore, health insurers are reluctant to implement selective contracting, because they expect that their enrolees will not accept it and change insurers [4]. Even so, restrictive health plans are currently being introduced and most health insurers offer restrictive health plans as well as non-restrictive ones. In 2015, around 7,5 per cent of enrolees in the Netherlands has a restrictive health plan [25].

Meanwhile, it has also been shown that many people in the Netherlands do not know what selective contracting is, and indeed, that it entails a restriction of provider choice [26]. When it is explained to people what selective contracting is, it was found that Dutch enrolees are very negative about such restrictions [10]. However, because it was found that a lot of people do not know what selective contracting is, it is not clear whether enrolees of restrictive health plans in the Netherlands consciously chose this restrictive health plan in exchange for a lower premium or whether they only looked at the premium and did not realize these health plans have a restricted care provider choice. Thus, it is unclear who would in fact choose a restrictive health plan in exchange for a lower premium. Also, it is unknown whether the current differences in premiums between restrictive and nonrestrictive health plans are substantial enough for people to choose a restrictive health plan consciously. We conducted a small scale choice experiment in order to answer these questions.

\section{Model and hypotheses}

In order to explain the choice of a restrictive health plan, we developed a model based on the rational choice theory [27] as was performed, for instance, by Kortenhoeven [28]. The focus here is on the core attributes of freedom of choice 
and price. In addition, the travelling time will be included since this can be a consequence of selective contracting and patients generally dislike travelling [29]. The goals of enrolees when choosing a health plan are: appropriate options for choosing care providers when they need care, low costs and a short travelling time to care providers. A short travelling time and appropriate options for choosing care providers are easily achieved when a non-restrictive health plan is chosen; while costs are lowest when a restrictive health plan is chosen.

\section{Free choice}

Choosing a health plan with restrictions in provider choice could feel like taking a risk, since individuals do not know what care they will need in the future and which care providers they will want or need [30]. Individuals who are more risk averse in nature are, therefore, expected to avoid restrictive health plans. Generally, women are shown to be more risk averse than men [31] and, therefore, it is likely that men would choose a restrictive health plan more often than women.

\section{H1: Men choose a restrictive health plan more often than women.}

Elderly people are more at risk of needing care in the near future. Therefore, choosing a restrictive health plan is more risky for them. Thus, older people are expected to be less likely to choose a restrictive health plan.

H2: Younger people choose a restrictive health plan more often than older people.

People who are unhealthy visit care providers more regularly and are, thus, likely to have built a relationship with their care provider. Choosing a restrictive health plan will risk losing that relationship. Therefore, it is expected that people who are unhealthy are less likely to choose a restrictive health plan compared to healthy people.

H3: Healthy people choose a restrictive health plan more often than people who are less healthy.

\section{Travelling time}

People who are older or in poorer health may experience more trouble with their mobility. A longer travelling time is, therefore, expected to be a greater problem for them compared to people who are younger or healthier. 
H4: People who are older or in poorer health will attach more value to a shorter travelling time and therefore be less likely to accept a longer travelling time in exchange for a lower premium.

People who are in poorer health are unlikely to opt for a longer travelling time, since that implies a switch of care providers and it is more uncomfortable for them to travel. However, income may play a role in this since it is expected that people with income constraints are more price sensitive $[32,33]$ or simply may not be able to afford a health plan offering a free choice of provider. Therefore, we expect the relationship between health status and the acceptance of a longer travelling time will be different for people on a low income compared to those on a high income.

H5: People who are in poorer health and on a low income will accept, more often, a longer travelling time in exchange for a lower premium compared to people who are unhealthy but on a higher income.

\section{Price}

People on a low income are expected to be more sensitive to price, and may therefore value, more highly, the benefit of a lower premium compared to people on a higher income [32-34]. However, one consequence of opting for a restrictive health plan could be that enrolees have to travel further to attend the nearest care provider with whom their insurer has a contract. A longer travelling time is more costly, but, depending on the frequency of visits, it is likely that the yearly savings on the premium will override the extra costs of travelling further. It is also possible that enrolees are restricted by their low income. They cannot afford to buy a nonrestrictive health plan and, therefore, have to choose a restrictive one. Thus, it is expected that individuals on a low income are more likely to give up their freedom of choice and/or short travelling time in exchange for a lower premium.

H6: People with a low income are more likely to exchange their freedom of choice and/or short travelling time for a lower premium.

H6 states that people on a low income would prefer to choose a restrictive health plan. However, the choice of a restrictive health plan poses more risks for individuals who are in poor health. The question is whether the savings on the premium are high enough to compensate for this risk. Choosing a restrictive health plan because 
of the low price may be less likely for people in poor health and on a low income compared to people in good health on a low income.

H7: People in good health on a low income would choose a restrictive health plan more often compared to people in poor health on a low income.

Figure 1 Model to explain the choice of a restrictive health plan

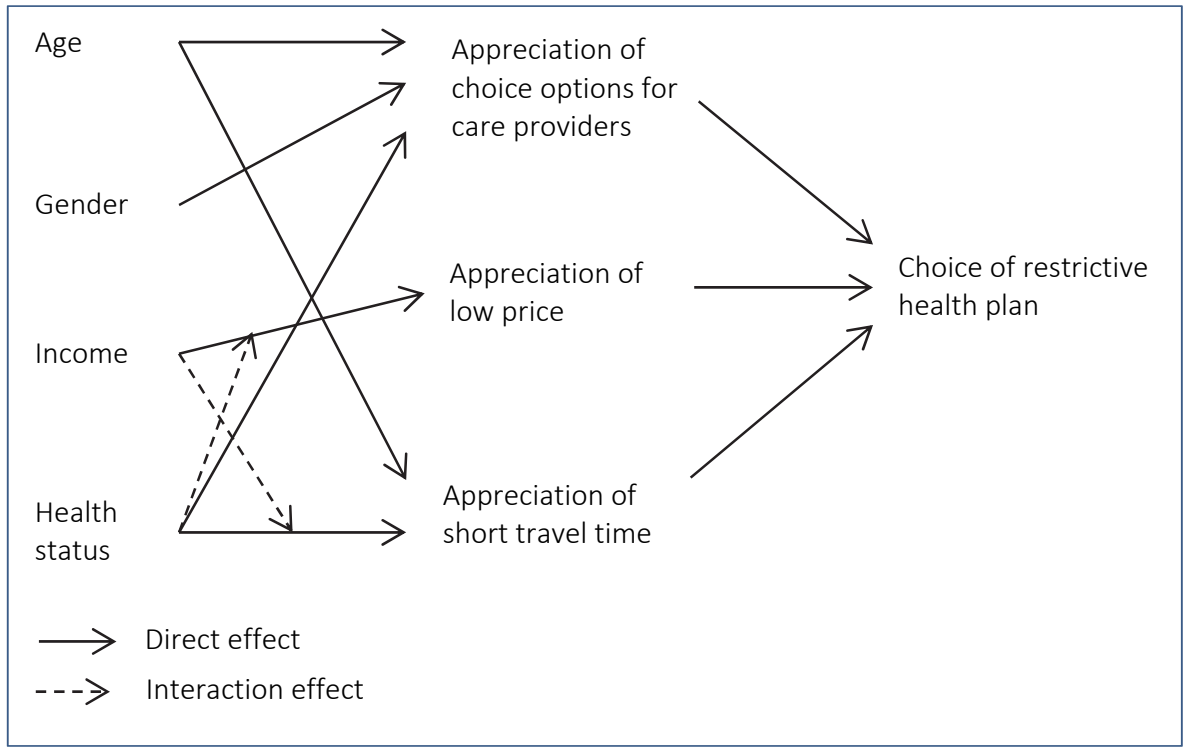

\section{Methods}

\section{Participants and procedure}

The participants are members of the Insurance Panel. The Insurance Panel is an access panel of people aged 18 years and older, who all have health insurance. This panel was set up by the Netherlands Institute for Health Services Research (NIVEL) together with a large Dutch health insurance cooperation (VGZ). Since earlier research showed that enrolees are not always aware of what health plan they have and what selective contracting is [26, 35], we chose to conduct a survey in which simplified, hypothetical choice options are given, instead of looking at real life choice of health plan. All panel members $(\mathrm{N}=4,370)$ were sent an online questionnaire by e-mail. The questionnaire was completed by 3,410 respondents (78 per cent). 


\section{Questionnaire}

In the questionnaire, we use two different methods. First, respondents were presented with three hypothetical options for health plans (Table 1). The options were kept as realistic as possible with regard to the situation in the Netherlands. The first health plan $(A)$ is the cheapest, but also the most restrictive and has a longer travelling time. The last health plan $(\mathrm{C})$ is the most expensive and has no restrictions in provider choice. Quality was kept constant between these choices, by stating that quality is high in every hypothetical health plan option, since research in the Netherlands has shown that people are hardly aware of any quality differences between hospitals or care providers [36]. Also, enrolees rarely indicate quality of care as a reason to switch health plans [37]. The benefits are the same between the three options since, in the Netherlands, benefits in terms of care provided in the basic health plan are determined by the government. The health plans differ in the number of care providers that are contracted and for what price. Respondents who did not choose the most restrictive health plan, were asked at what monthly premium they would be willing to choose this health plan, or, if they would never choose it and, if not, why not?

Table 1 Three options for choosing a health plan shown to respondents

\begin{tabular}{|c|c|c|c|}
\hline & Health plan A & Health plan B & Health plan C \\
\hline Monthly premium & $€ 75$ & $€ 85$ & $€ 95$ \\
\hline $\begin{array}{l}\text { Number of contracted hospitals in } \\
\text { the Netherlands }\end{array}$ & 40 & 80 & 100 (all) \\
\hline $\begin{array}{l}\text { Travelling time to the nearest } \\
\text { hospital }\end{array}$ & $40 \mathrm{~min}$ & $20 \mathrm{~min}$ & $20 \mathrm{~min}$ \\
\hline $\begin{array}{l}\text { Reimbursement for non-contracted } \\
\text { hospitals }\end{array}$ & $50 \%$ & $70 \%$ & n.a.* \\
\hline Quality of contracted care providers & High & High & High \\
\hline
\end{tabular}

Note: Contracting only applies to non-emergency care. Emergency care is always fully reimbursed by all health plans at all hospitals.

* not applicable

Second, in order to look further into how enrolees weigh their freedom of choice and travelling time against price, respondents were given three sets of choices based on two health plans (Table 2 ). In set 1 , respondents had to make a choice between price and freedom of choice. In set 2 , respondents had to choose between 
price and travelling time and in set 3, respondents had to weigh price against both their travelling time and their freedom of choice. Again, the situations for the different choices were made to correspond, as realistically as possible, to the situation in the Netherlands. To control for left right bias, the choice sets were reversed for half the respondents.

Table 2 Overview of the three sets of choices presented to respondents

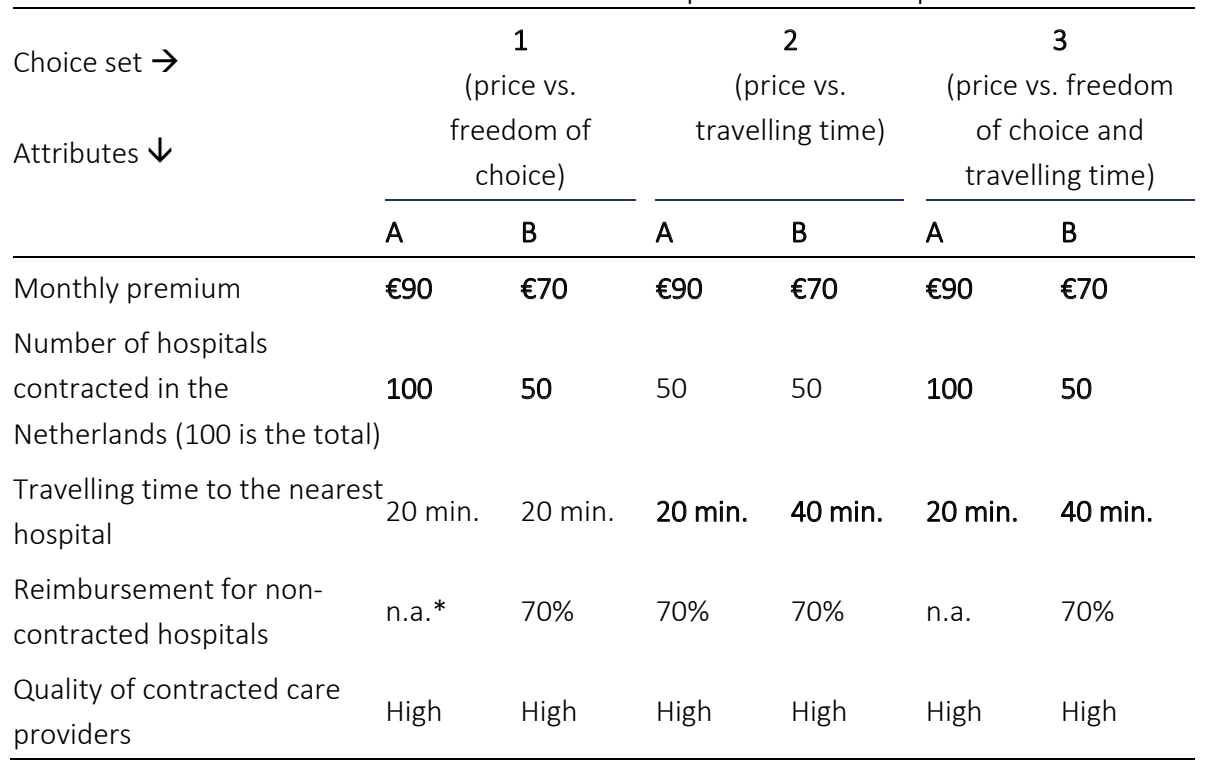

Note: Contracting only applies to non-emergency care. Emergency care is always fully reimbursed by all health plans at all hospitals. Attributes in bold differ from each other in the choice set.

*not applicable

\section{Background characteristics}

Respondents fill in a questionnaire about their background characteristics when they register as a panel member. For every year following, they fill in a questionnaire about characteristics that can change over time. Therefore, background characteristics such as gender, age, self-reported health status (5-point scale from poor to excellent) and household income (ascending scale of 16 categories) are known. However, for this study, we wanted to include an indicator of health status that is more specifically aimed to measure use of care. Therefore, we added to the questionnaire the question, 'How often do you use your health insurance?'. The categories of responses were (1) never or barely, (2) sometimes, but I usually stay below my deductible, (3) regularly, I usually have to pay my deductible, and (4) 
often. We use this variable in our analyses, except for the testing of $\mathrm{H} 4$ and 5 . There, we believe self-reported health status is a more appropriate measure, since it about how healthy someone feels to be able to travel.

\section{Analyses}

Data are analysed using STATA 13.0. First, the frequencies of the choices are presented. The frequencies are weighed to match the general Dutch adult population for age and gender. Second, logistic regression analyses are conducted for the three sets of choices shown in table 2, in order to analyse differences in subgroups. Interaction effects that are not significant, are removed from the logistic regression models to facilitate interpretation of the other effects.

\section{Results}

\section{Descriptive statistics}

Table 3 shows the descriptive statistics. Compared to the general Dutch population of 18 years and older, men are overrepresented in our sample (57.2 vs. 49.1 per cent in general population) and the respondents are older on average (66.4 vs. 48.7 in general population). Therefore, further results are weighted to match the general population for age and gender. We used six weighting factors ranging from 0.24 to 6.45 .

Table 3 Descriptive statistics

\begin{tabular}{lll}
\hline Variables & Percent / mean & N \\
\hline Men & $57.2 \%$ & 3,410 \\
Age (SD) & $66.4(12,5)$ & 3,410 \\
Self-reported health status $^{a}$ & 3.0 & 3,359 \\
\hline a
\end{tabular}

a Measured on a 5-point scale from poor (1) to excellent (5)

\section{The choice between three health plan options}

Table 4 shows that a small percentage of respondents (6.6 per cent) chose health plan A, the cheapest, most restrictive option. More respondents (37.9 per cent) chose health plan $B$, but the majority of respondents (55.7 per cent) chose health plan $C$, which is the non-restrictive, most expensive, health plan. Furthermore, the table shows that women chose the non-restrictive health plan more often and that respondents who chose the non-restrictive health plan are older compared to 
respondents who chose a restrictive health plan (A or B). Respondents who chose a restrictive health plan report a higher health status compared to respondents who chose the non-restrictive health plan, although the differences here seem very small. However, respondents who chose a restrictive health plan report significantly less use of health plan i.e. less use of care providers.

Table 4 Results for the first choice situation, three options for a choice of health $\operatorname{plan}^{\mathrm{a}, \mathrm{b}}(\mathrm{N}=3,367)$

\begin{tabular}{|c|c|c|c|}
\hline & Health plan A & Health plan B & Health plan C \\
\hline Total (\%) & 6.6 & 37.9 & 55.6 \\
\hline Men (\%) & 51.6 & 51.0 & 47.7 \\
\hline Age (mean) & 48.3 & 48.6 & 54.7 \\
\hline Self-reported health status ${ }^{c}$ (mean) & 3.1 & 3.3 & 3.1 \\
\hline Use health plan regularly-a lot (\%) & 38.9 & 34.0 & 49.7 \\
\hline
\end{tabular}

${ }^{a}$ For a description of the options for making a choice, see Table 1

b Results are weighted to match the general Dutch population for age and gender.

c Measured on a 5-point scale from poor (1) to excellent (5)

Of the respondents who chose health plan B, 74 per cent indicated that they would never choose health plan A. Of the respondents who chose health plan C, 87 per cent indicated they would never choose health plan $A$ and 78 per cent indicated they would never choose health plan B. Others indicated they would choose the other, more restrictive, health plans if they cost less. The reasons why respondents would never choose health plan A are that the number of contracted hospitals is too low, the travelling time is too long, and reimbursement for non-contracted care is too low. The reasons why respondents who chose health plan $\mathrm{C}$ would never choose health plan B are comparable to this.

\section{Choice sets}

Table 5 shows the results from the different sets of choices. Overall, most respondents chose the more expensive health plan options, i.e. the option with the most freedom of provider choice and/or the least amount of travelling time. However, this does not apply to all respondents. When the respondents weighed freedom of choice against price (choice set 1), 37 per cent chose the cheaper health plan with restrictions on choice, indicating that they are willing to give up some freedom of choice in exchange for a lower premium. When the cheaper option also includes a longer travelling time to the nearest care provider (choice set 3 ), then the 
number of people choosing the restrictive health plan decreases to 22 per cent. When respondents only weighed a longer travelling time against price (choice set 2), 45 per cent chose the cheaper health plan with the longer travelling time. Overall, 15.8 per cent chose the restrictive health plan in all the three situations and 37.9 per cent chose the most expensive option in all three situations (not in table).

Table 5 Results for the different choice sets ${ }^{a, b}$

\begin{tabular}{|c|c|c|c|c|c|}
\hline \multicolumn{2}{|c|}{$\begin{array}{c}\text { Choice set } 1 \\
\text { (price vs. freedom of choice) }\end{array}$} & \multicolumn{2}{|c|}{$\begin{array}{l}\text { Choice set } 2 \\
\text { (price vs. travelling time) }\end{array}$} & \multicolumn{2}{|c|}{$\begin{array}{c}\text { Choice set } 3 \\
\text { (price vs. freedom of choice } \\
\text { and travelling time) }\end{array}$} \\
\hline$A$ & B & A & B & $A$ & $B$ \\
\hline 62.6 & 37.4 & 55.0 & 45.0 & 77.9 & 22.1 \\
\hline
\end{tabular}

\section{Differences in subgroups}

Table 6 shows three logistic regression analyses which we conducted for the three sets of choices. The results show that gender has no effect when respondents weigh freedom of choice against price (choice set 1). However, when they had to weigh price against freedom of choice and travelling time (choice set 3 ), the results show that men more often choose a restrictive health plan compared to women, partly confirming $\mathrm{H} 1$. Furthermore, the results show that age is an important predictor for the choice of a restrictive health plan (choice sets 1 and 3). Younger enrolees are more likely to choose a restrictive health plan, confirming $\mathrm{H} 2$. The use of health insurance has an effect when freedom of choice is involved in the choice set (choice sets 1 and 3), showing that enrolees who use their health insurance less, i.e. less often visit a care provider, choose a restrictive health plan more often, confirming H3.

Older people and those in poorer health are less likely to choose a restrictive health plan, in general, but also when a longer travelling time is part of the restrictive health plan (choice set 1 and 3 ). When respondents weighed travelling time against price (choice set 2 ), then the interaction effect between self-reported health status and income was significant. To determine the nature of the effect, income was divided into two groups, low (income group 1 through 8; 45 per cent of respondents) and high (income group 9 through 16; 55 per cent of respondents). We estimated a model with two interaction terms, "health status*low income" and 
"health status*high income". In Figure 2 the relationship between health status and choice was plotted for the two income groups. This shows that the relationship between health status and a willingness to accept a longer travelling time in exchange for a lower premium is stronger when income is high. This effect is also significant. When income is low, the relationship between health status and accepting a longer travelling time is not significant. $\mathrm{H} 4$ and $\mathrm{H} 5$ are therefore confirmed, since mobility influences the willingness to accept a longer travelling time in exchange for a lower premium. This effect does not exist for people on a low income. They are more likely to choose the cheaper health plan with a longer travelling time.

Lastly, $\mathrm{H} 6$ is confirmed, since income has a significant effect on all three choices. Furthermore, it was found that health status does not affect the relationship between income and the choice of a restrictive health plan, rejecting $\mathrm{H} 7$ (this effect was removed from the logistic regression models to facilitate the interpretation of the other effects).

Table 6 Logistic regression analyses per choice set

\begin{tabular}{|c|c|c|c|}
\hline Dependent var $\rightarrow$ & Choice set $1^{a}$ & Choice set $2^{a}$ & Choice set $3^{a}$ \\
\hline Independent vars $\downarrow$ & Coef. & Coef. & Coef. \\
\hline Gender $(0=f 1=m)$ & 0.086 & 0.117 & $0.218^{*}$ \\
\hline Age & $-0.022 * *$ & $-0.014^{* *}$ & $-0.013 * *$ \\
\hline Income & $-0.025^{*}$ & $-0.079 *$ & $-0.030 *$ \\
\hline Health status ${ }^{b}$ & -- & -0.022 & -- \\
\hline Use of health plan ${ }^{c}$ & $-0.297 * *$ & -- & $-0.302^{*}$ \\
\hline Health status*Income & -- & $-0.023 *$ & -- \\
\hline \multicolumn{4}{|c|}{${ }^{a} 0=$ expensive option and $1=$ cheap option; ${ }^{*} p \leq 0.05 ;{ }^{*} p \leq 0.001$} \\
\hline \multicolumn{4}{|c|}{ b Measured on a 5-point scale from poor (1) to excellent (5) } \\
\hline \multicolumn{4}{|c|}{$\begin{array}{l}\text { c Measured on a 4-point scale and divided into two groups: } 0 \text { ( never or barely - sometimes) and } 1 \\
\text { (regularly - often). }\end{array}$} \\
\hline \multicolumn{4}{|c|}{$--=$ not included in the model } \\
\hline
\end{tabular}


Figure 2 The relationship between health status and a willingness to accept a longer travelling time (on a logistic scale) in exchange for a lower premium, plotted for two income groups ${ }^{a}$

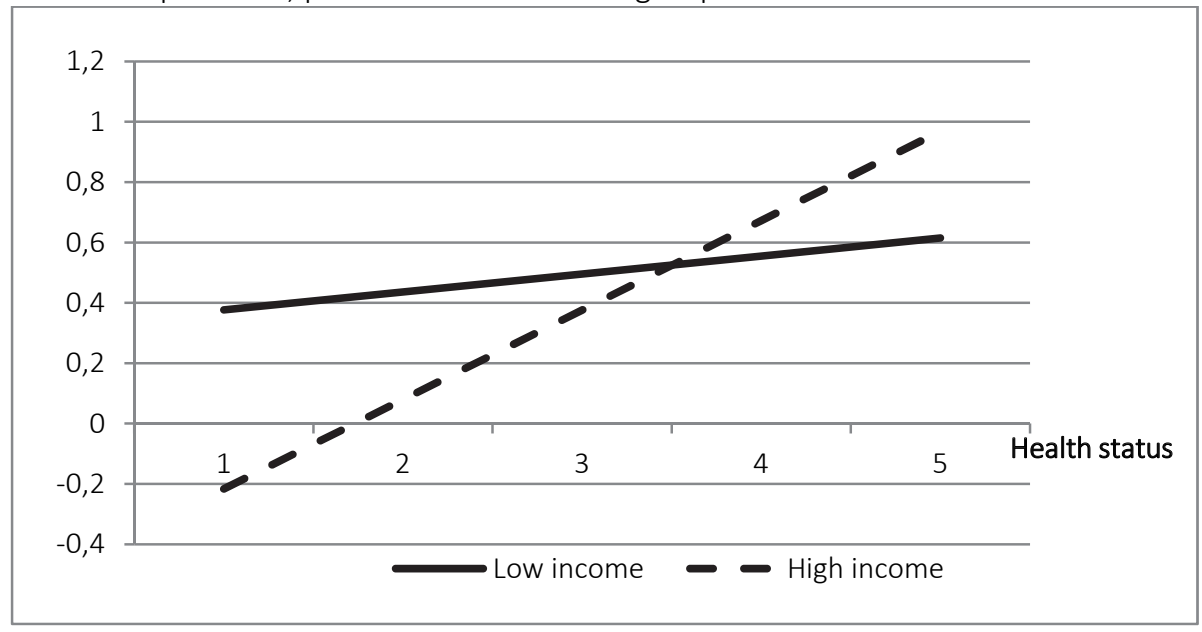

a The following equation was used to calculate the plots:

$Y=$ Constant $+X_{\text {low }}($ income; $1=$ low, $0=$ high $)+Z$ (health $) X_{\text {low }}+Z X_{\text {high }}$ (income; $1=$ high, $0=$ low $)$

\section{Discussion}

Selective contracting and channelling enrolees to contracted care providers is very important for a health care system based on managed competition if it is to reach its goals of improving the quality of care and containing the cost. This is because it stimulates competition between care providers. In a restrictive health plan the choice of care provider is limited which may result in longer travelling distances for enrolees. However, restrictive health plans are also cheaper. The aim of this study was to find out who are willing to choose a restrictive health plan.

The results show that a significant number of people state that they are willing to accept restrictions to their freedom of provider choice in exchange for a lower premium (37 per cent). In the Netherlands, a restrictive health plan will not necessarily result in a longer travelling time, depending on how many care providers are contracted and where enrolees live. However, when the cheaper option also includes a longer travelling time to the nearest care provider, the number of people who choose the restrictive health plan decreases to 22 per cent. This shows that travelling time is important to many enrolees. The importance of travelling time is 
also found in other studies and is even used as a 'cost', as an alternative for price $[38,39]$. Older enrolees and those in poorer health find travelling time more important compared to younger enrolees and those in better health since they are less willing to accept a longer travelling time in exchange for a lower premium. However, the effect of health status is dependent on income. For people on a low income, the relationship between health and the willingness to accept a longer travelling time is not significant. People earning a higher income can afford the higher costs and, therefore, can determine their choice on their ability to travel. People on a low income do not have this luxury. The people who are willing to give up their freedom of provider choice for a lower premium are younger and healthier than the people who are not. This finding is consistent with literature from other countries $[19,20,22]$.

It is important to note that the results are highly dependent on the values of the attributes in the options that were given. We do not know if the results would be the same if the restricted choice option would have been 30 instead of 50 hospitals, or when restricted choice option would have cost a monthly premium of 60 Euros instead of 70. It is expected that more people would have chosen the option of having a restricted choice if the price was lower and less if the option of having a restricted choice had included fewer hospitals. A more comprehensive choice experiment (DCE) needs to be conducted in order to be certain about this. Recently, the results of such an experiment were published by Determan et al. [40]. However, since the aim of our study was to find out which people are more likely to choose a restrictive health plan, the method of our study was sufficient. This is also true because the values of the attributes were chosen to match the realistic situation in the Netherlands. Furthermore, in the Netherlands, health insurers are obliged to reimburse part - usually around 70 per cent - of the costs of non-contracted hospitals. This means that the risk of choosing a restrictive health plan in the Netherlands is lower compared to countries where there is a lower reimbursement or no reimbursement at all for non-contracted care providers. In those countries the share of people who are willing to choose a restrictive health plan is likely to be lower compared to what was found in this study.

\section{Strengths and limitations}

A strength of this study is that in these different options, there was no status quo bias and respondents did not experience switching costs. In addition, the values chosen for the attributes in the different options were realistic with regard to the 
Dutch situation. Therefore, the results of this study indicate in how far people in the Netherlands are open to choosing a health plan with a restricted freedom of choice against price differences that currently exist in the market. However, a limitation is that since there are no switching costs or status quo bias, the results are likely to be an overestimation of the actual percentage of people who would choose a restrictive health plan. Furthermore, in practice, the options for making a choice between health plans are not as straightforward as shown in our experiment. When there is more information, or the information is presented in a complicated way, it is to be expected that people will rely more on price information instead of weighing up carefully all the different aspects of a health plan. Or they may even decide not to choose at all and to stay with their current health plan. Lastly, the respondents are all members of the Insurance Panel. Most of them have been with their current health insurer for a long time and can be considered loyal customers. We expect them to have more trust in their health insurer than other people. Therefore, it is expected that they would sooner choose a restrictive health plan compared to others [10]. However, since the choices were hypothetical and the objective of this study was to look into differences in demographic characteristics, we believe that this has not influenced our results.

\section{Scientific implications}

A model was created to explain enrolees' choice of a restrictive health plan. Most of the connections hypothesised in the model were confirmed by the results. The effect of gender on the choice of a restrictive health plan is not completely clear since gender did not have an effect on the choice of price versus freedom of choice, but it did have an effect when the travelling time was included in this choice. It is likely that the experienced risk of choosing a restrictive health plan was greater when the travelling time increased while the price stayed the same, and thus did not compensate for the longer travelling time.

The interaction effect of health status and income on the choice of a restrictive health plan which we hypothesised was not confirmed. Income and health status both have a direct effect on the choice of health plan, but the effect of income is not different for respondents who enjoy good health compared to those who do not. Based on our available data, we cannot yet explain this, but it may be possible that the respondents in our panel are relatively healthy. Therefore, it would be very interesting to test the model in a natural experiment as well, for instance by monitoring which health plans are chosen by people who are forced to choose a 
new health plan, for instance when a collective health plan of an employer is cancelled.

The fact that enrolees who use care, less often choose restrictive health plans compared to healthier enrolees, could point at the absence of an important incentive for competition between care providers. If this incentive for competition is absent, the health care system based on managed competition theory is unlikely to reach its goals of improving quality of care while containing the costs by stimulating competition between care providers. This may also be the case in other countries where enrolees have a choice between restrictive and non-restrictive health plans.

\section{Policy implications}

The results of this paper show that there are enrolees willing to accept restrictions to their choice of provider in exchange for a lower premium. However, it also shows that these enrolees are healthier and less likely to need care. To reach the intended goals of the health care system, it is important that enrolees who use care also choose a restrictive health plan. The question then is: under what circumstances would more enrolees in poor health be willing to accept restrictions to their choice of provider? It is possible that the difference in price between restrictive and nonrestrictive health plans is not large enough. Furthermore, the results may be different when the quality of care is taken into account. Enrolees in poor health are more likely to have experience with care providers and may find the quality of care more important. The idea of selective contracting is that health insurers select care providers based on price and quality. Assuming health insurers are indeed capable of selectively contracting higher quality care providers, it is possible that people in poor health or the elderly would choose a restrictive health plan. An important precondition for this is, however, that objective quality indicators are available and widely accepted. In the Netherlands, this is still a work in progress. Furthermore, since the elderly and people in poorer health are more concerned about increased travelling time, health insurers could, for instance, offer transportation to contracted care providers to overcome enrolees' unwillingness to travel further. Yet, selective contracting remains a negative incentive and therefore it may be questionable whether it will ever work as intended. Thus, one could also think about other solutions that might be regarded as more positive. Maybe health insurers should focus on positive incentives or simply only give advice to their enrolees about their choice of care provider. However, this is also difficult since enrolees are not used to asking their health insurer for advice and do not have much trust in their 
health insurer to act as a prudent purchaser of care on their behalf $[10,41]$. The questions whether health insurers will be able to contract selectively based on quality and whether enrolees will ever trust health insurers to purchase good quality care on their behalf, are relevant for all countries implementing health care systems based on managed competition. 


\section{References}

1. Laske-Aldershof T, Schut E, Beck K, Gress S, Shmueli A, Van de Voorde C: Consumer mobility in social health insurance markets: a five country comparison. Applied Health Economics and Health Policy 2004, 3:229-241.

2. Van de Ven WPMM, Beck K, Buchner F, Schokkaert E, Schut FT, Shmueli A, Wasem J: Preconditions for efficiency and affordability in competitive healthcare markets: are they fulfilled in Belgium, Germany, Isreal, the Netherlands and Switzerland? Health Policy 2013, 109:226-245.

3. Enthoven AC: The history and principles of managed competition. Health Affairs 1993, 12(1):24-48.

4. Boonen LHHM, Schut FT: Preferred providers and the credible commitment problem in health insurance: first experiences with the implementation of managed competition in the Dutch health care system. Health Economics, Policy and Law 2011, 6:219-235.

5. Sorensen AT: Insurer-hospital bargaining: negotiated discounts in post-deregulation Conneticut. Journal of Industrial Economics 2003, 51(4):469-490.

6. Wu VY: Managed care's price bargaining with hospitals. Journal of Health Economics 2009, 28:350-360.

7. Bes RE, Curfs EC, Groenewegen PP, de Jong JD: Selective contracting and channelling patients to preferred providers: a scoping review. In.: Health Policy (Under review); 2015.

8. Boonen LHHM, Schut FT, Donkers B, Koolman X: Which preferred providers are really preferred? Effectiveness of insurers' channeling incentives on pharmacy choice. International Journal of Health Care Finance Economics 2009, 9:347-366.

9. Boonen LHHM, Schut FT, Koolman X: Consumer channeling by health insurers: natural experiments with preferred providers in the Dutch pharmacy market. Health Economics 2008, 17:299-316.

10. Bes RE, Wendel S, Curfs EC, Groenewegen PP, de Jong JD: Acceptance of selective contracting: the role of trust in the health insurer. BMC Health Services Research 2013, 13:375.

11. Chu-Weininger MYL, Balkrishnan R: Consumer satisfaction with primary care provider choice and associated trust. BMC Health Services Research 2006, 6:139.

12. Davis K, Collins KS, Schoen C, Morris C: Choice matters: enrollees' views of their health plans. Health Affairs 1995, 14(2):99-112.

13. Schmittdiel J, Selby JV, Grumbach K, Quesenberry CP: Choice of a personal physician and patient satisfaction in a health maintenance organization. Journal of the American Medical Association 1997, 278(19):1596-1599. 
14. Tai-Seale M, Pescosolido B: The public's opinions of physicians: Do perceived choice and exercised choice matter? The American Journal of Managed Care 2003, '9(9):631-638.

15. Chernew M, Scanlon DP, Hayward R: Insurance type and choice of hospital for coronary artery bypass graft surgery. Health Services Research 1998, 33(3):447-466.

16. Kemper P, Tu HT, Reschovsky JD, Schaefer E: Insurance product design and its effects: trade-offs along the managed care continuum. Inquiry 2002, 39:101-117.

17. Dutch Health Care Authority: Richting geven aan keuzes. Kunnen verzekeraars consumenten stimuleren naar gecontracteerde voorkeursaanbieders te gaan? [Directions to choices. Can health insurers stimulate consumers to visit contracted referred providers?]. Utrecht, The Netherlands: Dutch Health Care Authority [NZa]; 2007.

18. Enthoven AC: A living model of managed competition: a conversation with Dutch health minister Ab Klink. Health Affairs 2008, 27(3):w196-w203

19. Hellinger FJ: Selection bias in HMOs and PPOs: A review of the evidence. Inquiry 1995, 32(4):135-142.

20. Hellinger FJ, Wong HS: Selection bias in HMOs: A review of the evidence. Medical Care Research and Review 2000, 57(4):405-439.

21. Mello MM, Stearns SC, Norton EC, Ricketts TC: Understanding biased selection in medicare HMOs. Health Services Research 2003, 38(3):961-992.

22. Lehman $H$, Zweifel $P$ : Innovation and risk selection in deregulated social health insurance. Journal of Health Economics 2004, 23:997-1012.

23. Tu HT: More Americans willing to limit physician-hospital choice for lower medical costs. Center for Studying Health System Change 2005, 94:1-5.

24. Rijken $M$, de Putter I, Reitsma-van Rooijen $M$, Spreeuwenberg $P$, de Jong JD, Groenewegen PP: Illness-related expenditures of people with chronic illness and qof the general Dutch population: mind the gap! In.: Health Policy (Under review); 2015.

25. Dutch Health Care Authority: Zeventien zorgpolissen nader bekeken. In relatie tot de zorgplicht [A closer look at seventeen health plans. In relation to the uty to care]. Utrecht, The Netherlands: Dutch Health Care Authority; 2015.

26. Bes RE, Brabers AEM, Reitsma-van Rooijen M, De Jong JD: Selectief mcontracteren? Prima, maar beperk mijn keuzevrijheid niet! [Selective contracting? Fine, but do not restrict my freedom of choice!]. Utrecht, The Netherlands: NIVEL 2014.

27. Lave CA, March JG: An introduction to models in the social sciences. New York: HarperCollins Publishers; 1975.

28. Kortenhoeven D: Vrouwelijke artsen en vestiging als huisarts [Female physicians establishing a general practice]. Utrecht, the Netherlands: Bohn, Scheltema \& Holkema; 1990. 
29. Varkevisser M, Van der Geest SA: Why do patients bypass the nearest hospital? An empirical analysis for orthopaedics care and neurosurgery in the Netherlands. European Journal of Health Economics 2007, 8(3):287-295.

30. Taylor JW: The role of risk in consumer behavior. Journal of Marketing 1974, 38:54-60.

31. Jianakoplos NA, Bernasek A: Are women more risk averse? Economic Enquiry 1998, 36(4):620-630.

32. Hoch SJ, Kim BD, Montgomery AL, Rossi PE: Determinants of store-level price elasticity. Journal of Marketing Research 1995, 32:17-29.

33. Marquis SM, Long SH: Worker demand for health insurance in the non-group market. Journal of Health Economics 1995, 14:47-63.

34. Scanlon DP, Chernew M, Lave JR: Consumer health plan choice: current knowledge and future directions. Annual Review of Public Health 1997, 18:507-528.

35. Cunningham PJ, Denk C, Sinclair M: Do consumers know how their health plan works? Health Affairs 2001, 20(3):159-166.

36. De Jong JD, Groenewegen PP, Van der Schee E: Consumenten en de stelselwijziging [Consumers and the health care reform]. Tijdschrift voor Gezondheidswetenschappen 2006, 84(5):288-2091.

37. Brabers AEM, Reitsma-van Rooijen M, de Jong JD: The Dutch health insurance system: mostly competition on price rather than quality of care. Eurohealth Systems and Policies 2012, 28(1):30-32.

38. Tai WTC, Porell FW, Adams EK: Hospital choice of rural medicare beneficiaries: patient, hispital attributes and patient-physician relationship. Health Services Research 2004, 39(6, part 1):1903-1922.

39. Varkevisser M, Van der Geest SA, Schut FT: Assessing hospital competition when prices don't matter to patients: the use of time-elasticities. International Journal of Health Care Finance Economy 2009, 10(1):43-60.

40. Determan D, Lambooij MS, de Bekker-Grob EW, Hayen AP, Varkevisser M, Schut FT, de Wit GA: What health plans do people prefer? The trade off between premium and provider choice. Social Science \& Medicine 2016, 165:10-18.

41. Bes RE, Wendel S, de Jong JD: Het vertrouwensprobleem van zorgverzekeraars [The trust issue of health insurers]. Economisch Statistische Berichten 2012, 97(4647):676677. 
Chapter 3 


\section{Chapter 4}

\section{Acceptance of selective contracting: the role of trust in}

the health insurer

Published as:

Bes RE, Wendel S, Curfs EC, Groenewegen PP, de Jong JD. Acceptance of selective contracting: the role of trust in the health insurer. BMC Health Services Research 2013, 13:375 


\section{Abstract}

\section{Background}

In a demand oriented health care system based on managed competition, health insurers have incentives to become prudent buyers of care on behalf of their enrolees. They are allowed to selectively contract care providers. This is supposed to stimulate competition between care providers and both increase the quality of care and contain costs in the health care system. However, health insurers are reluctant to implement selective contracting; they believe their enrolees will not accept this. One reason, insurers believe, is that enrolees do not trust their health insurer. However, this has never been studied. This paper aims to study the role played by enrolees' trust in the health insurer on their acceptance of selective contracting.

\section{Methods}

An online survey was conducted among 4,422 people insured through a large Dutch health insurance company. Trust in the health insurer, trust in the purchasing strategy of the health insurer and acceptance of selective contracting were measured using multiple item scales. A regression model was constructed to analyse the results.

\section{Results}

Trust in the health insurer turned out to be an important prerequisite for the acceptance of selective contracting among their enrolees. The association of trust in the purchasing strategy of the health insurer with acceptance of selective contracting is stronger for older people than younger people. Furthermore, it was found that men and healthier people accepted selective contracting by their health insurer more readily. This was also true for younger people with a low level of trust in their health insurer.

\section{Conclusion}

This study provides insight into factors that influence people's acceptance of selective contracting by their health insurer. This may help health insurers to implement selective contracting in a way their enrolees will accept and, thus, help systems of managed competition to develop. 


\section{Background}

In recent last decades, health care reforms have been implemented in several countries. A general aspect of most of these reforms is a shift from a supplyoriented system to a demand-oriented one. In several countries these reforms were based on introducing managed competition, for instance in Germany, Switzerland and the United States [1-3]. In a system of managed competition, health insurers play an important role. The idea is that they become prudent buyers of care on behalf of their enrolees. Health insurers can negotiate contracts with care providers and in some forms of managed competition health insurers are allowed to selectively contract care providers. This is supposed to increase competition between care providers and in turn increase the quality of care and contain the costs of health care. However, when health insurers choose to selectively contract with care providers, it is important that they channel their enrolees towards these contracted care providers. Competition between care providers will only happen when care providers fear they will lose a share of the market if they are not contracted by the insurers [4-7]. In addition, in a system of managed competition there is also competition between health insurers. People have the option of switching insurers if they are not satisfied or can get a better offer elsewhere. Selective contracting has an important implication for enrolees. It means that their freedom of choice of care provider is restricted to those care providers selected by their health insurer. There are two forms of selective contracting. One is based on 'preferred' provider networks and means that enrolees are also allowed to use providers that are not contracted by their health insurer, but this care will only partially be reimbursed. The other form is 'exclusive', which means that enrolees will receive no reimbursement at all when they to go to a care provider that is not contracted by their insurer. The premium for restrictive health plans, in which care providers are selectively contracted by the health insurer, is usually lower, because the health insurer can purchase greater volumes of care from fewer care providers at a lower unit price.

Health insurers, however, are still reluctant to implement selective contracting in the Netherlands, even though a system of managed competition was implemented in 2006 (the key points of the Dutch health care system are listed in Box 1). This is because they fear they will lose their enrolees, since both provider and consumer organisations are critical about restrictions to the freedom of choice of provider [8]. Boonen et al. interviewed large health insurance companies in the Netherlands 
about why they are reluctant to implement selective contracting [9]. The most important reason given by the insurers is that they expect that their enrolees do not trust them to act as good purchasing agents on their behalf [9]. Other literature also points out that trust in the health insurer could play a key role in whether or not enrolees accept selective contracting [10-13]. Yet, trust may not be the only factor, there could be other factors that influence in how far enrolees accept selective contracting by their health insurer, such as reluctance to change and the importance of autonomy in the choice of care provider. However, we specifically focus in this article on the trust of enrolees in their health insurer, because this relationship has not yet been studied. No research has yet been done to see whether enrolees who have more trust in their health insurer, are more accepting of selective contracting by their health insurer. Neither has it been made clear what it is that people trust which influences their acceptance of selective contracting. Is it their trust in their health insurer in general, or is it their trust in the way their health insurer selects care providers? Additionally, we will investigate to what extent enrolees' characteristics play a role in the relationship between the trust in their health insurer and their acceptance of selective contracting. Therefore, the following research question will be answered in this paper: What role does enrolees' trust in their health insurer play in their acceptance of selective contracting? This question is relevant for all countries where a system of managed competition is implemented or will be implemented in the future.

\section{Trust}

Trust is very important in health care [14-17], not only between patients and physicians, but also between patients and medical institutions such as hospitals and health insurers. Studies have found that trust has the same functional attributes as satisfaction. However, in contrast to satisfaction, which is an assessment of past events, trust is a forward-looking evaluation of an on-going relationship. Factors that generally underlie trust include fidelity, competence, honesty, confidentiality and global trust [17]. Trust is closely related to risk, which is derived from the uncertainty of the trustor regarding the motives, intentions and future actions of the trustee [14]. Theory states that if there is no uncertainty, no trust is needed and the higher the initial perception of risk, then the higher the trust needed to facilitate transactions[18]. Furthermore, trust is shown to reduce the perceived risk [18, 19]. When trusting someone, you allow yourself to be vulnerable by running the risk that that person will exploit you [14]. We define trust according to definitions based on the work of Gilson and Hall et al. as the optimistic acceptance of a vulnerable 
situation where the trustor believes that the trustee has his best interests at heart $[14,17]$.

Trust has previously been researched in the context of health insurers. There, results show, for instance, that trust in the health insurer correlates positively with a lower desire to switch insurers and fewer disputes with the insurer [17, 20, 21]. Trust is also related to enrolees' overall assessment of their health insurer [22].

Box 1 Key elements of the Dutch health care system (From: Enthoven and Van de Ven, 2007)

Mandatory basic health insurance for everyone, purchased through private insurance companies

Annual consumer choice of insurer and insurance products

Open enrolment and community rating

Premium subsidies for elderly people and those at high risk of disease, through a riskequalisation system

Mandatory deductible of $€ 165$ per person per year*

Voluntary deductible up to $€ 500$ per person per year

Insurers allowed to sell other types of insurance (e.g., supplementary insurance)

Insurers intended to be the prudent buyers of care on behalf of their members

General practitioners to serve as gatekeepers

Insurers permitted to contract selectively with doctors and hospitals

Health maintenance organisations and preferred provider arrangements allowed

In transition toward managed competition

* The government assesses the amount of the mandatory deductible every year. When this survey was conducted (end of 2010) it was €165.

\section{Hypotheses}

As has been mentioned, the literature implies that trust in the health insurer could play an important role in the willingness of enrolees to let their health insurer select care providers for them $[9-11,13]$. This is consistent with the literature on trust and risk. Enrolees do not know what care they will need in the future and neither do they have experience with all the care providers their health insurer contracts with. Because of this uncertainty or risk, they need to trust that their health insurer will have their best interests at heart. Therefore, we expect that trust in the health insurer is an important prerequisite for their enrolees' acceptance of selective contracting. 
H1: Enrolees who have more trust in their health insurer will be more accepting of selective contracting by their health insurer.

The perceived risk of enrolling in a health insurance policy with limited choice may be greater for less healthy people, because they are more likely to need care, now and in the near future. Since trust reduces perceived risk [18, 19], we expect that, compared to healthy enrolees, less healthy ones need to have more trust in their health insurer in order to accept selective contracting. Therefore, we expect that the relationship between trust in the health insurer and acceptance of selective contracting will differ between healthy and unhealthy enrolees.

H2: The role of trust in the acceptance of selective contracting is stronger for unhealthy enrolees compared to healthy enrolees.

The same goes for older people, who are also more likely to need care in the near future. Therefore, they take a greater risk than younger people do when they agree to selective contracting by their health insurer. Hence, we expect that older people need to have more trust in their health insurer in order to accept selective contracting. Thus, we expect that the relationship between trust and openness to selective contracting will differ with age.

H3: The role of trust in the acceptance of selective contracting is stronger for older enrolees than for younger ones.

Women are more risk averse than men [23]. Thus, they may perceive greater risks in agreeing to selective contracting than men. Therefore, we expect that women need to have more trust in their health insurer when they agree to selective contracting.

H4: The role of trust in the acceptance of selective contracting is stronger for women than for men.

We also expect health, age and gender to be directly associated with the acceptance of selective contracting by the health insurer. This expectation is based on literature showing that young and healthy people more often choose cheaper health policies with restrictions on the range of providers than older people and people with health problems [24-26]. The reason for this may be that young and healthy people use less care and are therefore less concerned about their freedom of choice of provider. 
This leads to the expectation that younger and healthier enrolees will be more open to selective contracting than older and less healthy ones. Another reason for less healthy enrolees to be more reluctant to accept selective contracting can be that they have more experience with receiving health care and may have a stronger relationship with one or more of their care providers. They may be afraid of losing these regular providers if selective contracting is implemented by their health insurer.

H5: Healthier enrolees are more accepting of selective contracting by their health insurer.

H6: Younger enrolees are more accepting of selective contracting by their health insurer.

As explained before, enrolees may perceive a risk in insuring through a health policy with selectively contracted care because they do not know what care they may need in the future and they do not have experience with all the contracted care providers. Since women are more risk averse than men [23], we expect that women are more reluctant to accept selective contracting than men.

H7: Women are more reluctant to accept selective contracting by their health insurer.

\section{Methods}

\section{Design}

This study was conducted in November 2010 among members of a panel of people with health insurance known as the Insurance Panel. This panel was set up in 2006 by the NIVEL (Netherlands Institute for Health Services Research) in cooperation with a large Dutch health insurance company. All members of the panel are insured through this health insurance company. At the time this research was undertaken, the Insurance Panel consisted of 6,732 members who could be approached online via e-mail and 4,759 members who can only be approached through postal surveys. On average, panel members are invited to participate in a survey three times a year. All survey topics are related to health care and health insurance. The panel was registered with the Dutch Data Protection Authority (nr. 1309664). According to 
Dutch legislation, neither obtaining informed consent nor approval by a medical ethics committee was obligatory for this study. Panel members were free to answer the questions or not.

This survey was conducted online, therefore only the online members of the panel were included. Two reminders were sent to the non-respondents, one seven days, and one 14 days after the initial sending. We received 4,422 completed questionnaires, a response rate of $66 \%$.

\section{Measures}

Variables were measured by single and multi-item measures. All items were measured using a seven point Likert-type scale ranging from completely disagree (1) to completely agree (7). An overview of the multi-item measures is provided in the appendix, see Additional file 1.

\section{Dependent variable}

The dependent variable is the enrolee's acceptance of selective contracting by their health insurer. Because health insurers in the Netherlands are reluctant to implement selective contracting, enrolees are not yet used to restrictions in their choice of provider. Therefore, the respondents were asked to read an introductory text, where the situation was described in which their health insurer selectively contracts with care providers and that this means that when they go to a not contracted provider they would have to pay a co-payment. Then, respondents were asked in five separate items, to what extent they would agree with their health insurer contracting with only certain hospitals, general practitioners (GPs), physiotherapists, dentists and pharmacies. We asked this question separately for different types of provider, because it is possible that the results differ between the types of provider. Boonen et al. state that the relationship enrolees have with their care provider influences their willingness to switch providers [27]. They find that enrolees have a stronger relationship with their GP than their pharmacy and are therefore more reluctant to accept the selective contracting of GPs than of pharmacies. Although we found slight differences in the acceptance of selective contracting between provider types, factor analysis showed one factor (eigen value $4.04,1.03$ of variance), $\alpha=0.96$ (Table 1 ). The items were merged into one variable by taking the average of the scores on these five items. There were no missing values. 
Table 1 Scale Alpha, item means and factor loadings for dependent variable acceptance of selective contracting ${ }^{a}$

\begin{tabular}{lccc}
\hline Item & Cronbach's Alpha & Mean & Factor loadings \\
\hline To what extent do you agree with your health & & & \\
insurer... & 0.96 & 2.85 & 0.83 \\
... only contracting specific hospitals? & 2.48 & 0.90 \\
$\ldots$ only contracting specific general practitioners? & 2.74 & 0.93 \\
$\ldots$ only contracting specific physiotherapists? & 2.62 & 0.94 \\
$\ldots$ only contracting specific dentists? & 2.74 & 0.89 \\
$\ldots$ only contracting specific pharmacies? & &
\end{tabular}

\section{Independent variables}

The independent variables are trust in the health insurer in general (general trust), trust in the purchasing strategy of the health insurer (specific trust) and demographic characteristics including, age, gender and self-reported health status.

Trust was measured in general and, more specifically, in the purchasing strategy of the health insurer in order to explore the influence of trust on the acceptance of selective contracting more in depth. General trust in the health insurer was measured using a validated scale [21], which was translated into Dutch and validated [28]. Trust in the health insurer's purchasing strategy was measured by asking respondents to indicate in how far they agree with the following statements: (1) I trust my health insurer to choose the best care providers; (2) I trust my health insurer not to compromise on quality in order to keep the price down; and (3) I trust my health insurer to choose the best care for me at the best price. A factor analysis was conducted in order to confirm that the general trust scale and the items that measure specific trust in the purchasing strategy of the health insurer do indeed measure two different constructs. The results of this are presented in Table 2. The factor analysis showed that there are indeed two factors, factor one consisting of 11 general trust items (Eigen value 5.13, 0.55 of variance), $\alpha=0.86$ and factor two consisting of three specific trust items (Eigen value $1.36,0.46$ of variance), $\alpha=0.89$. The composite scale general trust was constructed by taking the average of the scores on the items. Specific trust was constructed comparably, using the three specific trust items. There were no missing values. Correlation between these two variables is 0.47 , which is acceptable considering both constructs measure trust, although on a different level. 
Every year members of the Insurance Panel receive a questionnaire to update their background characteristics. Therefore, age (continuous), gender ( $0=$ male; $1=$ female) and self-reported health status ( 1 poor, 2 moderate, 3 good, 4 very good, and 5 excellent) are known for almost all of the 4,422 respondents to the trust and acceptance questionnaire. Finally, 4,396 respondents could be used for the analyses.

Table 2 Scale Alpha's, item means and factor loadings statistics for independent variables general and specific trust

\begin{tabular}{|c|c|c|c|c|c|}
\hline Construct & Item $^{a, b}$ & $\begin{array}{l}\text { Cronbach's } \\
\text { Alpha }\end{array}$ & Mean & $\begin{array}{l}\text { Factor } \\
\text { loading }\end{array}$ & \\
\hline \multirow[t]{8}{*}{$\begin{array}{l}\text { General } \\
\text { trust scale }\end{array}$} & $\begin{array}{l}\text { You think the people at your health } \\
\text { insurance company are completely honest. }\end{array}$ & 0.86 & 4.87 & 0.56 & - \\
\hline & $\begin{array}{l}\text { Your health insurer cares more about saving } \\
\text { money than about getting you the treatment } \\
\text { you need. }\end{array}$ & & 4.00 & 0.41 & - \\
\hline & $\begin{array}{l}\text { As far as you know, the people at your } \\
\text { health insurance company are very good at } \\
\text { what they do. }\end{array}$ & & 4.86 & 0.51 & - \\
\hline & $\begin{array}{l}\text { If someone at your health insurance } \\
\text { company made a serious mistake, you think } \\
\text { they would try to hide it. }\end{array}$ & & 4.14 & 0.53 & - \\
\hline & $\begin{array}{l}\text { You feel like you have to double check } \\
\text { everything your health insurer does. }\end{array}$ & & 4.55 & 0.61 & - \\
\hline & $\begin{array}{l}\text { You worry that private information your } \\
\text { health insurer has about you could be used } \\
\text { against you. }\end{array}$ & & 4.93 & 0.66 & - \\
\hline & $\begin{array}{l}\text { You worry there are a lot of loopholes in } \\
\text { what your health insurer covers that you do } \\
\text { not know about. }\end{array}$ & & 4.42 & 0.65 & - \\
\hline & $\begin{array}{l}\text { You believe your health insurer will pay for } \\
\text { everything it is supposed to, even really } \\
\text { expensive treatments. }\end{array}$ & & 4.54 & 0.29 & - \\
\hline
\end{tabular}

- table 2 continues - 


\begin{tabular}{|c|c|c|c|c|c|}
\hline Construct & $\begin{array}{l}\text { Item }^{\mathrm{a}, \mathrm{b}} \\
\text { If you got really sick, you are afraid your }\end{array}$ & $\begin{array}{l}\text { Cronbach's } \\
\text { Alpha }\end{array}$ & $\begin{array}{l}\text { Mean } \\
5.29\end{array}$ & \multicolumn{2}{|c|}{$\begin{array}{l}\text { Factor } \\
\text { loadings }\end{array}$} \\
\hline & $\begin{array}{l}\text { If you got really sick, you are afraid your } \\
\text { health insurer might try to stop covering } \\
\text { you altogether. }\end{array}$ & & 5.29 & 0.59 & - \\
\hline & $\begin{array}{l}\text { If you have a question, you think your } \\
\text { health insurer will give a straight answer. }\end{array}$ & & 5.24 & 0.61 & - \\
\hline & $\begin{array}{l}\text { All in all, you have complete trust in your } \\
\text { health insurance company. }\end{array}$ & & 4.97 & 0.64 & - \\
\hline \multirow{3}{*}{$\begin{array}{l}\text { Specific trust } \\
\text { in purchasing } \\
\text { strategy }\end{array}$} & $\begin{array}{l}\text { I trust my health insurer to choose the } \\
\text { best care providers. }\end{array}$ & 0.89 & 4.61 & - & 0.81 \\
\hline & $\begin{array}{l}\text { I trust my health insurer not to } \\
\text { compromise on quality in order to keep } \\
\text { the price down. }\end{array}$ & & 4.78 & - & 0.82 \\
\hline & $\begin{array}{l}\text { I trust my health insurer to choose the } \\
\text { best care for me at the best price. }\end{array}$ & & 4.77 & - & 0.82 \\
\hline
\end{tabular}

\section{Statistical analyses}

Descriptive statistics were computed to describe the characteristics of the study population. In order to test the hypotheses a regression model was constructed. We examined the main and the interaction effects. The interaction effects were examined to test the hypotheses that state that the relationship between trust and the acceptance of selective contracting is modified by another variable $(\mathrm{H} 2, \mathrm{H} 3$ and $\mathrm{H} 4)$. The variables were centred prior to entering the independent continuous variables, general trust, specific trust, self-reported health status, age and their cross-product terms into the regression model. Centring variables means converting each continuous variable to deviation score form, by subtracting a score from respondents' raw scores, making 0 a meaningful value while preserving the units of the scale. This ensures that the interpretation of effects will occur at a meaningful value of the continuous variable, and it reduces multicollinearity [29]. For age, the rounded mean (56) was subtracted and for general trust, specific trust, and selfreported health scales, the score for 'neutral' was subtracted. Interactions that were not significant were removed from the regression model, to facilitate interpretation of the other effects. 


\section{Results}

\section{Descriptives}

Table 3 presents descriptive statistics. The mean age of the respondents is 55.6 years ranging from 19 to 90 years and $55.6 \%$ of the respondents are male. Less than $14 \%$ of the respondents report a poor to moderate health status. The population is older and contains more men compared to the Dutch general population. General trust and specific trust in the health insurer score 4.71 and 4.72 on a scale of one to seven, where seven is the highest and one is the lowest level of trust. These means of 4.71 and 4.72 can be interpreted as moderate general and specific trust. Respondents in general are not very accepting of selective contracting by their health insurer, the average score is 2.69 on a scale of one to seven where seven is most accepting of selective contracting.

Table 3 Descriptive statistics of the variables in the model

\begin{tabular}{lll}
\hline Variables & Percent / mean & N \\
\hline Female & $44.4 \%$ & 4422 \\
Age (SD) & $55.58(14.55)$ & 4421 \\
Self-reported health status $^{\mathrm{a}}$ & 3.31 & 4396 \\
General trust (SD) $^{\mathrm{b}}$ & $4.71(0.87)$ & 4422 \\
Specific trust (SD) $^{\mathrm{b}}$ & $4.72(1.48)$ & 4422 \\
Acceptance of selective contracting (SD) $^{\mathrm{b}}$ & $2.69(1.43)$ & 4422 \\
\hline
\end{tabular}

a Measured on a five-point scale ranging from poor (1) to excellent (5)

b Items were measured using a seven-point Likert-type scale ranging from completely disagree (1) to completely agree (7)

\section{Regression model}

Table 4 shows the final regression model. The interaction effect of age and specific trust is significant and was therefore kept in the model. The other hypothesised interaction effects were not significant and therefore removed from the model. Coefficients and standardised regression coefficients are presented to indicate the magnitude of the results found, as well as the level of significance. The main effects will be discussed first, followed by the interaction effect. 
Table 4 Regression of general trust, specific trust, self-reported health status, age, and gender on acceptance of selective contracting ( $N=4396)$

\begin{tabular}{lll}
\hline & Coef. & Beta \\
\hline General trust & 0.125 & $0.076^{* *}$ \\
Specific trust & 0.324 & $0.335^{* *}$ \\
Self-reported health & 0.048 & $0.029^{*}$ \\
Age & -0.003 & -0.029 \\
Female & -0.231 & $-0.080^{* *}$ \\
Age*specific trust & 0.002 & $0.032^{*}$ \\
Constant & 2.443 & \\
Adj. R-square & 0.15 & \\
\hline
\end{tabular}

$* p<0.05 ; * * p<0.001$

Coef. $=$ Coefficient

Beta $=$ Standardised regression coefficient

The influence of trust on the acceptance of selective contracting

In line with $\mathrm{H} 1$, Table 4 shows that general and specific trust in the health insurer are significantly associated with enrolees' acceptance of selective contracting by their health insurer. The more trust enrolees have in their health insurer, the more accepting they are of selective contracting by their health insurer. The effect of specific trust is stronger compared to general trust.

The influence of self-reported health status, age and gender on the acceptance of selective contracting

Table 4 shows that self-reported health status and gender are significantly associated with the acceptance of selective contracting. Age is unrelated to the acceptance of selective contracting. This is in line with $\mathrm{H} 5$ and $\mathrm{H} 7 ; \mathrm{H} 6$ is rejected.

The interaction effect of age and specific trust on the acceptance of selective contracting

The hypothesised interaction effects between self-reported health and trust and between gender and trust were not significant, therefore $\mathrm{H} 2$ en $\mathrm{H} 4$ are rejected. Also, the interaction effect between age and general trust was not significant. The results do demonstrate a significant interaction of age and specific trust on the acceptance of selective contracting, partially confirming H3. This means that the relationship between specific trust and acceptance of selective contracting varies by age. In order to determine the nature of the effect, we examined the relationship between specific trust and the acceptance of selective contracting for people with 
different ages. The coefficient of specific trust presented in Table 4, is indicative of people with a mean age in the model (age $=0$, since age is centred ${ }^{1}$ ). In Figure 1 the relationship between specific trust and acceptance of selective contracting is plotted for people with the highest and the lowest age ${ }^{2}$. For all other ages the plots lie in between the two presented. For both values of age, the relationship between specific trust and the acceptance of selective contracting is positive, meaning that the higher the level of trust, the more accepting enrolees are of selective contracting. However, for the highest age the slope is steeper, that is, the coefficient is higher, which means that the relationship of specific trust and the acceptance of selective contracting is stronger for older people. The effect of specific trust on the acceptance of selective contracting is significant for all ages $(p<0.001)$. This means that specific trust has an effect on the acceptance of selective contracting, no matter the respondent's age.

The significant interaction effect of specific trust and age also indicates that the effect of age on the acceptance of selective contracting varies with the level of specific trust. The coefficient presented for age in Table 4 is indicative for people who score neutral on specific trust ( 0 , since specific trust is centred). In this situation, the relationship between age and the acceptance of selective contracting is not significant. When plotted for the highest specific trust score, the relationship between age and the acceptance of selective contracting is still not significant. However, when plotted for the lowest specific trust score, the relationship is significant $(P<0.05$; coef. $=-0.009)$, showing that younger enrolees are more accepting of selective contracting. This shows that it depends on the level of trust whether or not age has a significant influence on the acceptance of selective contracting. When it does, however, it shows that younger enrolees are more accepting of selective contracting by their health insurer than older enrolees.

\footnotetext{
1 This is illustrated by the following regression equations:

2 In order to do this, the regression model was run with age centred in alternative ways. First, the model was run with age subtracted by the oldest age (90). The results then showed the constant and coefficient for the oldest respondents. Then, the model was run with age subtracted by the youngest age (19), so the results showed the constant and coefficient for the youngest respondents. With these results the plots were made (Figure 1 ).
} 
Figure 1 Association between specific trust and acceptance of selective contracting for people with the lowest age (19) and people with the highest age (90) $)^{\text {a }}$

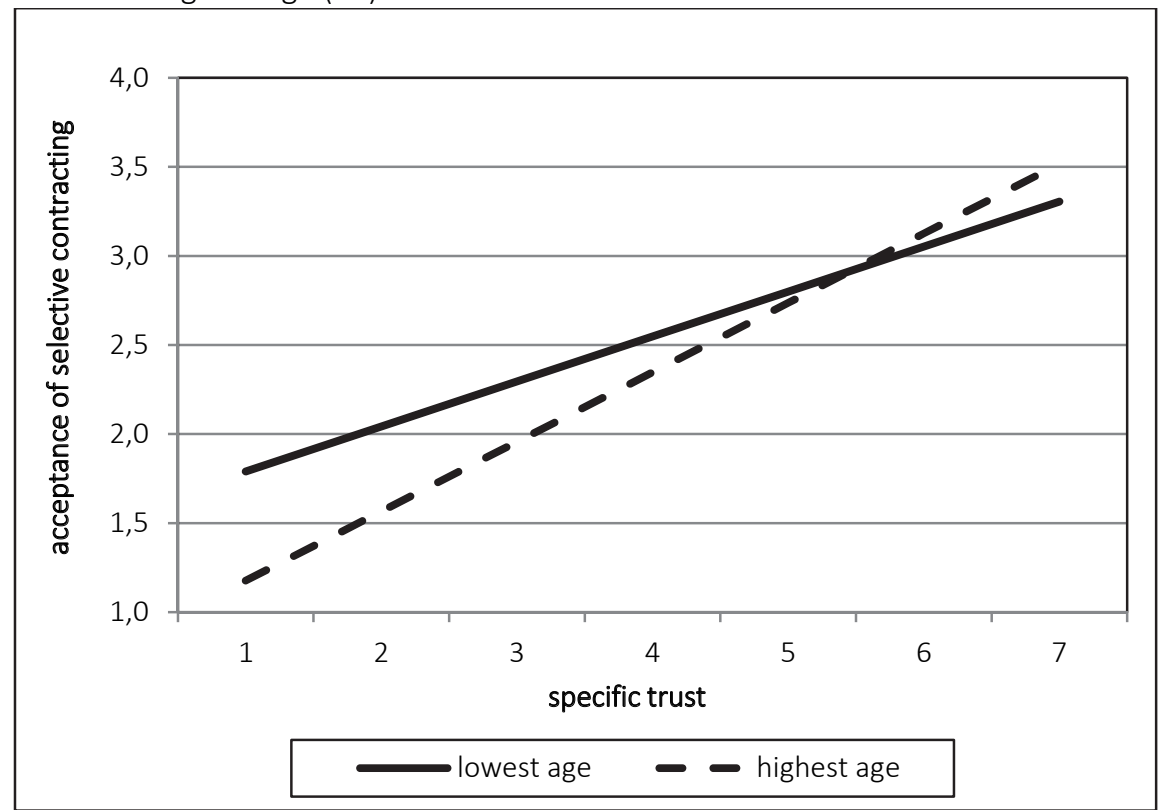

a For neutral general trust, male, good self- perceived health.

\section{Discussion}

Since the shift from a supply-oriented health care system to a demand-oriented one, health insurers have incentives to become prudent buyers of care on behalf of their enrolees. Health insurers are allowed to selectively contract care providers, which is supposed to stimulate competition between care providers and to increase the quality and contain costs in the health care system. However, health insurers are still reluctant to implement selective contracting. Health insurers fear that enrolees lack trust in their health insurer and that enrolees have negative attitudes toward restrictions in their freedom of provider choice. However, is this really the case? In this paper we studied the role of trust on enrolees' acceptance of selective contracting by their health insurer. Consistent with our hypotheses, we found that enrolees who have more trust in their health insurer in general, and specifically in their health insurer's purchasing strategy, are more open to selective contracting by 
their health insurer. Thus, trust is indeed an important prerequisite for enrolees to accept selective contracting by their health insurer. The effect of specific trust on the acceptance of selective contracting is stronger for older people than for younger people. This could mean that trust is more important for enrolees who are more likely to need care in the near future. Furthermore, in line with our hypotheses, we found that less healthy and female enrolees are less likely to accept selective contracting by their health insurer than healthier and male enrolees. Also, younger enrolees are more likely to accept selective contracting compared to older enrolees. However, this only applies when people have a low level of trust in the purchasing strategy of their health insurer. Thus, besides trust, gender, self-reported health status and age also have an influence on the acceptance of selective contracting. We must note that even when trust is very high, the acceptance of selective contracting is still relatively low. This means that there are other factors besides trust and respondent characteristics that influence the acceptance of selective contracting by health insurers. One of these factors may be the price of the insurance policy. Insurance policies with restrictions in choice of care provider are usually cheaper, this may positively influence the acceptance of selective contracting.

Contrary to our hypotheses, there were no interaction effects found between trust and self-reported health status, and trust and gender, with regard to the acceptance of selective contracting. This means that the effect of trust on the acceptance of selective contracting by the health insurer does not differ for enrolees with different self-reported health status or gender. The expectation was that less healthy enrolees would need more trust because they need to take a greater risk, since they are more likely to need care now and in the near future. Women, too, would need more trust, because they perceive a greater risk, since they are more risk averse. It is possible that these interaction effects are somehow compensated. This is true when health status and gender affect trust. Because we have this data available we checked for this and found that men and healthier enrolees have more trust in their health insurer. This means that gender and health status partly determine the level of trust while trust has a direct effect on the acceptance of selective contracting.

\section{Scientific implications}

This paper adds to the literature that trust in the health insurer is indeed an important prerequisite for enrolees' acceptance of selective contracting. Most of the variance in acceptance of selective contracting is however not explained by the model. This means there are more factors besides trust and the characteristics of 
the enrolees that influence their acceptance of selective contracting by their health insurer. A possible explanation is the importance of autonomy. The selfdetermination theory states that people have a need for autonomy and fulfilment of this autonomy leads to increased well-being [30]. When the health insurer restricts provider choice, people may feel their autonomy is impaired. This could explain why enrolees do not accept selective contracting by their health insurer. It would therefore be interesting to include autonomy in future research on this subject. Furthermore, we also expect that the reason why enrolees do not accept selective contracting is partly due to the effect of loss aversion. Here, a reference point, usually the status quo, determines individual preferences and the lack of benefits in giving up an object being greater than the benefits associated with acquiring it [31, 32]. Individuals still experience great difficulty in relinquishing their current situation although it was stated that the health insurer contracts care providers selectively based on quality, price and accessibility. So, how to overcome this status quo bias? It may be possible that status quo bias is non-existent or low when people are already looking for a different health insurance policy. This may be the case when their financial situation or their family composition has changed. For future research, it could therefore be important to include in the model whether or not enrolees are currently considering changing their health plans.

\section{Practical implications}

The results of this study indicate that in practice, when health insurers want to implement selective contracting, it is important that their enrolees trust them, especially the older ones. Although trust may not appear to be very low (4.7 on a scale of 1 to 7), there is still room for improvement. Also, it is known that trust in the health insurer is quite low compared to trust in medical specialists, GPs and hospitals [33]. But how can health insurers increase their enrolees' trust in them? Literature shows that general trust in a company can be increased by improving elements of technical and functional quality [34]. Functional quality refers to how the service is being delivered. For instance, in how responsive the health insurer is to a customer's complaint and the friendliness of the insurer's personnel. Technical quality addresses the what question and reflects customers' perceptions of the outcome they receive, such as a timely payment of claims. These aspects are relatively easy for health insurers to invest in. However, this is aimed at increasing general trust in the insurance company, not at specific trust in the way health insurers select care providers. US literature shows that enrolees question the motives of a health insurer that practices selective contracting, because they expect 
their health insurer to be more interested in making money than in selecting good quality care providers for them $[12,13]$. Also, having knowledge of the trustee's behaviour is very important in order to enhance trust [35]. Possibly, more trust in health insurers' purchasing strategies can be generated when health insurers convince enrolees of their motives for selective contracting. Furthermore, Boonen and Schut [9] state that the availability of objective quality information on care providers can solve the problem of a lack of trust, because such information will help health insurers to select care providers based on objective quality information. It will also help communicate this information to their enrolees. This will reduce uncertainty about the health insurer's behaviour. However, information from the health insurer still needs to be trusted and credible. When information from the health insurer is not trusted, it may be better if health insurers refer to other, highly trusted, parties to present objective quality information such as a GP or patient organisation.

As mentioned above, even when trust is very high, the acceptance of selective contracting is still relatively low. Therefore, solely increasing trust will probably not be enough to significantly increase the acceptance of selective contracting. Future research is needed to investigate other methods that contribute to increasing acceptance of selective contracting.

The finding that male, healthier and, depending on level of trust, younger enrolees are more likely to accept selective contracting, suggests there is the possibility of risk selection in health plans with selectively contracted care. This is consistent with literature where it was found that younger and healthier people more often choose a restrictive health policy where not all care providers are contracted [24-26]. In practice, in the Netherlands, more men than women are enrolled in a restrictive health policy and most of these enrolees are young and perceive themselves as healthy [36]. This presents a problem given the intended goals of selective contracting, because it is especially important that the people who use most care also accept selective contracting by their health insurer. If not, the financial benefits of channelling patients to selectively contracted care providers cannot be realised. It is very important to find out under which circumstances people who use or need care will choose a health plan with restrictions. 


\section{Limitations}

We have only included respondents who are enrolees of one health insurance company. Although this is a large company with enrolees from different insurance labels scattered over rural and urban areas, it is possible that levels of trust or acceptance of selective contracting slightly differ from the total Dutch population. The respondents that participated in this study are older than the general population and include more men. However, this does not affect our regression model results, because all subgroups are of sufficient size to perform the association analyses. Furthermore, we have used an online questionnaire, this could bias results as respondents who have no computer or access to internet could not participate. Usually, these are older adults [37], however, since our panel includes older people filling out online questionnaires, and we have performed association analyses, we do not think this has a significant impact on our results. Additionally, it is likely that the role of trust in the acceptance of selective contracting by the health insurer is not independent of context, this could limit generalizability of our findings. For instance, in the Netherlands, enrolees are not used to selective contracting by health insurers compared to the US where selective contracting is more common. Therefore acceptance of selective contracting may be lower in the Netherlands compared to the US. However, the hypotheses are based on international literature. Therefore, we believe that the relationships we found are also interesting in an international context. Furthermore, we must note that there are no standardised measures available to measure enrolees' acceptance of selective contracting by their health insurer and to measure trust in the purchasing strategy of their health insurer. Yet, we believe that this study provides a good starting point for developing such measures. In addition, the questions were hypothetical because Dutch citizens are not yet familiar with selective contracting. This could influence the outcomes of our study. Lastly, our data was obtained using a cross-sectional study design and, therefore, cannot provide any information about causal links. However, in this study we looked at a situation that is still uncommon in the Netherlands and not yet very dynamic. This survey could be looked at as a first measurement.

\section{Conclusions}

This study provides insight into factors that influence the acceptance by enrolees of selective contracting by their health insurer. It has confirmed that trust plays an important role in this acceptance. This paper is relevant for health insurers because 
it provides insight into how enrolees feel about selective contracting. Because hypotheses are based on international literature, the results are relevant not only for health insurers in the Netherlands, but also in other countries with demandoriented health care systems. 


\section{References}

1. Light DW: Comparative institutional response to economic policy: managed competition and governmentality. Social Science \& Medicine 2001, 52(1):1151-1166.

2. Saltman RB, Figueras J: Analyzing the evidence on European health care reforms. Health Affairs 1998, 17:85-108.

3. Laske-Aldershof T, Schut E, Beck K, Gress S, Shmueli A, Van de Voorde C: Consumer mobility in social health insurance markets: a five country comparison. Applied Health Economics and Health Policy 2004, 3:229-241.

4. Boonen LHHM, Schut FT: Sturing op de zorgmarkt. Economisch Statische Berichten 2006, 91(4486):226-228.

5. Pauly MV: Monopsony power in health insurance: thinking straight while standing on your head. Journal of Health Economics 1987, 6:73-81.

6. Sorensen AT: Insurer-hospital bargaining: negotiated discounts in post-deregulation Conneticut. Journal of Industrial Economics 2003, 51(4):469-490.

7. Varkevisser M, Polman N, Van der Geest SA: Zorgverzekeraars moeten patiënten kunnen sturen. Economisch Statische Berichten 2006, 91(4478):38-40.

8. Van de Ven WPMM, Schut FT: Managed competition in the Netherlands: still work-inprogress. Health Economics 2009, 18:253-255.

9. Boonen LHHM, Schut FT: Preferred providers and the credible commitment problem in health insurance: first experiences with the implementation of managed competition in the Dutch health care system. Health Economics, Policy and Law 2011, 6:219-235.

10. Boonen LHHM, Schut FT: Zorgverzekeraars kampen met vertrouwensprobleem (Health insurers face problems with trust). Economisch Statistische Berichten 2009, 94(4572):678-681.

11. Gawande AA, Blendon RJ, Brodie M, Benson JM, Levitt L, Hugick L: Does dissatisfaction with health plans stem from having no choices? Health Affairs 1998, 17(5):184-194.

12. Heinemann S, Leiber S, Gress S: Managed competition in the Netherlands - A qualitative study. Health Policy 2013, 109:113-121.

13. Miller $\mathrm{NH}$ : Insurer-provider integration, credible commitment, and managed-care backlash. Journal of Health Economics 2006, 25:861-876.

14. Gilson L: Trust and the development of health care as a social institution. Social Science \& Medicine 2003, 56:1453-1468.

15. oold SD, Klipp G: Managed care members talk about trust. Social Science \& Medicine 2002, 54:879-888.

16. Goudge J, Gilson L: How can trust be investigated? Drawing lessons from past experiences. Social Science \& Medicine 2005, 61:1439-1451. 
17. Hall MA, Dugan E, Zheng B, Mishra AK: Trust in physicians and medical institutions: what is it, can it be measured, and does it matter? The Milbank Quarterly 2001, 79(4):613-639.

18. Pavlou PA: Consumer acceptance of electronic commerce: integrating trust and risk with the technology acceptance model. International Journal of Electronic Commerce 2003, 7(3):69-103.

19. Das TK, Teng BS: Trust, control and risk in strategic alliances: an integrated framework. Organization Studies 2001, 22(2):251-283.

20. Balkrishnan R, Dugan E, Camacho FT, Hall MA: Trust and satisfaction with physicians, insurers, and the medical profession. Medical Care 2003,41(9):1058-1064.

21. Zheng B, Hall MA, Dugan E, Kidd KE, Levine D: Development of a scale to measure patients' trust in health insurers. Health Services Research 2002, 37(1):185-200.

22. Donselaar CG, de Boer D, Zegers M, Rademakers J, Hendriks M: Wat is belangrijker bij het bepalen van het algemene oordeel over de zorgverzekeraar: concrete ervaringen of vertrouwen, loyaliteit en beeldvorming? [What is more important in determining the overall assessment of the health insurer: practical experience or trust, loyalty and image?]. Utrecht, the Netherlands: NIVEL; 2011.

23. Jianakoplos NA, Bernasek A: Are women more risk averse? Economic Enquiry 1998, 36(4):620-630.

24. Block LE: Evolution, growth, and status of managed care in the United States. Public Health Reviews 1997, 25(3/4):193-244.

25. Hellinger FJ: Selection bias in HMOs and PPOs: A review of the evidence. Inquiry 1995, 32(4):135-142

26. Hellinger FJ, Wong HS: Selection bias in HMOs: A review of the evidence. Medical Care Research and Review 2000, 57(4):405-439.

27. Boonen LHHM, Donkers B, Schut FT: Channeling consumers to preferred providers and the impact of status quo bias: does type of provider matter? Health Services Research 2010, no. doi: 10.1111/j.1475-6773.2010.01196.x.

28. Hendriks M, Delnoij DMJ, Groenewegen PP: Het meten van vertrouwen in de zorgverzekeraar: psychometrische eigenschappen van een Nederlandse vragenlijst. Tijdschrift voor Gezondheidswetenschappen 2007, 85(5):280-286.

29. West SG, Aiken LS, Krull JL: Experimental personality designs: analyzing categorical by continuous variable interactions. Journal of Personality 1996, 64(1):1-48.

30. Deci EL, Ryan RM: Intrinsic motivation and self-determination in human behaviour. New York, NY: Plenum Press; 1985.

31. Kahnemann D, Knetsch JL, Thaler RH: The endowment effect, loss aversion and status quo bias. Journal of Economic Perspectives 1991, 5(2):193-206. 
32. Samuelson W, Zeckhauser R: Status quo bias in decision making. Journal of Risk and Uncertainty 1988, 1:7-59.

33. Brabers AEM, Reitsma-van Rooijen $M$, de Jong JD: Barometer Vertrouwen in de gezondheidszorg [Barometer trust in health care]. In.; 2013.

34. Wendel S, de Jong JD, Curfs EC: Consumer evaluation of complaint handling in the Dutch health insurance market. BMC Health Services Research 2011, 11(doi:10.1186/1472-6963-11-310).

35. Goold SD: Trust and the ethics of health care institutions. The Hastings Center Report 2001, 31(6):26-33.

36. Ministerie van VWS [Dutch Ministry of Health Welfare and Sports]: Bevindingen NZa monitor Zekur polis en onderzoek naar de werking van het risicovereveningssysteem voor portefeuilles met jonge gezonde verzekerden [Findings NZa monitor Zekur policy and research into the effects of the risk equalization system for portfolios with young and healthy enrolees]. Den Haag, The Netherlands: Z/F-2957347; 2009.

37. Sengpiel M, Dittberner D: The Computer Literacy Scale (CLS) for older adults development and validation. Mensch \& Computer 2008:7-16. 


\section{Appendix}

\section{Overview of multi-item measures}

All items were measured on a 7 point Likert-type scale from completely disagree (1) to completely agree (7)

\section{Openness to selective contracting by the health insurer $\alpha=0.955$}

Mean

Introductory text: The health insurer contracts selected care providers based on quality, price and availability. Care providers that are not selected by your health insurer will not be (fully) reimbursed.

1 To what extent do you agree with your health insurer contracting only certain hospitals?

2 To what extent do you agree with your health insurer contracting only certain GPs?

3 To what extent do you agree with your health insurer contracting only certain physiotherapists?

4 To what extent do you agree with your health insurer contracting only certain dentists?

5 To what extent do you agree with your health insurer contracting only certain pharmacies? 
1 You think the people at your health insurance company are completely honest.

2 Your health insurer cares more about saving money than about getting you the treatment you need.

3 As far as you know, the people at your health insurance company are very good at what they do.

4 If someone at your health insurance company made a serious mistake, you think they would try to hide it.

5 You feel like you have to double check everything your health insurer does.

6 You worry that private information your health insurer has about you could be used against you.

7 You worry there are a lot of loopholes in what your health insurer covers that you don't know about.

8 You believe your health insurer will pay for everything it is supposed to, even really expensive treatments.

9 If you got really sick, you are afraid your health insurer might try to stop covering you altogether.

10 If you have a question, you think your health insurer will give a straight answer.

\section{Specific trust $\alpha=0.894$}

Introductory text: Imagine that your health insurer decides to exclude several care providers from reimbursement. In this case, only the care providers that were selected by your health insurer will be fully reimbursed. If you would want to consult a care provider that has not been selected by your health insurer, you would have to pay an out-of-pocket payment. Your health insurer selects care providers based on quality, price and accessibility.

1 I trust my health insurer to choose the best possible care providers.

2 I trust my health insurer not to let the price prevail over quality. 
Chapter 4 


\section{Chapter 5}

Ranking sources of hospital quality information for orthopaedic surgery patients: Consequences for the system of managed competition

Published as:

Bes RE, van den Berg B. Ranking sources of hospital quality information for orthopaedic surgery patients: consequences for the system of managed competition. The Patient: Patient centered outcomes research 2013, 6:75. 


\section{Abstract}

\section{Background}

Healthcare quality information is crucial for the system of managed competition. Within a system of managed competition, health insurers can selectively contract care providers and are allowed to channel patients towards contracted providers. The idea is that insurers have a stronger bargaining position compared to care providers when they are able to channel patients. In the Dutch system of managed competition that was implemented in 2006, channelling patients to preferred providers has not been very successful yet. Empirical knowledge about which sources of hospital quality information they find important may help to understand how to channel patients to preferred providers.

\section{Objectives}

The objective of this survey is to measure how patients rank various sources of hospital quality information in a system of managed competition.

\section{Methods}

A written survey was conducted among clients of a large Dutch health insurance company. These clients recently underwent orthopaedic surgery to hip or knee no longer than 12 months ago.

\section{Results}

Two major players within a system of managed competition, health insurers and the government, are not seen as important sources of hospital quality information. In contrast, own experience and general practitioners (GPs) are seen as the most important sources of hospital quality information within the Dutch system of managed competition.

\section{Conclusions}

Health insurers should take the main finding that GPs are the most important source of hospital quality information into account when they contract care providers and develop strategies about how to channel patients towards preferred providers. A goo d functioning system of managed competition will benefit the patients as it involves incentives for care providers to increase healthcare quality and to produce at the lowest costs per unit of quality. 


\section{Introduction}

A new health insurance act in the Netherlands, introduced in 2006, places great emphasis on consumer and patient choice and competition among insurers. The new act, which replaced the former public and private health insurance systems, is part of a broader reform of the Dutch healthcare system based on the principles of managed competition [1]. Introduction of the Health Insurance Act is arguably the most significant health policy reform in Europe in decades [2]. Under the new law, all citizens are required to purchase a basic health insurance policy. They can choose any insurer they like. Competing health insurance companies are required to accept all applicants during a yearly open enrolment period ${ }^{1}$. The government determines the content of the basic health insurance package (medical care except long term care) insurers have to offer. Basic benefits are not defined in terms of providers but in functions of care [1]. This offers flexibility to health insurers to design their products and contracts with care providers to better appeal to the preferences of the consumers [2]. Health insurers are allowed to selectively contract care providers, which could lead to more competition between care providers. The central idea of the new system is that provider competition has either a downward pressure on prices/costs given a certain level of healthcare quality or has better incentives to improve or differentiate healthcare quality, potentially at higher prices/costs, as long as consumers and patients are willing to pay for better quality or diversification [2]. Typical for the Dutch healthcare system is also that general practitioners (GPs) act as gatekeepers for medical specialists/hospital care, partly to avoid unnecessary use of relatively expensive care [3]. In practice, a GPs' gatekeeper function implies that the GP decides whether specialist treatment is necessary. If it is, the patient chooses a hospital ${ }^{2}$. Please note that it is not necessary for the system of managed competition to work that GPs act as gatekeepers.

A necessary condition for the system of managed competition to work is that quality information about care providers and health insurers is available. Without quality information, health insurers can only negotiate with care providers on prices and without this information consumers can neither choose between insurers' quality of contracted care nor on the quality of their service provision. A complementary requirement is that insurers use this information to purchase healthcare and consumers and patients use this information to choose a health insurer and a care provider when they need care. If consumers and patients do not use quality information in making decisions, it is likely that managed competition just becomes 
a price competition involving a race to the bottom. However, if they do use this information, a system of managed competition involves incentives for care providers to become conscious about the costs and the quality of the services they provide [2].

In Dutch healthcare, different sources provide healthcare quality information, for instance the government, health insurers and the media. An unanswered question within managed competition is: what sources of quality information do patients find important when they compare care providers, for example to choose a hospital ${ }^{3}$ ? Surprisingly, there has been limited discussion about this question, while the answer is important within managed competition, where insurers have to find ways to channel patients to preferred care providers ${ }^{4}$, for the government as the regulator of the managed competition system, and ultimately for the patients as the healthcare reform only involves incentives to improve quality if quality information is available and if patients use available quality information. Providing quality information via a source that consumers and patients find unimportant might therefore limit the potential impact of the system of managed competition in terms of involving incentives to improve quality. The objective of this preliminary study is to present initial evidence on sources of quality information from a small scale survey $^{5}$ and to test how patients rank sources of hospital quality information.

\section{Background}

In the Netherlands, prices of hospital care were regulated before the new health insurance act went into effect. Price regulation has slowly decreased since, but decreased dramatically in 2012 and will continue to do so. This implies that health insurers can negotiate with hospitals about prices of hospital care. As described above, in theory, the system of managed competition involves incentives for health insurers to negotiate with hospitals on prices and quality of provided care. The government slowly decreases price regulation in hospital care to allow health insurers and hospitals to get used to negotiations, as before the introduction of the new system in 2006 health insurers mainly negotiated with hospitals about the size of the budget. Allowing the insurers to negotiate on prices is supposed to lead to increased competition between hospitals and ultimately between health insurers. It is anticipated that health insurers will increasingly implement selective contracting and preferred provider arrangements as the literature suggests that the bargaining 
power of health insurers depends on their ability to channel patients towards preferred providers $[4,5]$. So far, only a few insurers have experimented with channelling patients [6]. Other insurers seem worried to lose their reputation and loose enrolees when arranging preferred provider arrangements.

As mentioned in the introduction, different sources of healthcare quality information are available in Dutch healthcare. The government developed a website and has an inspectorate to monitor care providers; a newspaper and magazine developed yearly national rankings; and health insurers imported the American Consumer Assessment of Health Plan Surveys [7]. Although the website under the supervision of the Dutch government is frequently visited (in 2008, ten percent of the Dutch population visited this website) [8], in practice patients often choose the hospital that is closest to their home [9-11]. This could either point at insufficient availability of information, or at availability of quality information that is perceived as insufficient to choose hospitals that are located further away.

\section{Methods}

\section{Sample selection and characteristics}

The sample was identified based on the client list of a large Dutch health insurance company. The individuals had to be the companies' clients for more than a year and they had to have undergone orthopaedic surgery to the hip- or knee joint not longer than one year ago. Orthopaedic surgery was chosen because this care can be planned (no emergency), so patients had time to choose a hospital. Also, at the time the survey was conducted this type of care was already in the so called B-segment, implying that the prices were already deregulated by the government. 395 individuals met these criteria.

In June 2009, the selected individuals received a written questionnaire with an informed consent form and a return envelope. The response rate was $27.3 \%$ $(n=108)$. This is comparable with similar surveys in the Netherlands [2]. Even lower response rates of around $10 \%$ have been reported using an alternative study design in which written surveys were randomly distributed over households [12]. The mean age of the respondents is 61.4 years (SD 15.3) and $43.5 \%$ of the respondents is male. The respondents are relatively older compared to the adult Dutch population (mean 
age 47.5 years) [13] obviously because problems with hip and knee joints are more common in older adults.

\section{Survey questions}

The respondents were asked to indicate which source of hospital quality information they found most important. Questions were hypothetical, as we asked the respondents to imagine they needed care and had to find information about hospital quality. Respondents could choose between: national ranking of newspaper/magazine, their health insurance company, friends/family, their GP, government website, own experience and patient-/consumer organizations ${ }^{6}$. We also asked the respondents to indicate the least important source of hospital quality information. Potentially this provides extra information: being indicated as most important does not necessarily imply that respondents consider this source as least important: a validity check of the first question. Exact survey questions are presented in the Appendix. Proportion tests are performed, to test whether the differences in importance are statistically significant.

\section{Results}

Table 1 presents the results. The first column shows that GPs and own experience are very popular sources of hospital quality information (34\% and $43 \%$ ). The table also suggests that despite their respective central roles as regulator and purchasers of healthcare within the system of managed competition, government websites (5.6\%) and insurers (3.7\%) are not frequently seen as an important source of hospital quality information. The second column shows that the most unimportant source of hospital quality information is a national ranking in newspaper or journal (42.6\%). But friends/family (19.4\%), government websites (16.7\%) and health insurers (15.7\%) are also frequently indicated as unimportant sources of hospital quality information. Overall, GPs, own experience and patient/consumer organizations are most frequently indicated as important sources. In contrast, the ranking of national newspaper and journals, friends/family, health insurers and government websites do not seem popular. Proportion tests showed that the difference between GPs and own experience is not statistically significant $(p=0.14)$, however, the differences between GPs and the other sources and between own experience and the other sources are statistically significant $(p<0.001)$. National rankings are significantly least important compared to the other sources $(p<0.001)$. 
Health insurer, friends/family and government websites do not differ from each other but do differ statistically significantly from the other sources $(p<0.001)$.

Table 1 Sources of hospital quality information $(n=108)$

\begin{tabular}{lcc}
\hline Source & \% Most important & \% Least important \\
\hline Own experience & 43.5 & 1.9 \\
GP & 34.3 & 1.9 \\
Patient/consumer organization & 7.4 & 1.9 \\
Friends/family & 5.6 & 19.4 \\
Government websites & 5.6 & 16.7 \\
Health insurer & 3.7 & 15.7 \\
Ranking newspaper/journal & 0.0 & 42.6 \\
\hline
\end{tabular}

\section{Conclusion and discussion}

This paper aimed to present initial evidence on how patients rank various sources of hospital quality information within a system of managed competition. Our results suggest that the quality information provided by two main players within the system of managed competition, health insurers and the government, are not considered as important sources of hospital quality information In contrast, own experience and GPs are by far the most important sources of quality information.

Our results are in line with previous Dutch findings that are not published in the international literature [14] and other literature. De Groot et al., found in the Netherlands that patients' hospital choice was mainly based on own experience and GP advice [15]. Internationally, Marshall et al. found that people rarely search for performance data because they do not understand or trust it and that it only has a small impact on their decision making [16]. Also, people tend to make easy decisions e.g. by relying on others or past experiences rather than using comparative quality data [17]. Previous research on what types of quality information patients find important also confirms the importance of own experience. Furthermore, hospital reputation, hospital atmosphere, patient ratings, preventive indicators and experiences from friends and family are found to be important [18-20].

Succeeding in channelling patients to preferred providers will give the health insurers more bargaining power and is supposed to involve incentives for care 
providers to increase quality and become cost conscious. This will eventually be beneficially for the Dutch healthcare system and for the patients. Health insurers should take the main finding that GPs are a very important source of hospital quality information into account when they contract care providers and develop strategies on how to channel patients towards preferred providers. They could try to convince GPs of their strategy in contracting hospitals. Alternatively they could take over GPs, although this strategy might involve loosing clients as people might change insurer. Health insurers could invest in building capacity about how GPs refer their patients. What types of quality information do GPs exploit and what would be potentials for improvement?

A limitation of our study is that we did not measure the importance of different types of quality information, since the type of information is strongly related to the source. This would be very interesting to incorporate in future research. Future research could also add hospital websites as a quality source and employ choice based approaches like conjoint or discrete choice experiments. This would enable to quantify patients' trade-offs. To find out why some sources are found unimportant it would also be interesting to conduct cognitive interviews with patients. A studystrength is the inclusion of patients who recently underwent orthopaedic surgery as they have recently chosen a hospital. Their ranking based on experience is very informative. However, although the response rate is comparable with similar studies, it is still low and because we have no data on the non respondents we do not know whether the non response is selective. This could have a negative influence on the representativeness of our study population. Furthermore, our respondents were clients of an insurer with enrolees concentrated in the northwest. In this part of the Netherlands there are rural areas with a small number of hospitals to choose from, as well as urban areas with quite a number of hospitals. It seems therefore not unlikely to assume that the respondents are representative with respect to urbanisation but not with respect to age. Older people might not use the internet as frequent as younger people. Therefore, the number of respondents who find government websites the most important source of quality information could have been underestimated.

Crucial and unanswered research questions that result from our empirical findings are: (1) How can health insurers channel patients towards preferred providers in a way patients are benefited, for instance by including GPs in their purchasing strategies? (2) What is the role of the government in relation to the provision of 
healthcare quality information within a system of managed competition, as their information ranks much lower compared with information provided by care providers? We encourage future research to answer these questions because this information is crucial to get the incentives within the system of managed competition right and a good functioning system of managed competition will ultimately benefit the patients as it involves incentives for care providers to increase healthcare quality and to produce at the lowest costs per unit of quality.

\section{Footnotes}

1 See Mosca and Schut-Welkzijn (2008) for an introduction on determinants of choice behaviour in the Dutch health insurance market [21].

2 Enthoven and Van de Ven (2007) give more details of the Dutch Health Insurance Act and also outline how the new Dutch system could be implemented in the United States [1].

3 Varkevisser and Van der Geest (2007) list determinants of hospital choice: proximity/accessibility, hospital reputation, (perceived) hospital expertise, previous experiences with a hospital, waiting time, 24/7 availability of an emergency department, a guaranteed regular physician, sufficient parking facilities and participation in a regional network of health providers. They also investigate for what reasons consumers will bypass the nearest hospital. Results indicate that travel time and hospital attributes (greater size and scope) as well as patient attributes (age and income) significantly affects patients' decisions to bypass the nearest hospital [22]. Please note that this study does not say anything about consumers sources of hospital quality information.

4 We are aware of only two studies that measures challenging to preferred providers in Dutch healthcare. Boonen et al. (2008) measure how to channel enrolees from health insurance plans to preferred providers in the Dutch pharmacy market [4]. Regarding channelling consumers to GPs, Boonen (2009) shows in her thesis using a discrete choice experiment that consumers prefer to stick with their current GP even compared with a very attractive preferred provider GP [23]. Please note that both studies did not measure sources of quality information.

5 Survey questions are partly based on a survey of the Dutch Healthcare Authority that was not published in English and also does not discuss implications of findings for the theoretical concept of managed competition [14]. 
6 Choice options were partially based on a survey of the Dutch Health Care Authority in 2007 [14]. Results are not published in the international literature. Sources of included information were GP, government websites, family and friends, and health insurer. We added ranking of national newspaper/journal to our answering categories as they were potentially another source that patients find important. We also added own experience because we used a sample of patients implying they could consider own experience as well as patient/consumer organizations as they increasingly publish quality information [24]. 


\section{References}

1. Enthoven AC: The history and principles of managed competition. Health Affairs 1993, 12(1):24-48.

2. Van den Berg B, Van Dommelen P, Stam P, Laske-Aldershof T, Buchmueller T, Schut FT: Preferences and choices for care and health insurance. Social Science \& Medicine 2008, 66:2448-2459.

3. Delnoij DMJ, van Merode G, Paulus A, Groenewegen PP: Does general practitioner gatekeeping curb health care expenditure? Journal of health Services Research Policy 2000, 5(1):22-26.

4. Boonen LHHM, Schut FT, Koolman X: Consumer channeling by health insurers: natural experiments with preferred providers in the Dutch pharmacy market. Health Economics 2008, 17:299-316.

5. Sorensen AT: Insurer-hospital bargaining: negotiated discounts in post deregulation Conneticut. Journal of Industrial Economics 2003, 51(4):469-490.

6. Van de Ven WPMM, Schut FT: Managed competition in the Netherlands: still work-inprogress. Health Economics 2009, 18:253-255.

7. Delnoij DMJ, Te Asbroek G, Arah OA: Made in the USA: the import of American Consumer Assessment of Health Plan Surveys (CAHPS) into the Dutch social insurance system. European Journal of Public Health 2006, 16(6):652-659.

8. van der Maat $\mathrm{M}$, de Jong JD: Internet meest gebruikte informatiebron bij het zoeken naar een passende zorgverzekering. Utrecht, The Netherlands: NIVEL; 2008.

9. Hibbard JH, Peters E, Slovic P, Finucane ML, Tusler M: Making health care report cards easier te use. Joint Commission Journal on Quality Improvement 2001, 27:591-604.

10. Hibbard JH, Slovic P, Peters E, Finucane ML: Strategies for reporting health plan information to consumers: evidence from controlled studies. Health Services Research 2002, 37(2):291-313.

11. Meijer A: Vreemde ogen dwingen. Maatschappelijke controle in de publieke sector via internet. Den Haag, The Netherlands; 2004.

12. van der Star SM, van den Berg B: Individual responsibility and health-risk behaviour: a contingent valuation study from the ex ante societal perspective. Health Policy 2011, 101:300-311.

13. Central Bureau of Statistics: Bevolking; kerncijfers. Homepage. http://www.cbs.nl. Den Haag: Central Bureau of Statistics; 2009. 
14. Dutch Health Care Authority: Richting geven aan keuzes. Kunnen verzekeraars consumenten stimuleren naar gecontracteerde voorkeursaanbieders te gaan? [Directions to choices. Can health insurers stimulate consumers to visit contracted preferred providers?]. Utrecht, The Netherlands: Dutch Health Care Authority [NZa]; 2007.

15. de Groot I, Otten W, Smeets H, Marang-van de Mheen P: Is the impact of hospital performance data greater in patients who have compared hospitals? BMC Health Services Research 2011, 11:214.

16. Marshall MN, Shekelle PG, Leatherman S, Brook RH: The public release of performance data. What do we expect to gain? A review of the evidence. Journal of the American Medical Association 2000, 283(14):1866-1873.

17. Marshall MN, McLoughlin V: How do patients use information on providers? British Medical Journal 2010, 341:1255-1257.

18 Dijs-Elzinga J, Otten W, Versluijs $M$, Smeets $H$, Kievit J, Vree R, van der Made WJ, Marang-van de Mheen PJ: Choosing a hospital for surgery: the importance of nformation on quality of care. Medical Decision Making 2010, 30:544-555.

19. Edgman-Levitan S, Cleary PD: What information do consumers want and need? Health Affairs 1996, 15(4):42-56.

20. Hibbard JH, Jewett JJ: Will quality report card help consumers? Health Affairs 1997, 16(3):218-228.

21. Mosca I, Schut-Welkzijn A: Choice determinants of the mobility in the Dutch health insurance market. European Journal of Health Economics 2008, 9:261-264.

22. Varkevisser M, Van der Geest SA: Why do patients bypass the nearest hospital? An empirical analysis for orthopaedics care and neurosurgery in the Netherlands. European Journal of Health Economics 2007, 8(3):287-295.

23. Boonen LHHM: Consumer channeling in health care: (im)possible?: Erasmus Universiteit Rotterdam; 2009.

24. Frewer LJ, Howard C, Hedderly D, Sheperd R: What determines trust in information about food-related risks? Underlying psychological constructs. Risk Analysis 1996, 16(4):473-486. 


\section{Appendix A Survey questions}

The box below presents seven sources of hospital quality information.
1. Health insurer
5. Patient/consumer organization
2. Friends/family
6. GP
3. Own experience
7. Government websites
4. Ranking national newspaper/journal

Please indicate which source you find the most important and which one the least important? (Please select one number from the box indicating a source of hospital quality information)

The most important I find source:

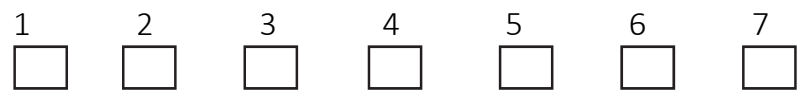

The least important I find source:

\begin{tabular}{lllllll}
1 & 2 & 3 & 4 & 5 & 6 & 7 \\
\hline & $\square$ & $\square$ & $\square$ & $\square$ & $\square$ & $\square$
\end{tabular}


Chapter 5 


\section{Chapter 6}

Acceptance of selective contracting in health insurance: importance of information

Submitted as:

Bes RE, van Erp KJPM, Curfs EC, Groenewegen PP, de Jong JD. Acceptance of selective contracting in health insurance: importance of information. 


\section{Abstract}

\section{Background}

Selective contracting by health insurers is important in managed competition health care systems. However, the acceptance of selective contracting is low since it can have negative consequences for enrolees. In addition to trust in the health insurer, it is yet unknown which factors play a role in enrolees' acceptance of selective contracting. In this paper, we research the influence of providing information about the selection of care providers upon the acceptance of selective contracting.

\section{Methods}

An online questionnaire was developed which included a vignette study with a two by two design. In the questionnaire, respondents read about a hypothetical situation describing a large or a small change in their health plan, containing, therefore, greater or fewer negative consequences of selective contracting. Half of them received only little information about the selection of care providers, while the other half received more detailed information.

\section{Results}

The amount of information positively influences the acceptance of selective contracting, especially when selective contracting has more severe consequences for enrolees. However, the negative effect of the consequences of selective contracting is not entirely cancelled out by giving information.

\section{Conclusion}

Persuading enrolees to accept selective contracting remains a difficult issue that has to be explored further. 


\section{Introduction}

Today, many European countries have reformed their health care systems along the lines of Enthoven's managed competition theory [1]. This is in order to increase the quality, and reduce the costs, of health care $[2,3]$. Third party payers, for instance health insurers, purchase care on behalf of their enrolees, the health care consumers. Health insurers are supposed to contract care providers selectively on the basis of the quality and cost of care. Such selective contracting is increasingly being carried out in Europe and has an extensive history in the US [4]. The idea is that care providers will compete with each other to sign contracts with health insurers in order to guarantee revenue. Therefore, they will, thus, make efforts to increase the quality, and reduce the costs, of care. The quality of care will then, in theory, increase. However, a negative consequence of this for enrolees is that there is a limited number of care providers with whom their insurers have signed contracts. It is only the care received from these providers which will be reimbursed by the enrolee's health insurer. This may result in having to switch care providers and may, consequently, lead to a longer travelling time as well. The advantage is that these health plans are usually cheaper compared to the health plans that contract with all care providers.

In the Netherlands, selective contracting has been slowly implemented over the last ten years. Even so, most health insurers will still offer health plans with a free choice of care providers. This is because they are afraid to loose enrolees, since many of them do not accept selective contracting and do not choose a restrictive health plan [5]. In 2015, 7.5 per cent of enrolees in the Netherlands chose a restrictive health plan [6]. This means that, according to the theory of managed competition, competition between care providers will not occur, and thus, care providers will have no incentives to improve quality and reduce costs. Therefore, according to this theory, it is important that selective contracting is more broadly accepted. But under which conditions will enrolees accept selective contracting?

Trust in the health insurer plays an important role in the acceptance of selective contracting [7]. However, it was found that even when trust is high, acceptance of selective contracting is still relatively low. This suggests that there are other factors that play a role [7]. Furthermore, younger and healthier enrolees are more likely to accept selective contracting compared to older people and people in poorer health. This is probably because they do not expect to need care in the near future $[5,8,9]$. 
It is as yet unknown which additional factors may play a role in the acceptance of selective contracting.

Selective contracting is a relatively new development, which can cause uncertainty among enrolees. They are unclear about the exact consequences of choosing a restrictive health plan and do not know what care they will need in the future. This is illustrated by the finding that enrolees agree with selective contracting in as far as it does not limit their freedom of choice [10]. This raises the question of whether people truly understand the consequences of selective contracting as by its very nature it always limits freedom of provider choice through the implementation of financial incentives. Because enrolees do not know exactly what the consequences of selective contracting are, it is hard for them to judge how they feel about it. They may, therefore, be inclined not to choose a restrictive health plan. Giving enrolees more concrete information about the consequences of having a restrictive health plan may, however, remove some of the uncertainty. Furthermore, it was found that providing information about the reason why a change is taking place is very important to people who are confronted with the unfavourable consequences of that change. This is known as procedural fairness [11, 12]. Communicating to enrolees the health insurers' motivation for changing health plans through the implementation of selective contracting may, therefore, be very important to its acceptance. In this paper we research how providing information to people about the selection of care providers influences their acceptance of selective contracting, while people are informed about the specific consequences of selective contracting.

\section{Background and hypotheses}

Many health insurance companies in the Netherlands offer three different types of health plans. In the first type all care providers are reimbursed - that is there is no selective contracting. In the second type, insurance is offered where only contracted care providers are reimbursed, but where most providers are contracted. This is minor selective contracting. Finally, the third type of insurance offers only reimbursement of contracted care providers, but here, fewer providers are contracted. This is significant selective contracting [5].We will look in this study at the two different types of selective contracting. One where selective contracting is minor and has few consequences for enrolees and one where selective contracting is more significant and has negative consequences for enrolees. The two 
consequences of selective contracting which are considered important by enrolees are the limitation of their choice of care provider $[5,10]$ and the travelling time to the nearest care provider $[5,13]$. The restriction of care provider choice causes negative feelings amongst enrolees and is a reason why enrolees do not recommend their health plan to others [8]. The reason for this may be that enrolees do not trust their health insurer to purchase good quality of care on their behalf $[8,14]$. Travelling time to the nearest care provider is very important to enrolees and is even used as a proxy for costs [13]. Therefore, we expect that selective contracting is perceived as less favourable the fewer care providers are contracted, and the greater the distance to the nearest one.

We do not include the level of the insurance premium in our research. The premium of health plans with strong selective contracting is usually lower, however the premium differences are small. In any case selectively contracted health plans are not often chosen by enrolees [6] and therefore it seems that the lower premium does not compensate for the limitation in the choice of care provider.

\section{The role of information in the acceptance of selective contracting}

Theoretically, the more unfavourable a situation is, the lower the acceptance of this situation will be. However, whether or not the negative consequences are accepted may depend on the perceived fairness of the procedures that determine the situation. This is defined as, procedural justice [15]. This means that, for instance, providing information about the procedures which led to the situation, could improve the overall judgement on, and acceptance of, the situation [12]. For instance, an experiment of Greenberg showed that the decision of a company to reduce pay by 15 per cent caused fewer employees to feel a sense of inequality, when the reason for this decision was carefully explained [12]. Additionally, providing information about the procedure was found to be more important when the situation has more severe consequences for people [11]. This importance of an explanation may also apply in the case of implementing selective contracting. In line with this research, we expect that enrolees will be more likely to accept selective contracting when they are provided with information about the selection procedure of care providers. This explanation is expected to be more important when selective contracting has more negative consequences for enrolees, such as a longer travelling time to the nearest care provider and/or having to switch care providers. This leads to the following hypotheses: 
Chapter 6

H1: The acceptance of selective contracting is greater when it has less severe consequences for enrolees.

H2: The acceptance of selective contracting is greater when enrolees receive more information about the selection of care providers.

H3: The provision of information has more effect upon the acceptance of selective contracting when this has more severe consequences for enrolees.

\section{Methods}

\section{Participants}

A questionnaire, including a vignette study, was sent to 3,707 members of the Insurance Panel in August 2015. This access panel was set up in 2006 by the Netherlands Institute for Health Services Research (NIVEL) and the large Dutch health insurance cooperative VGZ. All members of the panel are 18 years or older and are covered by one of the health insurance policies of the different brands of this cooperative. The total response to the questionnaire was 3,145 (response rate $84,8 \%)$.

\section{Design and procedure}

A questionnaire was developed which included a vignette study with a two (small change versus large change) by two (little versus much information) design. In the questionnaire, respondents read a hypothetical situation in which a change in their health plan was described: "Imagine the following situation: You receive a letter from your health insurer to inform you about a change in your health plan. Your health insurer has contracted with fewer hospitals." This change entails the implementation of selective contracting. The respondents in the small change condition were told: "From 01 January 2016, your insurer has contracted with 5\% fewer hospitals. When you look at the list of contracted hospitals, you see that this change has hardly any consequences for you: (1) Your insurer has contracts with most hospitals near you; (2) The travelling time to a hospital remains approximately the same." This means that the small change group experiences changes of little consequence. By contrast, the respondents in the large change condition were told: "From 01 January 2016, your insurer has contracted with 15\% fewer hospitals. When you look at the list of contracted hospitals, you see that this change has significant 
consequences for you: (1) Your insurer does not have contracts with a number of hospitals near you; (2) This means that the travelling time to a hospital increases by approximately 20 minutes." This group experiences more severe consequences since they have to switch hospitals and have a longer travelling time.

Respondents in the little information condition only received one sentence explaining why some hospitals have not been contracted. They were told: "We have not signed contracts with hospitals that do not meet the quality norms." The respondents in the much information condition received more detailed information. They were told: "Our knowledge about the quality of health care has increased. For this we draw upon the expertise of patient organisations, medical norms and scientific research. For instance, we look at the number of complications that occur after surgery. We also look carefully at how the patient experienced the treatment. We have not signed contracts with the hospitals that do not meet the quality norms."

This 2 by 2 design led to four versions of the questionnaire and, therefore, the respondents were equally divided into four groups, based on age and gender ( $N=781-791)$. The response rate was equal for the four groups.

Table 1 Four groups of respondents

\begin{tabular}{lll}
\hline & Small change & Large change \\
\hline Little information & $A(N=789)$ & $C(N=784)$ \\
Much information & $B(N=781)$ & $D(N=791)$ \\
\hline
\end{tabular}

\section{Measures}

Acceptance of selective contracting

We measured satisfaction in order to see the extent to which respondents accept this new, though hypothetical situation. The respondents were asked to what extent they are satisfied with the conditions of their new health plan described in the questionnaire. This was measured on a 7-point Likert-type scale from completely disagree (1) to completely agree (7). In addition, we measured loyalty in order to see whether the changes to their health plan would be a reason for enrolees to switch insurers. This was measured using two items. The first one measured respondents' intention to stay with their health insurer and the second one their intention to leave and switch health insurers. These two items were measured on a 7-point 
Likert-type scale from very unlikely (1) to very likely (7). The items were combined by calculating the mean score on these two items for each respondent ( $\alpha=.82$ ).

\section{Covariates}

Trust in the health insurer is included in the model, since previous studies showed that trust in the health insurer plays an important role in the acceptance of selective contracting [7]. Trust was measured using a five-item measure developed by Dugan et al. [16]. The items were measured on a 7-point Likert- type scale from completely disagree (1) to completely agree (7) and combined by taking the mean of the five items for each respondent $(\alpha=.76)$. Furthermore, we corrected for age, since this was also found to influence the acceptance of selective contracting [7]. We also corrected for sex, level of education (low, middle, high), and self-reported health status which is measured on a five-point scale ranging from poor (1) to excellent (5). The variables age, sex, level of education and self-reported health status are known, since all panel members fill in a questionnaire each year in order to update their background characteristics.

\section{Analyses}

To test the hypotheses, two linear regression models were constructed for each outcome measure (satisfaction and loyalty). Each of the linear regression models was constructed both without the interaction term, and including the interaction term, in order to be able to interpret the results better. For the analyses, STATA 14.0 is used.

\section{Results}

\section{Descriptive statistics}

Table 2 presents the descriptive statistics. The mean age of the respondents is 66.5 years, which is higher than the general Dutch population. Also, men are somewhat overrepresented in the sample. There are no significant differences in age and gender between the four groups of respondents. In Figure 1, satisfaction with the new health plan conditions and loyalty is shown separately for the four groups. 
Table 2 Descriptive statistics

\begin{tabular}{lccc}
\hline & Per cent/mean & SD & N \\
\hline Satisfaction with new health plan conditions $^{\text {a }}$ & 4.3 & 1.5 & 3,044 \\
Loyalty $^{\mathrm{a}}$ & 5.3 & 1.6 & 3,048 \\
Age & 66.5 & 12.3 & 3,145 \\
Male & $57,0 \%$ & & 3,145 \\
Trust $^{\mathrm{a}}$ & 4,7 & 1.1 & 3,073 \\
Self-reported health status $^{\mathrm{b}}$ & 3.0 & 0.9 & 3,100 \\
Level of education: $^{\text {low }}$ & & & \\
$\quad$ middle & $4.0 \%$ & & 3,018 \\
$\quad$ high & $51.0 \%$ & & 3,018 \\
\hline a Measured on a 7-point Likert-type scale & & & \\
b Measured on a scale from 1 (very bad) to 5 (excellent) & & &
\end{tabular}

Figure 1 Uncorrected means of satisfaction and loyalty by group

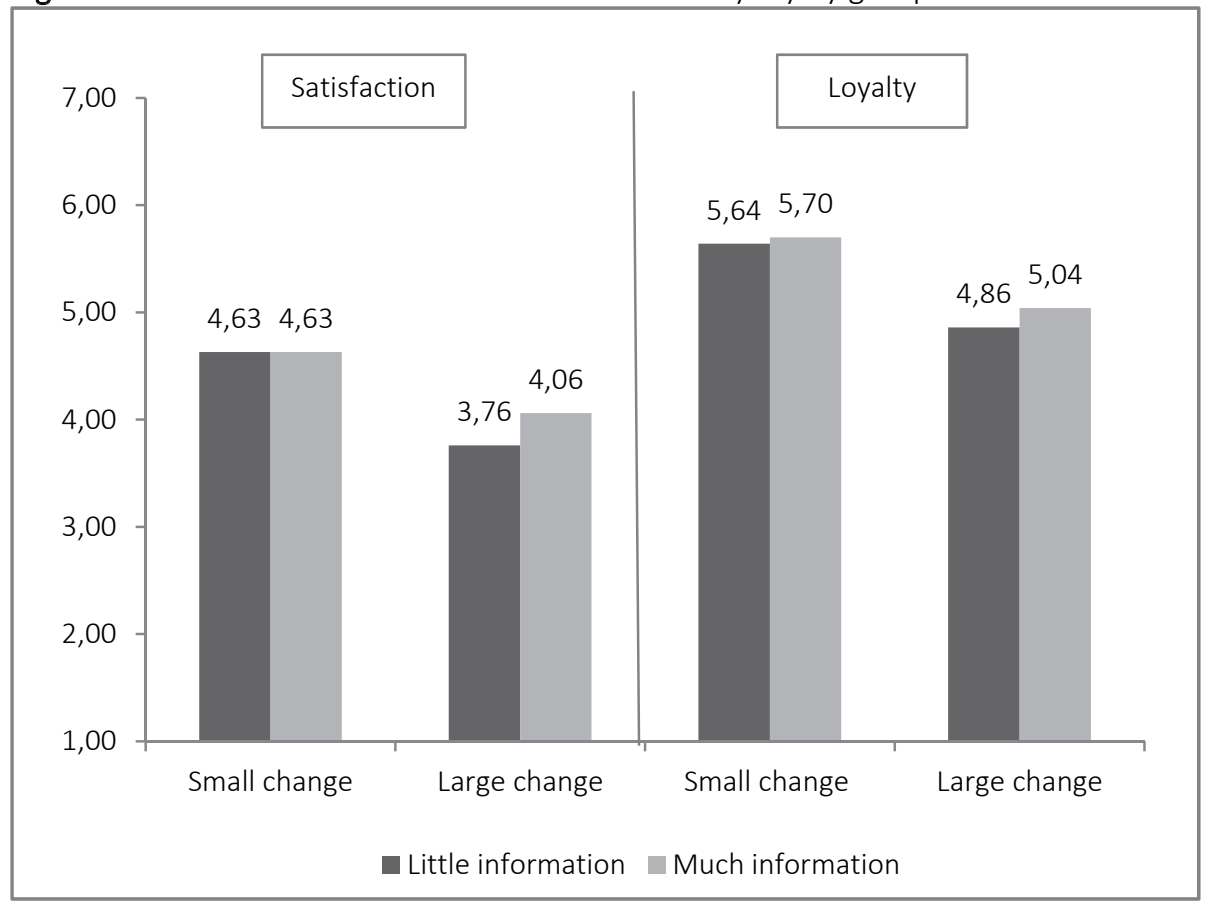




\section{Regression model}

The regression models without the interaction term (model 1) show that the change itself, compared to the information, is a more important predictor of satisfaction with the situation and loyalty towards the health insurer (Table 3). When the change has more severe consequences for enrolees (large change), they are less satisfied with the change and less likely to want to stay with their health insurer. This confirms H1. Furthermore, Table 3 shows that information has a significant effect on satisfaction with the situation and, although the effect is not as strong, information also has an effect on loyalty. This confirms $\mathrm{H} 2$.

Table 3 Regression coefficients of the change, and level of information about selective contracting on satisfaction and loyalty $(N=2,860-2,864)$

\begin{tabular}{|c|c|c|c|c|}
\hline \multirow[t]{2}{*}{ Outcome measure } & \multicolumn{2}{|c|}{ Satisfaction } & \multicolumn{2}{|c|}{ Loyalty } \\
\hline & Model 1 & Model 2 & Model 1 & Model 2 \\
\hline Constant & $1.216^{* *}$ & $1.299 * *$ & $2.557^{* *}$ & $2.587^{* *}$ \\
\hline Age & $.005^{*}$ & $.005 *$ & $.013^{* *}$ & $.013^{* *}$ \\
\hline Gender (female=ref) & $.106^{*}$ & $.107^{*}$ & .010 & .011 \\
\hline Trust & $.543^{* *}$ & $.544^{* *}$ & $.532 * *$ & $.533^{* *}$ \\
\hline Health status & $.066^{*}$ & $.066^{*}$ & -.037 & -.036 \\
\hline Education & .062 & .064 & -.089 & -.088 \\
\hline Change (small=ref) & $-.694 * *$ & $-.865 * *$ & $-.717^{* *}$ & $-.780 * *$ \\
\hline Information (little=ref) & $.157 * *$ & -.013 & $.133^{*}$ & .071 \\
\hline Change*information $^{\text {a }}$ & & $.341 * *$ & & .125 \\
\hline Adj. R-square & .234 & 0.237 & .205 & .205 \\
\hline Delta R-square & & $.0033^{* *}$ & & .0004 \\
\hline
\end{tabular}

${ }^{a}$ Small change with little information is the reference category

* $p \leq 0.05 ;{ }^{* *} p \leq 0.001$

The models with the interaction term (model 2) show that the interaction term change*information is significant for satisfaction but not for loyalty. For satisfaction this means when the situation has more severe consequences (large change), adding information has a positive effect on satisfaction with this situation. When the change is small and, thus, there are less severe consequences for enrolees, then information has no effect on satisfaction. However, although information can reduce the negative effect of the large change on satisfaction, it cannot cancel it out. Thus, compared to selective contracting that entails no severe consequences for enrolees, implementing selective contracting that entails more severe 
consequences will have a negative impact upon satisfaction with the health plan. Information will reduce the magnitude of this effect, but it will still be negative. This is also illustrated in Figure 1.

For loyalty, the interaction term of change and information is not significant, meaning that the effect of information on loyalty is not significantly different either for when the change is large or small.

\section{Discussion}

Selective contracting is supposed to be an important incentive for care providers to improve the quality of care and reduce costs in a health care system based on the theory of managed competition [1]. However, in order to implement this selective contracting, it is important that enrolees accept it. Earlier studies found that trust in the health insurer is an important predictor of the acceptance of selective contracting and that younger and healthier enrolees choose restrictive health plans more often. This study aimed to build upon this knowledge by finding out whether providing information about why certain care providers are not contracted, can influence the acceptance of selective contracting. Furthermore, we aimed to see how this relates to the severity of the consequences of selective contracting for enrolees. The results showed that information about why certain care providers are not contracted can reduce the negative feelings of enrolees about the implementation of selective contracting. For satisfaction, this holds especially true when the implementation of selective contracting has more negative consequences for enrolees. However, the negative feelings are not entirely cancelled out by the information received. It is possible that results are different depending on the nature of the information and how this is presented. Many studies have been carried out into how to present information to consumers who have to choose a health plan or care provider [17-19]. It is possible that some of the recommendations from this literature will also apply in our setting where enrolees are presented with a change, in particular a negative one, in their health plan. These could include recommendations about the amount of information and the form of the information, such as text versus a graph. Future research could test how far it is possible to cancel out the negative effect of the outcome by giving more information, different information or information presented in a different way. 


\section{Strengths and limitations}

When enrolees are asked in a hypothetical situation how they feel about selective contracting [20-22], or in research on the acceptance of selective contracting [7], selective contracting is often explained in general terms. As a result enrolees are not sure what the exact consequences for them will be. A strength of this study is that the acceptance of selective contracting is measured while the direct consequences of selective contracting are explained to enrolees. This reduces the uncertainty about the outcome and makes enrolees able to assess better how they feel about selective contracting. Another strength is the large sample size, which allowed us to divide the respondents into four equal groups of more than 780 each. Although the situation described to respondents was realistic, it is still hypothetical. Therefore, we only measure how respondents expect to feel after the health plan change and their intentions to stay or switch health plans. Although intentions are found to be a predictor of actual behaviour [23], it is still important to test this in practice. It would be very interesting to monitor how enrolees behave when their health insurer actually implements such a change to their health plan. Our respondents are all members of a large Dutch health insurer and have been a member of the Insurance Panel for several years. Therefore, it is expected that this group has more trust in their health insurer compared to the general Dutch population. Since greater trust means greater acceptance of selective contracting, it is expected that the acceptance is also greater in this group. When acceptance is already significant, it is difficult to increase it even more. Our results could therefore indicate an underestimation of the effect of information.

\section{Scientific implications}

In justice literature, it was found that information about the process is important when people are confronted with a situation that has negative consequences [11, 12]. This study confirms this research and shows that this can also be applied to health sciences. Furthermore, this study adds to the knowledge about the acceptance of selective contracting. Contrary to our expectations, we did not find a direct effect of information on satisfaction when the situation was of little consequence for enrolees. This is notable, since one might expect the implementation of selective contracting in itself - even if it has no direct consequences for enrolees - to still be experienced as negative when no concrete explanation is given. Maybe enrolees are not that negative about selective contracting in itself, but only when it has significant consequences for them. This is something that has not been found before. There has not been any research to 
compare the attitude towards selective contracting of enrolees who are given different specific consequences and who are unsure about these consequences. Previous research only investigated how enrolees assessed selective contracting, while being uncertain about the exact consequences of selective contracting $[7,9]$. We found that information only has a small effect on loyalty and that there is no difference in the effect of information for a large change compared to a small one. It is likely that other, more important, factors play a role in the intention to switch health insurers. A lot of enrolees experience barriers towards switching insurers, such as a fear of being refused by a different insurance company, concerns about the time and effort it takes to find a better health plan and fear of administrative problems. These barriers are experienced even more by enrolees with a chronic illness $[24,25]$.

\section{Policy implications}

The results show that it is important to inform enrolees about why certain decisions have been made when health plans are changed. This is because this can affect their satisfaction with the changes positively. This is especially true when these decisions have negative consequences for enrolees. It is also important to take these findings into account in other policy decisions which affect people negatively. However, compared to the acceptance of a decision with little consequences, the negative feelings of enrolees about a decision with large consequences will be reduced by information, but not entirely cancelled out. Enrolees are still negative about selective contracting when they experience negative consequences, even when they have received information.

This study shows that it is very difficult to persuade enrolees to accept selective contracting when they are negatively affected by it. This means that it is still likely that enrolees will not choose restrictive health plans and that, therefore, the theoretical incentive for care providers to improve quality and contain the costs through this mechanism, is absent. This means that the incentive of selective contracting does not work as it was intended. However, the threat of health insurers being able to cancel contracts with care providers that do not deliver high quality of care still exists. Whether this is enough to make care providers work more efficiently and cost-effectively is still unknown.

The model leaves room for other factors that could influence acceptance of selective contracting. These might include personality traits such as a reluctance to 
change and how far people feel impaired in their autonomy when their health insurer interferes with their choice of care provider [7]. Since our research focuses on mechanisms related to policy, we looked at factors that can be relevant in practice, such as the provision of information. Factors such as personality traits can hardly be influenced by policy and are therefore not included in this research.

\section{Conclusion}

The implementation of selective contracting which entails negative consequences for enrolees, namely a longer travelling time and stronger restrictions on their choice of care provider, is experienced as negative by enrolees. This study shows that these negative feelings can be reduced, but not cancelled out, by explaining to enrolees why contracts have not been signed with certain care providers. Persuading enrolees to accept selective contracting remains a difficult issue which should be explored further. 


\section{References}

1. Enthoven AC: The history and principles of managed competition. Health Affairs 1993, 12(1):24-48

2. Laske-Aldershof T, Schut E, Beck K, Gress S, Shmueli A, Van de Voorde C: Consumer mobility in social health insurance markets: a five country comparison. Applied Health Economics and Health Policy 2004, 3:229-241.

3. Van de Ven WPMM, Beck K, Buchner F, Schokkaert E, Schut FT, Shmueli A, Wasem J: Preconditions for efficiency and affordability in competitive healthcare markets: are they fulfilled in Belgium, Germany, Isreal, the Netherlands and Switzerland? Health Policy 2013, 109:226-245.

4. Duijmelinck DMID: Choice of health insurer and healthcare provider. An analysis of regulated competition in the Dutch healthcare system. Rotterdam, the Netherlands: Erasmus University Rotterdam; 2015.

5. Bes RE, Curfs EC, Groenewegen PP, de Jong JD: Health plan choice in the Netherlands: restrictive health plans preferred by young and healthy individuals. Health Economics Policy and Law 2017:1-18.

6. Dutch Health Care Authority: Zeventien zorgpolissen nader bekeken. In relatie tot de zorgplicht [A closer look at seventeen health plans. In relation to the duty to care]. Utrecht, The Netherlands: Dutch Health Care Authority; 2015.

7. Bes RE, Wendel S, Curfs EC, Groenewegen PP, de Jong JD: Acceptance of selective contracting: the role of trust in the health insurer. BMC Health Services Research 2013, 13:375.

8. Bes RE, Curfs EC, Groenewegen PP, de Jong JD: Selective contracting and channelling patients to preferred providers: a scoping review. Health Policy 2017, 121(5):504-514.

9. Determan D, Lambooij MS, de Bekker-Grob EW, Hayen AP, Varkevisser M, Schut T, de Wit GA: What health plans do people prefer? The trade off between premium and provider choice. Social Science \& Medicine 2016, 165:10-18

10. Bes RE, Brabers AEM, Reitsma-van Rooijen M, De Jong JD: Selectief contracteren? Prima, maar beperk mijn keuzevrijheid niet! [Selective contracting? Fine, but do not restrict my freedom of choice!]. Utrecht, The Netherlands: NIVEL 2014.

11. Folger R, Bies RJ: Managerial responsibilities ans procedural justice. Employee Responsibilities and Rights Journal 1989, 2(2):79-90.

12. Greenberg J: Employee theft as a reaction to underpayment inequity: the hidden cost of pay cuts. Journal of Applied Psychology 1990, 75(5):561-568. 
13. Varkevisser M, Van der Geest SA, Schut FT: Assessing hospital competition when prices don't matter to patients: the use of time-elasticities. International Journal of Health Care Finance Economy 2009, 10(1):43-60.

14. Boonen LHHM, Schut FT: Preferred providers and the credible commitment problem in health insurance: first experiences with the implementation of managed competition in the Dutch health care system. Health Economics, Policy and Law 2011, 6:219-235.

15. Lind EA, Tyler T: The social psychology of procedural justice. New York: Plenum Press; 1988.

16. Dugan E, Trachtenberg F, Hall MA: Development of abbriviated measures to assess patient trust in a physician, a health insurer, and the medical profession. Health Services Research 2005, 40(5).

17. Hibbard JH, Slovic $\mathrm{P}$, Jewett JJ: Informing consumer decisions in health care: implications from decision-making research. The Milbank Quarterly 1997, 75(3):395414.

18. Hibbard JH, Slovic P, Peters E, Finucane ML: Strategies for reporting health plan information to consumers: evidence from controlled studies. Health Services Research 2002, 37(2):291-313.

19. Waters EA, Weinstein ND, Colditz GA, Emmons K: Formats for improving risk communication in medical tradeoff decisions. Journal of Health Communication 2006, 11:167-182.

20. Allen HM: Consumers and choice: costcontainment strategies for health care provision. Health Psychology 1984, 3(5):411-430.

21. Curbow B: Health care and the poor: psychological implications of restrictive policies. Health Psychology 1986, 5(4):375-391.

22. Schur $\mathrm{CL}$, Dorosh $\mathrm{E}$ : Attitudes toward cost-containment features of managed care: differences among patient subgroups. The American Journal of Managed Care 1998, 4(10):1385-1391.

23. Kerpershoek E, Bes RE, Curfs EC, de Jong JD: Verzekerden bezuinigen vooral door aanpassing van hun lopende zorgverzekering, niet door te wisselen van zorgverzekeraar. [Enrolees save money by adjusting their current health plan, not qby switching to another health insurer.]. Utrecht, The Netherlands: NIVEL 2013.

24. Reitsma-van Rooijen M, de Jong JD, Rijken M: Regulated competition in health care: switching and barriers to switching in the Dutch health insurance system. BMC Health Services Research 2011, 11:95.

25. Vos L, de Jong JD: Percentage overstappers van zorgverzekeraar 3\%. Ouderen wisselen nauwelijks van zorgverzekeraar [Percentage that switched health insurance $3 \%$. Elderly barely switch]. Utrecht, the Netherlands: NIVEL 2009. 


\section{Chapter 7}

Advice from the health insurer as a channelling strategy: a natural experiment at a Dutch health insurance company

Submitted as:

Bes RE, Curfs EC, Groenewegen PP, de Jong JD. Advice from the health insurer as a channeling strategy: a natural experiment at a Dutch health insurance company. 


\section{Abstract}

\section{Background}

In a health care system based on managed competition it is important that health insurers are able to channel their enrolees to preferred care providers. However, enrolees are often very negative about financial incentives and any limitations in their choice of care provider. Therefore, a Dutch health insurance company has conducted an experiment to study the effectiveness of a new method of channelling their enrolees. This method entails advising enrolees about the choice of physiotherapists when they call customer service. By offering this advice as an extra service this method is supposed to improve service quality ratings.

\section{Methods}

In this experiment, one of the health insurer's customer service call teams began advising enrolees on their choice of physiotherapist. Three data sources were used. Firstly, all enrolees who call customer service received an online questionnaire in order to measure enrolees' evaluation of the quality of service. Enrolees who were offered advice received a slightly different questionnaire which, in addition, asked about whether they intended to follow the advice they were offered. Secondly, employees logged each call, registering, if they offered advice, whether the enrolee accepted it, and if so, which care provider was advised. Thirdly, data from the insurance claims were used to see if enrolees visited the recommended physiotherapist.

\section{Results}

The results show that enrolees are positive about being offered advice on the choice of physiotherapist. Furthermore, $45 \%$ of enrolees who received advice and then went on to visit a care provider, followed the advice. The service quality ratings were higher compared to control groups. However, it could not be determined whether this effect was entirely due to the intervention.

\section{Conclusions}

Channelling enrolees towards preferred care providers by offering advice on their choice of care provider when they call customer service is successful. The effect on service quality seem positive, although a causal relationship could not be determined. 


\section{Background}

Several European countries such as Germany, Switzerland and the Netherlands, have reformed their health care system reform based on managed competition [14]. In health care systems that are based on managed competition, health insurers or other third parties, play an important role. They are supposed to prudently purchase care, on behalf of their enrolees. Health insurers also compete with each other, since enrolees are allowed to switch health insurers if they can get a better offer elsewhere. This is an incentive for health insurers to contract care providers on the basis of price and quality of care in order to be able to offer attractive health plans. Additionally, they can compete by offering a high service quality [5]. Care providers compete with each other to be contracted by health insurers. However, the bargaining power health insurers have towards care providers depends largely on their ability to channel their enrolees towards contracted care providers [6, 7]. When they are successful in doing so, the market share of these contracted providers increases, which gives health insurers more bargaining power in negotiations with care providers.

There are different ways to channel enrolees towards contracted care providers. Those which have been researched include positive, and negative, financial incentives and quality incentives [8]. With positive financial incentives enrolees are given a discount, bonus or an exemption to paying a deductible when they use a preferred care provider [9]. Negative financial incentives mean that enrolees either have to pay a co-payment or they are not reimbursed, in full or in part, when they use a non-contracted care provider. Quality incentives may include, for instance, offering extended opening hours or a free health check at preferred care providers [10]. Positive financial or quality incentives, so called 'soft' incentives, are found to be successful. For instance, in the choice of a pharmacy, a quality certificate and extended opening hours were found to be effective channelling incentives $[9,10]$. Yet, negative financial incentives are shown to be more effective. This is also the most implemented type of incentive [8]. However, multiple studies show that enrolees feel negative about such incentives and do not want their health insurer to limit their choice of care provider [11-13]. This has led to the so called managed care backlash in the US, a collective resentment against managed care [14]. For this reason, health insurers in the Netherlands are reluctant to implement selective contracting [15]. 
However, a health care system based on managed competition requires strong competition between health insurers. Therefore, it is important for health insurers to deliver a high quality of service since this can improve customer loyalty and satisfaction with the company [16-18]. Ideally, health insurers will channel their enrolees towards preferred care providers in a positive manner, oriented towards the service, and in a way that does not emphasise a limitation in care provider choice.

Health insurers are contacted by their enrolees many times every day. This provides an opportunity for health insurers to offer a good quality of service and improve the relationship with their enrolees $[19,20]$. A Dutch health insurance company saw these calls as an opportunity to channel enrolees towards preferred care providers, while, at the same time, increasing customer satisfaction. The idea is to channel enrolees to a preferred care provider when, for instance, they ask a question about the reimbursement of care. After answering the question, the employee has a chance to ask the enrolee if he or she has already chosen a specific care provider and to offer advice on which care provider to choose. This could be offered as an extra service during the phone call. The health insurance company tried this out with one of their customer service call teams. Because of the prolonged collaboration between the research institute NIVEL and this health insurance company, the researchers were informed about this initiative and were given the opportunity to collaborate with the health insurance company. Therefore, we were able to collect data for this study during this initiative. The research question we aimed to answer was: Is it possible to channel enrolees towards preferred care providers by giving them free advice when they call customer service and what is the effect of this service on enrolees' rating of the service quality?

\section{Context}

A health care system based on managed competition was implemented in the Netherlands in 2006. However, the implementation of selective contracting by health insurers has proceeded slowly since health insurers have been reluctant to implement selective contracting and negative financial incentives. This is because they feared their enrolees would distrust them and change insurers. Enrolees in the Netherlands are allowed to switch health insurers every year during a specific period [21]. In 2014, article 13 of the Health Insurance Act was to be revised in order to 
allow health insurers to determine the level of reimbursement for non-contracted care providers. However, this was rejected by the First Chamber of parliament, which resulted in health insurers still being obliged to reimburse at least $75 \%$ of the costs of non-contracted care providers [22]. This has made channelling enrolees towards contracted care providers harder [23]. Some health insurers however still offer restrictive health plans where non-contracted care providers are reimbursed up to $75 \%$. However, enrolees do not often choose these types of health plans [24]. Additionally, it is the younger and healthier enrolees who are more likely to choose these restrictive health plans [25]. This means that care providers hardly lose any business because of these contracts since most enrolees who use care, have health plans with a free choice of provider. This has negative consequences for the bargaining power of health insurers in relation to care providers. Thus, although it is important for health insurers to be able to channel their enrolees towards preferred care providers, they are hardly able to do so. Research showed that qualitative incentives can also have an effect upon enrolees' care provider choice, although to a lesser degree than negative financial incentives. There was hardly any information found about whether health insurers in the Netherlands currently use these types of incentives.

In addition to offering a good quality of care for a good price, it is also very important for health insurers to create a good relationship with their enrolees in order to build loyalty. A way to channel enrolees towards preferred providers, while maintaining or building a good relationship with enrolees is therefore essential. The current study investigates whether it is possible to channel enrolees towards preferred care providers when they call customer service and to measure how far this affects enrolees' assessment of the quality of service.

\section{Methods}

\section{Setting}

The setting for this study was a large Dutch health insurance cooperative (VGZ), which is one of the four market leaders in health insurance in the Netherlands. Their customer service is called by many enrolees for a variety of questions. Every week 40.000-100.000 calls are handled. This is an opportunity for them to give, when applicable, enrolees advice on the quality of care providers and channel them towards good quality, preferred, care providers. They focused on physiotherapists, 
since the health insurance company had recently implemented a system to determine the quality of the performance of physiotherapists [26]. This is based on effectiveness, in which the physiotherapist who cures conditions with the fewest number of treatments, is considered the best. There are four tiers, the first tier being the most effective, the fourth the least effective. The goal of the insurance company is to channel enrolees towards physiotherapists in tier one or two. For the enrolees, there is no financial incentive to use a more effective physiotherapist. They do, however, benefit from undergoing fewer treatments, since enrolees are entitled to a limited amount of treatments per year.

One of the customer service call teams, comprising 14 employees, was chosen to try out the new channelling method which we were studying. They received eight hours of training so they could recognise when and how they could offer advice about the care provider choice of enrolees and how to explain this to enrolees. For instance, for all calls about physiotherapy, employees were supposed to ask their customers whether they had already chosen a physiotherapist and whether they would like advice about the quality of physiotherapists in the area where they live. The employees were given access to information about the effectiveness of physiotherapists on a local level. So when they received a call from an enrolee about physiotherapy, they were able to identify all the physiotherapists in the neighbourhood where the enrolee lived together with information about their effectiveness, which they could in turn explain to the enrolee. Of course, besides effectiveness, there are other aspects of quality which enrolees may find important, such as how patients are treated and how physiotherapists communicate with their patients. However, the employees only had information on effectiveness of the physiotherapists - that is which physiotherapist can help to cure conditions using the fewest number of treatments. It was found that enrolees find this aspect of quality important [27]. The pilot team started offering this extra service in August 2016. Normally, customer service call teams start their week with a short meeting. The pilot team had these meetings three to four times during the week to discuss progress and any difficulties. After the initial period, in October 2016, a session was held with the employees in order to evaluate the calls and to make sure calls were logged correctly by the customer service employees. After this meeting the official data collection started. 


\section{Design}

We used three data sources for this study. Firstly, data were used from questionnaires sent to enrolees who had contact with customer service. Two different questionnaires were sent. At this health insurance company, all enrolees who call customer service, receive a short questionnaire afterwards via e-mail about the service they received (general CS questionnaire, Figure 1). This questionnaire has been developed by the health insurer. For enrolees who, during the study period, had contact with an employee of the pilot team who offered extra advice on the choice of care provider, a specific questionnaire was developed by the researchers (research questionnaire, Figure 1).

Figure 1 Questionnaire scheme

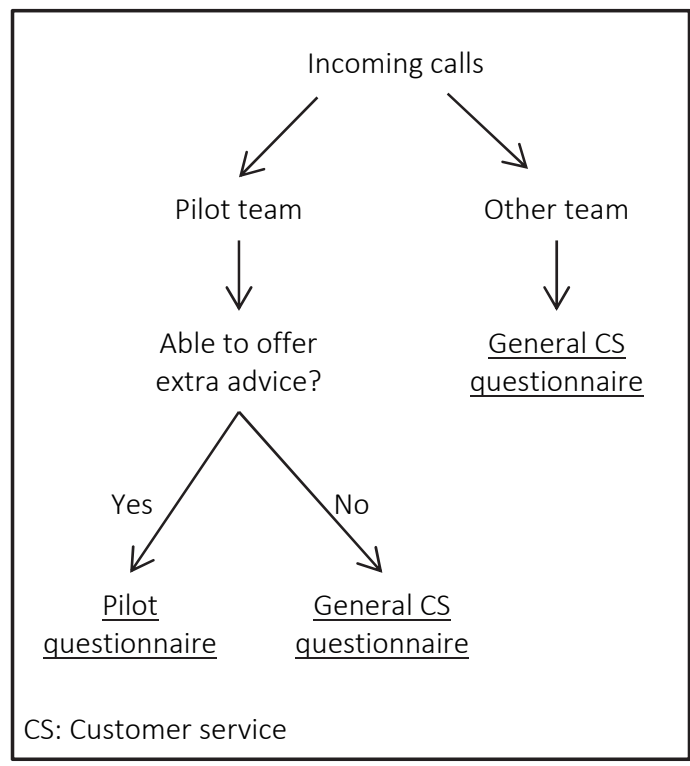

In the research questionnaire, service quality was measured in the same way as in the general customer service questionnaires. This enabled us to compare the results from different customer service teams and, thus, to analyse the service quality scores of the pilot team. Other questions were added in the research questionnaire in order to find out why customers were open to advice or not, how they felt about the advice and if they intended to follow the advice to go to the preferred care provider. All questionnaires were sent out automatically by e-mail within a few days of the phone call. Secondly, customer service employees logged every phone call, 
registering the enrolee who called, the subject of the phone call and the answer they gave to the enrolee. Employees of the pilot team also specifically registered if they were able to offer extra advice to the enrolee and whether the enrolee accepted this advice. Furthermore, they marked the specific code of the physiotherapist practice (AGB-code) they referred the enrolee to.

Thirdly, the logged data of the employees was combined with data from the insurance claims of enrolees that have received an advice in order to see if enrolees chose the recommended care provider or not. This was performed by employees of the health insurer.

\section{Outcome measures and analyses \\ Channelling}

In order to see whether this method can be a successful channelling method two outcome measures were used. Firstly, we looked in the questionnaire at how far enrolees were willing to follow the advice of their health insurer with the question: 'How likely is it that you will follow the advice of the employee?' This was measured on a scale of one (not likely) to five (very likely). Secondly, we could see whether enrolees actually follow the advice of the health insurer when the registration data of employees is combined with the claims data. The data that is logged by the employee for each call contained information on whether a specific advice was given and which care provider was recommended. This information was linked to the claims data to see whether enrolees had actually visited the recommended physiotherapists.

\section{Service quality}

To measure the effect of the intervention on the quality of service, we measured customers' evaluation of the phone calls. The quality of service was measured in the questionnaires by asking: 'Could you grade the conversation you had with the employee?' Respondents could indicate a number from one to ten, where one is the worst and ten is the best score. Half way through the research period, in the middle of January 2017, the insurance company revised their general customer service questionnaire by altering this question to: 'Could you grade the employee you had contact with?' This was still on a scale from one to ten. Although the questions are very similar, they are not the same. Therefore, we also added this new question to the research questionnaire. In this way we were able to check if we could use this variable as a proxy for the original question on the quality of service. Furthermore, 
in the research questionnaire, enrolees who accepted the offered advice were specifically asked to rate the advice they were given.

In order to measure how the pilot team scored on service quality compared to regular customer service, we compared the scores of the pilot team on the quality of service with two other teams on T0 (January - March 2016) and T1 (research period, from 20 October 2016 - March 2017) (Figure 2). For the pilot team, the research questionnaire data was merged with the data from regular customer service questionnaires in order to get an overall score for the quality of customer service. The other two teams were chosen to be as similar as possible to the pilot team in terms of the subjects of the calls they receive and the clients that call them - that is they were customers from the same health plans. The data was hierarchical, since calls were clustered within employees and employees were clustered within teams. Multilevel regression analyses were conducted using Stata 14. The dependent variable was the service quality rating and the independent variables were the team (pilot team/customer service team M/ customer service team D) and the period (T0/T1). The model contained the employee as the level, to correct for the cluster effect of this hierarchical data. To research whether the pilot team performed better compared to the other teams on T1 an interaction term of team and period was added.

On T0, the teams did not exist in the current formation. Around April 2016, the current teams were formed. The composition of the teams stands apart from the intervention. In order to have a score for the teams on TO, the scores of all individual employees who are currently in the pilot team and the two similar teams were used.

Figure 2 Overview of the timeline

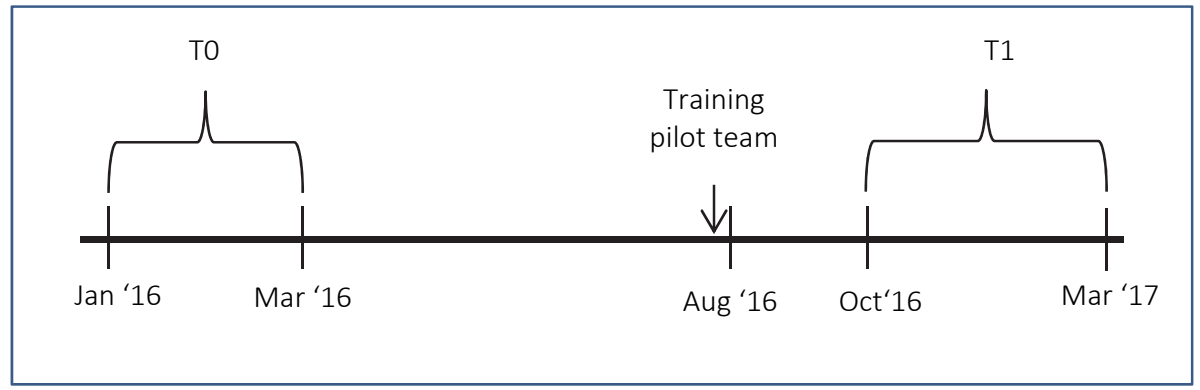




\section{Results}

During the research period (24th October 2016 - 31st March 2017) advice was offered by the pilot team in 1,727 calls - that is $5 \%$ of the total number of calls they handled in this period. The team logged $51.3 \%$ of the 1,727 calls as conversations where the enrolee was open to the advice that was offered. In $27.5 \%$ of the calls advice was offered, but the enrolee declined it. In $21.2 \%$ of the cases enrolees already went to a physiotherapist from tier one or two. Furthermore, most of the 1,727 calls (93.6\%) were categorised by employees under two subject categories; (1) the enrolee had a question about the reimbursement of care they had not yet received; and (2) an enrolee called to inform them about a change in their personal information, such as a change of address. We found considerable differences between employees. Some employees were able to offer advice more often than others and some employees logged relatively higher numbers of advice as accepted by the enrolees compared to others. The differences between employees still existed even after the session on 20th October where these kinds of differences were discussed (Figure 3).

Figure 3 Differences in offering advice between employees of the pilot team

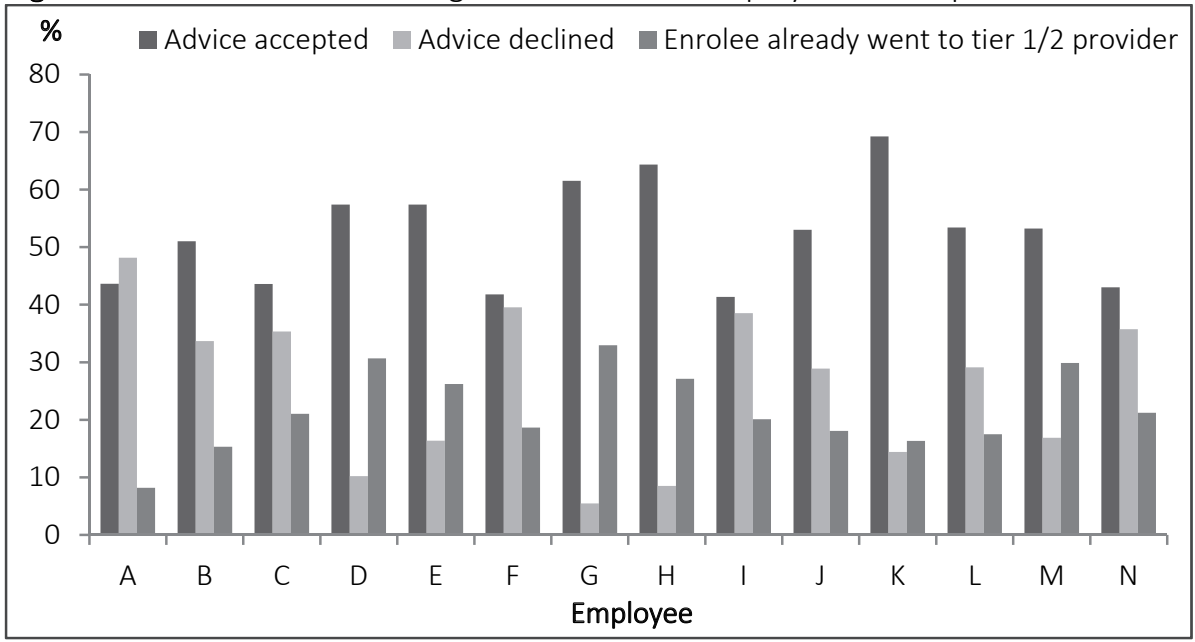

Unfortunately, it turned out that the insurance company did not have e-mail addresses of all their enrolees. Therefore, only 658 of the 1,727 enrolees received a research questionnaire. Ninety-five research questionnaires were completed, a response rate of $14,9 \%$ (Figure 4). This is a low response rate, however, it was 
somewhat higher than the response to the standard customer service surveys $(12,3 \%)$ this insurance company sends to their enrolees.

Figure 4 Overview of the response to the research questionnaire and the general customer service questionnaires on T1

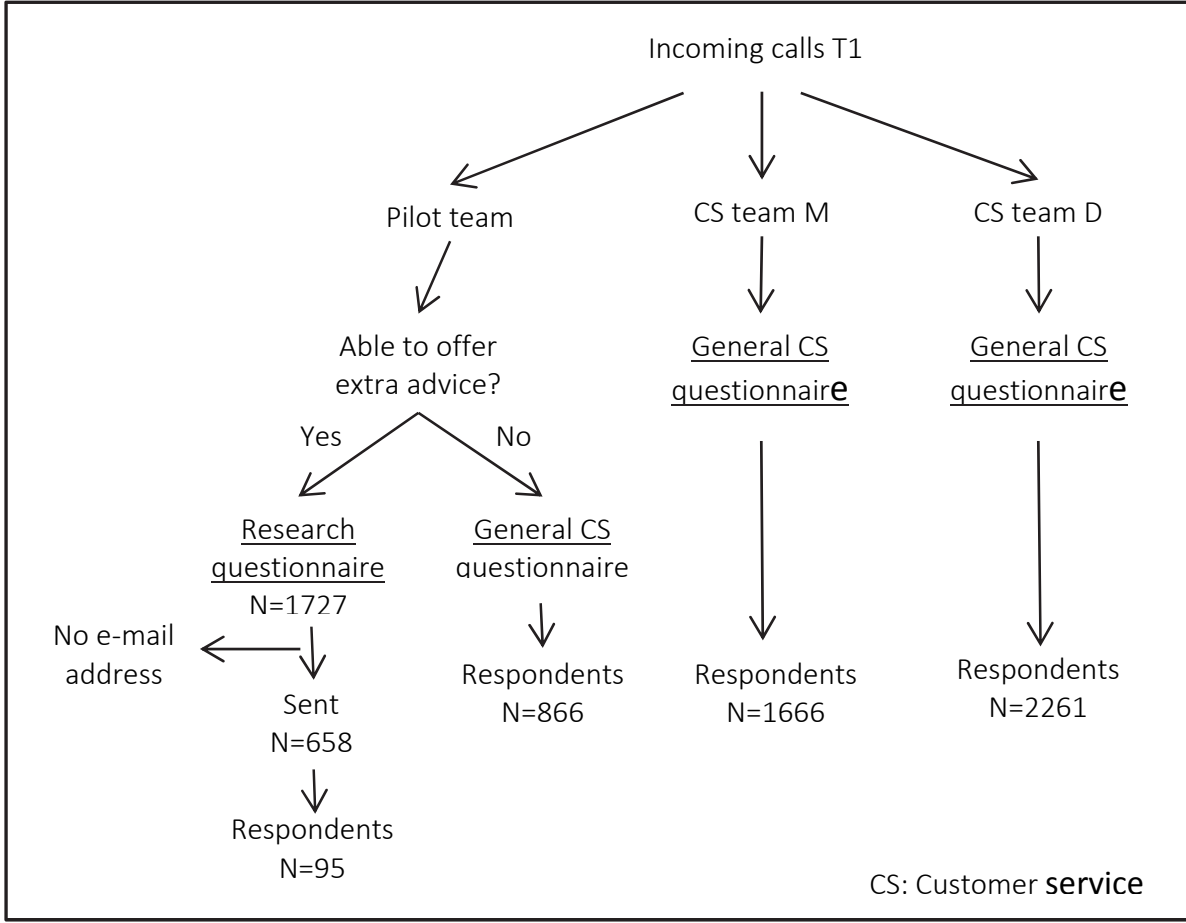

The average age of the 95 respondents to the research questionnaire is 56,7 years (SD 12,7), and $71 \%$ is female. All respondents were asked if they accepted the advice the employee offered them. Twenty-eight respondents indicated they had not been offered advice or did not remember. Thirty-two respondents indicated they had accepted the advice and 35 indicated they had not. Most indicated that the reason not to accept the advice was that enrolees had already chosen a care provider $(\mathrm{N}=19)$. Other answers were, "I do not want advice from my health insurer" $(\mathrm{N}=4)$, and, "it is not yet necessary to use a care provider" $(\mathrm{N}=4)$. Compared to the data which was logged by the employees, data from the questionnaire shows a lower percentage of calls where enrolees accepted the advice offered. Also, many enrolees indicated they had not been offered advice about their choice of care 
provider. Employees apparently sometimes registered that an enrolee had accepted advice while the enrolee did not see it that way.

\section{Channelling}

Respondents who were offered advice and indicated they had accepted it ( $N=32$ ) were asked if they plan to follow up on the advice. Only 16 respondents answered this question, of which 13 indicated a 4 or a 5, meaning that they were likely, or very likely, to follow it. Since this is a very small group, we also looked at the data that was collected during the initial period (August 2016 - 20 October 2016). This resulted in 35 respondents answering this question. Of these respondents 31 indicated a 4 or a 5 , meaning that they were likely, or very likely, to follow it. This confirms the results from the study period.

The logged data from the employees shows that 484 enrolees were given a specific advice on which physiotherapist to choose. Claims data showed that a large part of these enrolees did not, or had not yet visited, a physiotherapist ( $N=193,39,9 \%)$. Of all enrolees who were given specific advice on which physiotherapist to choose and who also went to a physiotherapist after the call ( $N=237), 45 \%$ followed the advice that was given ( $N=106)$. Of these 106 enrolees that followed the advice, $60 \%$ did not have a physiotherapist before, $26 \%$ switched, and $14 \%$ already went to the advised physiotherapist before the call.

\section{The quality of service}

Respondents to the research questionnaire $(\mathrm{N}=95)$ rated the general quality of service on average with a 7.8 (SD 1.4). Respondents who indicated they accepted advice from the employee $(\mathrm{N}=32)$ rated the advice on average with an 8.3 (SD 0.9). Forty-two of the 65 respondents who indicated they were offered advice partly or completely agreed with the statement, 'I appreciated it that the employee offered me advice on the choice of care provider'.

Since the question about the quality of service in the general customer service questionnaires was changed during the research period, we looked at the cases of the research questionnaire where both versions of the service quality question were answered $(\mathrm{N}=54)$. The correlation between both questions is $89(\mathrm{p}<0.001)$. Furthermore, we compared the means of both questions and found little to no differences. Therefore, we chose to use the new question as a proxy for the quality of service in the cases where the original question was removed. In Table 1 the 
scores for the quality of service for each team are shown on T0 (January to March 2016) and in the research period T1 (20th October 2016 to March 2017). On T0, the pilot team scored the lowest on service quality compared to the other two teams. On T1, all teams had improved their scores. However, the pilot team had improved more compared to the other two teams.

Table 1 Scores on service quality for pilot team and two similar teams on T0 and $\mathrm{T} 1$

\begin{tabular}{lcrrrr}
\hline & $\begin{array}{c}\text { T0 } \\
\text { Jan-Mar'16 }\end{array}$ & $\mathrm{N}$ & $\begin{array}{c}\text { T1 } \\
\text { 20 Oct '16- } \\
\text { Mar'17 }\end{array}$ & $\mathrm{N}^{\mathrm{a}}$ & Difference \\
\hline Pilot team & 7.44 & 1037 & 8.14 & 959 & +.70 \\
CS team M & 7.47 & 998 & 7.67 & 1659 & +.20 \\
CS team D & 7.56 & 848 & 7.71 & 2258 & +.15 \\
\hline
\end{tabular}

$\mathrm{CS}=$ customer service

a $\mathrm{N}$ on $\mathrm{T} 1$ differs slightly from numbers in Figure 3 , because of a small number of missing values on the question of the quality of service.

Multilevel regression analyses showed that the increase of the pilot team from T0 to T1 is significant $(p<.001)$. Furthermore, it showed that the pilot team significantly increased their score more compared to both other teams (both $p<.001$ ).

We know from the registration data that most incidents of advice were given when enrolees asked questions about the reimbursement of care they had not yet consumed and when they reported a change in their personal information, such as a change of address. Therefore, we decided to repeat the analyses while selecting only these subject categories for all three teams. In Table 2, only the scores for the quality of service for these subject categories were presented for T0 and T1. This shows that for these subjects the quality of service overall was rated slightly higher compared to the scores in Table 1. Still, the pilot team improved the most compared to both the other teams.

Multilevel regression analyses showed that the increase in the quality of service of the pilot team from T0 to T1 is significant $(p<.001)$. Furthermore, the pilot team score improved significantly more compared to customer service team $D(p=.003)$. The difference in improvement between the pilot team and customer service team $M$ is not significant. Customer service team $M$ did not significantly improve more compared to customer service team D. 
Table 2 Scores for the quality of service for the pilot team and two similar teams on T0 and T1 for subjects 'expectations' and 'changes'

\begin{tabular}{lccccc}
\hline & $\begin{array}{c}\text { T0 } \\
\text { Jan-Mar'16 }\end{array}$ & $\mathrm{N}$ & $\begin{array}{c}\text { T1 } \\
\text { 20 Oct '16- } \\
\text { Mar'17 }\end{array}$ & $\mathrm{N}$ & Difference \\
\hline Pilot team & 7.84 & 274 & 8.32 & 576 & +.48 \\
CS team M & 7.73 & 266 & 7.90 & 584 & +.17 \\
CS team D & 7.98 & 235 & 7.90 & 859 & -.08 \\
\hline
\end{tabular}

$\mathrm{CS}=$ customer service

\section{Discussion}

This study aimed to investigate the possibility of channelling enrolees towards preferred care providers by offering them advice on care provider choice when they call customer service. The idea is that this way of channelling is more positive compared to negative financial incentives. In addition, as it is offered as an extra service, it may even increase enrolees' evaluation of the quality of customer service. The results show that offering advice on the choice of a care provider when enrolees call about something else is most applicable at certain moments. These are when enrolees have questions about the reimbursement of care they may want to consume in the future or when they want to report a change in their personal records such as a change of address. In general, enrolees are positive about their insurer offering advice. Giving advice is also an effective channelling method, since it was found that $45 \%$ of enrolees who went to see a physiotherapist after they were given advice, actually go to the recommended physiotherapist. In addition, results show that service quality ratings increased.

\section{Channelling}

This way of channelling enrolees to preferred care providers has not been studied before. The results seem very promising since a large part of the enrolees that go to see a physiotherapist after they received advice, followed the advice. However, whether or not it is possible to channel enrolees to preferred care providers during a call to customer service may depend on different factors. Some enrolees may be opposed in principal to receiving advice from their health insurer about the quality of care providers. Previous research from the Netherlands showed that almost 55\% of enrolees do not welcome advice about their choice of care provider from their 
health insurer. Respondents mostly indicated that they wanted, and/or were able, to choose a care provider themselves, they think their health insurer has its own interests at heart or is not objective, and they would rather accept advice from their GP [28]. These reasons point towards a trust issue. Health insurers are generally not very highly trusted by enrolees $[28,29]$. However, trust in a company (institutional trust) is usually lower compared to trust in a person (interpersonal trust) [30]. Therefore, it may be different when an employee personally gives advice instead of the health insurer in general, for instance on their website or by sending a letter. However, the current study showed that only a small part of the enrolees who did not want advice indicated they did not want advice from their health insurer. Most of them did not, or did not yet, need a care provider and therefore declined the offered advice. Furthermore, the advice was given for free and whether one followed the advice or not did not have any negative financial consequences for enrolees.

When employees gave advice they also had the chance to explain the reason why a certain physiotherapist was better than others. Research showed that information about the selection of care providers is important in order to accept the negative consequences of selective contracting [31]. Therefore, it is very important that the health insurer is able to explain to enrolees why a certain care provider is preferred, or delivers better quality of care, compared to other care providers. If such processes are explained well, it is possible that enrolees are more willing to accept the advice they are offered [31]. It is important that enrolees agree with the health insurer on aspects of the quality of care they use. If enrolees do not care about the duration of the treatment, but more about the communication skills of the physiotherapist or the convenience of the location, it may not work. It is likely that most enrolees are interested in having an effective physiotherapist, since many enrolees followed the advice in the current study.

Previous research has shown that it is very hard to channel enrolees towards preferred care providers when they already have a relationship with another care provider, even when a better alternative is available [32]. This is called status quo bias. If enrolees are currently being treated by a physiotherapist, it is unlikely they will follow the advice of the health insurer if the employee advises another physiotherapist. An exception to this can be when enrolees are not satisfied with their current care provider. This may even make it easier to channel them towards a preferred care provider. This is also found in the current study. Most enrolees who 
followed the advice had not chosen a physiotherapist yet and were therefore relatively easy to channel towards a preferred provider. However, there were also some enrolees who switched physiotherapists after the advice. It would be interesting to look further into why they switched, how many treatments they already had and whether they were unhappy with their current provider. Given that it seems to be important for successful channelling that enrolees have not already chosen a care provider, it will be hard to channel enrolees to preferred GPs, dentists or other care providers with whom they already have a relationship. Boonen et al. found that in 2009, in the Netherlands, the willingness of enrolees to listen to advice from the health insurer about their choice of care provider is greatest for hospitals and pharmacies. For GPs and dentists this willingness is the lowest and for physiotherapists this is a little bit higher than GPs but much lower than pharmacies and hospitals. This suggests that advising enrolees on hospitals and pharmacies may be very interesting to investigate next. It is expected, however, that enrolees will be hard to channel if they already have a relationship with a specialist at a specific hospital, for instance when enrolees have a chronic condition.

\section{Service quality}

It is important to note that the results show that ratings of the quality of service have not decreased in the pilot team. Enrolees generally dislike their health insurer interfering with their choice of care provider. A successful channelling method that does not decrease these quality ratings is therefore already very valuable. However, the idea was that offering enrolees help with choosing a care provider as an extra service, whether enrolees accept it or not, could improve enrolees' rating on service quality. Research by Rafaeli et al. shows that offering personalised information and giving explanations lead to a higher evaluation of customer service interactions [33]. The current study points to a possible improvement in the quality of service. However, since the teams in their current form did not exist in T0, the improvement in service quality scores could also be caused, at least partly, by the change in the composition of the teams. Although the job of customer service call centre employee is very individual, there are team meetings and, thus, interactions between team members. Furthermore, the pilot team was very happy with their new task. They really liked giving enrolees extra advice and they liked being informed by other departments that purchase care and assess the quality of care providers. An employee satisfaction survey showed high scores for the pilot team. Furthermore, the pilot team had more meetings during the week compared to other teams. A positive feeling and satisfaction with their job is likely to have had a 
positive influence upon other calls the pilot team handled. Such a situation can be referred to as the Hawthorne effect. To be more certain of the effect on service quality scores, the pilot team should be followed longer to see what happens when the new task is not new anymore, but more integrated into their standard work process. It is also possible to use a control group in which the same amount of attention is given but who are not given the extra task of giving advice on the choice of care provider.

High service quality ratings are very important for health insurers since these could lead to more trust in the company [34]. Trust was found to lead to customer loyalty [35] and was found to play an important role in the acceptance of selective contracting [36]. Also, when the health insurer enjoys greater trust, all information the health insurer provides may also be trusted more. This could be very important with regard to the intention of enrolees to follow advice from the health insurer [8].

\section{Strengths and limitations}

A strength of this study is the unique opportunity to evaluate a channelling experiment designed by a large Dutch health insurance company. Furthermore, we were able to use different data sources. It was possible to find out exactly how far enrolees followed up on the advice that was given. However, a few limitations need to be discussed. The response rate to the questionnaires was low. This goes for the research questionnaire, but of course also for the other questionnaire data we used to compare the service quality scores of the pilot team to other teams. Unfortunately, the health insurer has no insight into response bias, since the questionnaires are filled in anonymously. When we compare the data from the research questionnaire to the claims data, we find that in the research questionnaire, almost all respondents state they are willing to follow the advice of the employee. This is more than the $45 \%$ who actually followed the advice according to the claims data. Thus, it seems that enrolees who fill in the questionnaire may be more positive about their conversation with the employee, compared to enrolees who do not. Furthermore, we had no background characteristics available for the general customer service questionnaires, therefore we were not able to correct for respondent characteristics such as age and sex in the multilevel analyses. However, the two teams that were chosen as control groups were as similar as possible to the pilot team, with respect to the enrolees they help and the types of questions they get asked. Therefore, the assumption was made that the enrolees did not differ in their background characteristics. 


\section{Policy implications}

The results of this study indicate that it is possible to channel enrolees by offering advice to those who call customer service. Since enrolees experience the offered advice as positive, this may be a good alternative to using financial incentives to channel enrolees towards preferred providers. However, compared to implementing financial incentives, this method does not reach all enrolees, but only the enrolees who call customer service. It is therefore crucial that when this service is implemented, health insurers promote this service among all their enrolees. Furthermore, the timing in the care chain is very important. If enrolees have already chosen a provider they are less likely to be open to advice on their choice of care provider.

There were great differences between employees in how many times they offered advice and in the percentages of the advice that was accepted or declined. This shows that the extra task of offering advice is quite difficult to generalise. It depends on the skills of the employee in recognising an opportunity to offer extra advice. Thus, this channelling method may require different competences from call centre employees. Higher educated employees may be necessary. This needs to be taken into account when implementing such a channelling strategy on a larger scale. Also, the calls may take longer. This was hard to measure during the current study, but the total handling time, based on the average of all calls of the pilot team, was about the same compared to the other two teams. However, advice was offered in only $5 \%$ of the total number of calls. If this share increases, once this channelling method is expanded to other care provider types, then the impact upon call handling time may be greater. However, if the channelling strategy is successful, then this will increase the health insurers' bargaining position with respect to care providers, which is supposed to lead to lower costs for the health insurer. This may compensate for extra costs in personnel and handling time.

Although it is not clear how far the improvement in scores for service quality can be attributed to the calls where extra advice was given, an improvement in service quality was found. From the perspective of the health insurer it may not even be that important what exactly caused the improvement in service quality. However, if it was caused by the Hawthorne effect, thus by simply being a part of the study and thus the job receiving more attention, then it is possible that the effect will wear off after some time. It is important to note that at least the ratings for quality did not go down. The study showed that channelling enrolees by offering advice is successful 
and that it does not provoke a negative response from enrolees. This is a very important finding, since this is the case with negative financial incentives.

\section{Scientific implications}

This study contributes to the literature on the effectiveness of channelling methods. Thus far this method of offering advice on care provider choice to enrolees when they call customer service has not yet been researched. One study from the US reported a natural experiment where enrolees were offered a telephone service to help them choose a care provider [37]. However, this service was provided by the employer, not the insurer, and relies on enrolees seeking help with choosing a care provider, whereas this method specifically offers advice to enrolees who did not seek help with this choice. Furthermore, this study shows that even when trust in health insurers is not very high, many enrolees may still be open to free advice from their health insurer. This may be because trust in the individual employee of the health insurer is higher than trust in the health insurer in general. Furthermore, this channelling method may even improve trust in the health insurer since it was found that improvement in the quality of service may lead to greater trust in the company [34].

\section{Conclusion}

This study shows that channelling enrolees towards preferred care providers by offering them advice on care provider choice when they call customer service can be successful. Since enrolees are very negative about financial incentives, this may be a good alternative channelling method. It is hard to draw solid conclusions from data on service quality, but the results seem positive. 


\section{References}

1. Enthoven AC: The history and principles of managed competition. Health Affairs 1993, 12(1):24-48.

2. Laske-Aldershof T, Schut E, Beck K, Gress S, Shmueli A, Van de Voorde C: Consumer mobility in social health insurance markets: a five country comparison. Applied Health Economics and Health Policy 2004, 3:229-241.

3. Light DW: Comparative institutional response to economic policy: managed competition and governmentality. Social Science \& Medicine 2001, 52(1):1151-1166.

4. Saltman RB, Figueras J: Analyzing the evidence on European health care reforms. Health Affairs 1998, 17:85-108.

5. Hendriks M, Spreeuwenberg P, Rademakers J, Delnoij DMJ: Dutch health care reform: did it result in performance improvement of health plans? A comparison of consumer experiences over time. BMC Health Services Research 2009, 9(167).

6. Pauly MV: Monopsony power in health insurance: thinking straight while standing on your head. Journal of Health Economics 1987, 6:73-81.

7. Sorensen AT: Insurer-hospital bargaining: negotiated discounts in post-deregulation Conneticut. Journal of Industrial Economics 2003, 51(4):469-490.

8. Bes RE, Curfs EC, Groenewegen PP, de Jong JD: Selective contracting and channelling patients to preferred providers: a scoping review. Health Policy 2017, 121(5):504-514.

9. Boonen LHHM, Schut FT, Donkers B, Koolman X: Which preferred providers are really preferred? Effectiveness of insurers' channeling incentives on pharmacy choice. International Journal of Health Care Finance Economics 2009, 9:347-366.

10. Boonen LHHM, Schut FT, Koolman X: Consumer channeling by health insurers: natural experiments with preferred providers in the Dutch pharmacy market. Health Economics 2008, 17:299-316.

11. Curbow B: Health care and the poor: psychological implications of restrictive policies. Health Psychology 1986, 5(4):375-391.

12. Draper DA, Hurley RE, Lesser CS, Strunk BC: The changing face of managed care. Health Affairs 2002, 21(1):11-23.

13. Kemper P, Tu HT, Reschovsky JD, Schaefer E: Insurance product design and its effects: trade-offs along the managed care continuum. Inquiry 2002, 39:101-117.

14. Duijmelinck DMID, Van de Ven WPMM: What can Europe learn from the managed care backlash in the United States? Health Policy 2016, 120(5):509-518.

15. Van de Ven WPMM, Schut FT: Managed competition in the Netherlands: still work-inprogress. Health Economics 2009, 18:253-255. 
16. Chiou J-S, Droge C: Service quality, trust, specific asset investment, and expertise: direct and indirect effects in a satisfaction-loyalty framework. Journal of the Academy of marketing science 2006, 34:613.

17. Lassar WM, Manolis C, Winsor RD: Service quality perspectives and satisfaction in private banking. Journal of Services Marketing 2000, 14(3):244-271.

18. Lien NH, Kao SL: The effects of service quality dimensions on cutomer satisfaction across different service types: alternative differentiation as a moderator. Proceedings of Advances in Consumer Research 2008, 35:522-526.

19. Kerssens JJ, Delnoij DMJ, Verweij JA, van der Schee E: De keuze van ziekenfondsverzekerden voor een zorgverzekeraar [The choice of sickness fund enrolees for a health insurer]. Tijdschrift voor Gezondheidswetenschappen 2002, 80(1):35-42.

20. Bes RE, Kerpershoek E, Curfs EC, de Jong JD: Ontevredenheid leidt tot wisselen van zorgverzekeraar [Dissatisfaction leeds to switching health insurers]. Economisch Statische Berichten 2014, 99(4686):330-332.

21. Van de Ven WPMM, Schut FT: Universal mandatory health insurance in the Netherlands: a model for the United States? Health Affairs 2008, 27(3):771-781.

22. Kroneman M, Boerma W, van den Berg M, Groenewegen PP, de Jong JD, van Ginneken E: The Netherlands: health systems review. Health Systems in Transition 2016, 18(2):1239.

23. Duijmelinck DMID, van de Ven WPMM: Hoge vergoeding niet-gecontracteerde zorg belemmert zorginkoop [High reimbursement of non-contracted care impedes selective contracting]. ESB 2015, 100(4717):532-534.

24. Dutch Health Care Authority: Zeventien zorgpolissen nader bekeken. In relatie tot de zorgplicht [A closer look at seventeen health plans. In relation to the duty to care]. Utrecht, The Netherlands: Dutch Health Care Authority; 2015.

25. Bes RE, Curfs EC, Groenewegen PP, de Jong JD: Health plan choice in the Netherlands: restrictive health plans preferred by young and healthy individuals. Health Economics Policy and Law 2017:1-18.

26. Visser J, De Bekker P, Koolman X, Van Drunen P, Stam P: Validatieonderzoek van de behandelindex [Validationresearch of the treatmentindex]. Den Haag, The Netherlands: Equalis Strategy \& Modeling B.V.; 2017.

27. Hopman P, De Boer D, Rademakers J: Kennisvraag - Wat heeft vijf jaar CQ-index opgeleverd? [What did five years of Consumer Quality-index produce?]. Utrecht, The Netherlands: NIVEL; 2011. 
28. Bes RE, Wendel S, de Jong JD: Het vertrouwensprobleem van zorgverzekeraars [The trust issue of health insurers]. Economisch Statistische Berichten 2012, 97(4647):676677.

29. Boonen LHHM, Schut FT: Preferred providers and the credible commitment problem in health insurance: first experiences with the implementation of managed competition in the Dutch health care system. Health Economics, Policy and Law 2011, 6:219-235.

30. Hall MA, Dugan E, Zheng B, Mishra AK: Trust in physicians and medical institutions: what is it, can it be measured, and does it matter? The Milbank Quarterly 2001, 79(4):613639.

31. Bes RE, van Erp KJPM, Curfs EC, Groenewegen PP, de Jong JD: Acceptance of selective contracting in health insurance: importance of information. Health Economics, Policy and Law (submitted) 2017.

32. Boonen LHHM, Donkers B, Schut FT: Channeling consumers to preferred providers and the impact of status quo bias: does type of provider matter? Health Services Research 2011.

33. Rafaeli A, Ziklik L, Doucet $L$ : The inpact of call center employees' customer orientation behaviours on service quality. Journal of Service Research 2008, 10(3):239-255.

34. Wendel S, de Jong JD, Curfs EC: Consumer evaluation of complaint handling in the Dutch health insurance market. BMC Health Services Research 2011, 11(doi:10.1186/1472-6963-11-310).

35. Wetzels $M$, de Ruyter $K$, van Birgelen M: Marketing service relationships: the role of commitment. Journal of Business \& Industrial Marketing 1998, 13(4/5):406-423.

36. Bes RE, Wendel S, Curfs EC, Groenewegen PP, de Jong JD: Acceptance of selective contracting: the role of trust in the health insurer. BMC Health Services Research 2013, 13:375

37. Donelan K, Rao SR, Rogers RS, Mailhot JR, Galvin R: Experience with health coachmediated physician referral in an employed insured population. Journal of General Internal Medicine 2010, 25(10):1071-1077. 


\section{Chapter 8}

Summary and general discussion 
In a health care system based on managed competition, health insurers play an important role. They are supposed to selectively contract care providers based on price and quality of care. This selective contracting is supposed to increase competition between care providers and thus lead to more affordable high quality health care. To realise this, health insurers have to be able to channel enrolees to contracted care providers in order to improve their bargaining position in negotiations with care providers [1, 2]. However, enrolees are very negative about restrictions in care provider choice. Therefore, in the Netherlands, health insurers are reluctant to implement selective contracting. The goal of this thesis was to identify mechanisms that explain enrolees' acceptance of selective contracting and channelling enrolees to contracted care providers. The central question we aimed to answer in this thesis is:

How can we explain acceptance of selective contracting and channelling enrolees to contracted care providers?

\section{Answers to the research questions}

Several research questions were formulated and answered. First, a scoping review was conducted to answer the research question:

RQ1: What is known about selective contracting from the enrolee's perspective; is it being done and how do enrolees feel about the role of their health insurer in their care provider choice?

We found that selective contracting and channelling is mainly practised in the US, but also in other countries such as Switzerland and Israel. There are different ways to channel enrolees to preferred or contracted care providers, the most effective being negative financial incentives such as co-payments or not reimbursing use of non-contracted care providers. It was found that there is a strong status quo bias, which means that enrolees want to stay with their current care provider, even if a better alternative is presented. Furthermore, the type of care provider, the seriousness of the condition and recommendations from others may influence in how far enrolees can be channelled to a certain care provider. Additionally, literature showed that enrolees are very negative about selective contracting, resulting in less satisfaction and lower trust in care providers and health insurers. Enrolees are also found to be more satisfied with their health plan if they have chosen it themselves. The question that was raised is under which conditions 
enrolees will choose a restrictive health plan. It is likely that specific groups are more inclined to choose a restrictive health plan than others, for instance, younger enrolees hardly use care, therefore they may be more focussed on getting the cheapest health plan and since in general restrictive health plans are less costly than other health plans they might therefore opt for a restrictive one. The scoping review also revealed that trust in the health insurer may play an important role in the acceptance of selective contracting. Thus, trust can be negatively influenced by selective contracting and it may also be a precondition for acceptance of selective contracting. Since the scoping review shows that enrolees resent restrictions in care provider choice and negative financial incentives, it may be interesting to look further into channelling enrolees using soft incentives. Thus, the results of the scoping review pointed at several knowledge gaps that we have addressed in this thesis. First, a study was conducted to explore characteristics of people who are willing to choose restrictive health plans.

RQ2: What are the demographic characteristics of people who are willing to choose a restrictive health plan and why are different groups of enrolees willing to choose a restrictive health plan or not?

There are roughly three different types of health plans to distinguish in the Netherlands, one where all care providers are reimbursed (no selective contracting), one where only contracted care providers are fully reimbursed, but where most providers are contracted (minor selective contracting), and one where only contracted care providers are fully reimbursed but where less providers are contracted (significant selective contracting). When enrolees were asked to choose between the different types of health plans available in the Netherlands, we found that healthier and younger enrolees are more likely to choose a restrictive health plan. This confirms the hypothesis stating that younger enrolees are more price sensitive and would therefore be more likely to choose a restrictive health plan. Also the results support the hypothesised mechanisms that elderly and enrolees in poorer health are less likely to choose a restrictive health plan since they may experience more trouble with their mobility and are more likely to have built a relationship with care providers. The effect of health status on willingness to accept a restrictive health plan is dependent on income. Enrolees on a higher income can afford free choice and therefore seem to determine their choice of health plan on their ability to travel. Enrolees on a low income do not have this luxury. The results show that enrolees who are more in need of care are less likely to choose a 
restrictive health plan. However, in theory, it is important that enrolees who need care are also enrolled in a restrictive health plan, since this is supposed to result in a larger market share for preferred care providers and thus a better bargaining position for health insurers in negotiations with care providers. If only people who hardly use care choose restrictive health plans, the incentive among care providers to compete with each other in order to be contracted by health insurers is absent, while competition between care providers is an important incentive to improve quality of care and reduce costs of health care. Therefore, it is important that enrolees in poorer health also accept selective contracting.

RQ3: What role does enrolees' trust in their health insurer play in their acceptance of selective contracting?

Since the scoping review showed that trust may play an important role in the acceptance of selective contracting, we explored the influence of trust in the health insurer on the acceptance of selective contracting. The results of our questionnaire study confirm the hypothesised mechanism that trust in the health insurer, and specifically trust in the purchasing strategy of the health insurer, plays an important role in the acceptance of selective contracting. This association is stronger for older people compared to younger people. However, even when trust is high, the acceptance of selective contracting is still quite low. This means there are other factors too that play a role in this, such as the importance of autonomy. The self determination theory states that a feeling of autonomy is associated with increased well-being. When health insurers restrict freedom of care provider choice enrolees' feelings of autonomy may be impaired. Also status quo bias may play a role since enrolees in the Netherlands are used to free choice of care provider.

\section{RQ4: How do enrolees rank sources of hospital quality information?}

In a health care system based on managed competition it is important that health insurers are able to channel enrolees to contracted or preferred care providers. Information about quality of care is therefore crucial. Health insurers need this to prudently purchase care on behalf of their enrolees and enrolees need it to choose a care provider and health insurer $[3,4]$. Health insurers in the Netherlands started to publish quality information on care providers on their websites to inform their enrolees about quality of care providers. We conducted a questionnaire study to see if health insurers are seen as an important source of quality information compared 
to other sources of information, such as government sponsored websites, information from care providers and advice from GP and friends and family. We found that quality information on care providers coming from health insurers is not seen as very important by enrolees when they need information to choose a care provider. The reason for this may be that health insurers suffer from a credible commitment problem [5]. Which means that in general health insurers are not trusted much by enrolees. Additionally, in the Netherlands enrolees are not used to look at their health insurer when they need information on care provider quality. Because GPs function as gatekeepers they are usually considered to be an important source of information on health care quality.

RQ5: How does providing information to enrolees about the selection of care providers influence their acceptance of selective contracting, when enrolees are informed about the specific consequences of selective contracting?

In justice literature, it was found that information about the process of how a certain situation originated can be important in the acceptance of the situation [6, 7]. In the context of selective contracting this could mean that when enrolees are explained about the reason why some care providers are not contracted, their acceptance of selective contracting may be higher. We conducted a vignette study with a two by two design and found that in the group where information about the process of the selection of care providers was provided, the attitude of enrolees about selective contracting is less negative compared to the group where no information was given about this process. We especially see this effect when the consequences of selective contracting for the enrolees are more severe (i.e. not all care providers in their region are contracted and they need to travel further to the nearest hospital). Thus, when enrolees experience no concrete consequences of selective contracting, information about the process does not significantly affect their opinion on selective contracting. However, providing information about the selection process of care providers does not entirely cancel out the negative effect of the consequences of selective contracting. Thus, getting enrolees to accept selective contracting remains a difficult issue.

RQ6: Is it possible to channel enrolees to preferred care providers by giving them free advice when they call customer service and what is the effect of this service on enrolees' rating of service quality? 
The scoping review also revealed that, although not as effective as negative financial incentives, it is also possible to channel enrolees to preferred care providers with soft incentives. These are for instance quality incentives such as offering extended opening hours or a free health check at preferred care providers. If quality incentives are accepted by enrolees it may be very important to explore this further. A Dutch health insurer started a try-out of a new channelling method where enrolees are offered advice on care provider choice when they call customer service. For instance, if enrolees called their health insurer about reimbursement of physiotherapy, employees were instructed to ask enrolees whether they would like to get advice on which physiotherapist to choose. We studied the effectiveness of this channelling method. Our study showed that this channelling method is effective, since $45 \%$ of enrolees who went to a physiotherapist after receiving advice from the customer service employee, followed the advice and went to the recommended physiotherapist. Additionally, we asked enrolees how they felt about this channelling method. Enrolees were positive about the offering of advice by the employee and service quality ratings were higher for the team that implemented this channelling strategy compared to other teams offering regular customer service. This may seem to contradict results from RQ4, that state that health insurers are not seen as an important source of quality information. However, it is possible that enrolees do not tend to look for such information at their health insurer, but when an employee of their health insurer offers this information to them, they are open to receiving this information. This shows that the way in which information is offered is also important for the acceptance of it.

\section{Methodological reflection}

For every study, strengths and weaknesses were already discussed. In this section, only the most important ones are discussed.

- In three studies we sent a questionnaire to members of the Insurance Panel. Use of an access panel usually generates a high response rate. However, it is already a selection of the population. Members of the insurance panel are all 18 years or older and are insured at a large Dutch health insurance company. The members of the panel are older compared to the Dutch general population of 18 years and older. Panel members were initially recruited trough a letter they received from their health insurer. Currently, the recruiting method changed to inviting enrolees to participate in the Insurance Panel in the standard customer service quality survey they receive after they had contact with their health insurer. It is likely that enrolees who have little to do with their health insurer, 
for instance because they hardly use any care, are less likely to be invited to participate in the Insurance Panel and will also be less likely to participate when they are invited because they have less affinity with the subject. On the other hand, people in very bad health may also not be likely to commit to a panel. Because of this, the Insurance panel is not representative of the Dutch insured population. However, in the three studies we used the Insurance Panel, we tested associations, and therefore this is not likely to have influenced the results.

- We used questionnaires to collect data. This means that mostly hypothetical situations were presented and were asked questions about. For instance in Chapter 3, we presented respondents with different choices of three or two health plans. In reality there are a lot more options to choose from. Also in Chapter 6 respondents were confronted with a hypothetical situation. Here, respondents were divided into four groups and to each group a different situation was described. These methods are appropriate to test our hypotheses, but it is unknown how enrolees will behave in a real situation, with more choice options, more and unclear information and a status quo bias. To resolve this problem, natural choice situations need to be studied. For instance when enrolees who are collectively insured through their employer change jobs, they need to choose a new health plan. These situations could be studied to discover how actual choices for a health plan are made and whether different groups choose differently.

\section{Policy implications}

The findings of this thesis reveal several implications for policy and practice. Findings suggest that restricting freedom of care provider choice by implementing negative financial incentives will not be accepted by many enrolees. This confirms experiences in the US where a managed care backlash, a general resentment against managed care, arose [8]. Not many enrolees choose restrictive health plans and we found that especially older people and people in poorer health are less likely to choose a restrictive health plan. Trust in the health insurer was shown to play an important role in enrolees' acceptance of selective contracting. However, trust in health insurers is generally quite low. Therefore, it is important that health insurers invest in improving their relationship with their enrolees. It is known that trust is built slowly but can be positively influenced by improving elements of functional and technical quality [9]. Functional quality is the way in which a service is delivered, for instance friendliness of the employees, and technical quality is about the outcome, 
for instance timely payment of claims. These aspects are relatively easy for health insurers to invest in. Furthermore, in order to enhance trust, knowledge of the trustee's behaviour is important [10]. Thus, health insurers need to convince enrolees of their motives to purchase good quality of care on their behalf. Additionally, the lack of trust in health insurers might be solved when more objective quality information on care providers becomes available [5]. With this information, health insurers can prudently purchase care based on price and quality of care and provide their enrolees with objective information on quality of care, which would make them more credible.

Enrolees in poor health or elderly take more risk when they choose a restrictive health plan, since they are more at risk of needing care in the near future. Therefore, if they have a restrictive health plan, they are more at risk of having to change care providers, having a longer travelling time or being confronted with extra costs if they choose a non-contracted care provider. However, depending on where they live exactly, travelling time will not always increase and their trusted care provider may be one of the contracted ones. Therefore, it is very important that enrolees know exactly what selective contracting entails and what the exact consequences for them are. Furthermore, we found that if selective contracting has negative consequences for enrolees, i.e. having to switch care providers with a longer travelling time, providing clear information about the selection process of care providers can reduce the negative attitude of enrolees towards selective contracting.

However, even when trust is high, acceptance of selective contracting is still relatively low. Also providing information cannot entirely cancel out the negative effect of the consequences of selective contracting. The question is then, should health insurers selectively contract or are there other ways of promoting competition between care providers in order to improve quality of care? We found that appointing preferred providers and channelling enrolees to these providers by offering advice to enrolees when they call customer service can be an effective channelling method. Additionally, it could contribute to a positive service quality rating of enrolees. This is an important result, since this points at the potential of channelling enrolees to preferred care providers in a more positive way. Furthermore, it preserves enrolees' freedom of care provider choice. This matches with government policy, since the First Chamber of parliament blocked the change of article 13 of the Health Insurance Act which entailed that health insurers could 
determine their own amount of reimbursement for non-contracted care providers, since this would limit freedom of care provider choice too much.

This method does not reach all enrolees since enrolees first need to call customer service. Additionally, not all enrolees who accept an advice and use a care provider follow the advice. Therefore, it is important that other ideas of soft channelling incentives are developed and studied. For instance, since this works during a phone call, it may also work to actively offer information on care provider quality when enrolees visit the website or in personal newsletters. Maybe just to let enrolees know that the health insurer can be seen as an important source of care provider quality information. Also the current method of offering advice when enrolees call customer service could be expanded to more types of care providers. Since status quo bias is an important obstacle when trying to channel enrolees to preferred providers [11], it is expected that this is most likely to work for hospitals and least likely to work for GPs and dentists, because practically all enrolees in the Netherlands have a regular GP and dentist. Also, chronically ill patients are likely to be hard to channel, since they already have a regular physician at a hospital. This shows that the timeliness of channelling is also very important for successful channelling.

The results of this thesis show that selective contracting is hard to implement, since enrolees are negative about restrictions in care provider choice. An alternative for health insurers is to select preferred providers and use soft channelling methods, such as providing advice on care provider choice, to channel enrolees. Such channelling methods are less effective compared to negative financial incentives, for instance because not all enrolees are reached with this method and enrolees are free to follow the advice or not. However, the channelling method we evaluated was successful since $45 \%$ of enrolees who used care followed the advice that was given. Therefore, care providers are still likely to compete with each other in order to be a preferred, and thus recommended, care provider since this could generate a higher income for them. However, this should be evaluated in future research.

\section{Scientific implications}

In addition to the policy implications, this thesis also contributes to scientific knowledge. It provides more knowledge about the implementation of selective contracting by health insurers in a health care system based on managed competition. Specifically, we focused on the acceptance of selective contracting by 
enrolees. We found that specific groups are more likely to choose a restrictive health plan, namely enrolees who are more healthy and younger. This was confirmed by a study of Determan et al. who conducted a discrete choice experiment to examine enrolees choices for health plans [12]. Our finding that trust in the health insurer plays an important role in the acceptance of selective contracting confirms suggestions from earlier studies where this relationship was suggested but never tested before [8, 13-15]. We showed that providing enrolees with information on why certain care providers are not contracted improves acceptance of selective contracting. This confirms that the theory from the justice literature, which stated that procedural justice (i.e. providing information on procedures that led to a situation) is important for acceptance of a situation, especially when this situation is unfavourable $[6,16]$, can also be applied in health policy research. Furthermore, our study to evaluate a new method of channelling enrolees to preferred care providers by offering them advice on care provider choice when they call customer service, adds to the literature on channelling incentives. Not many soft or qualitative incentives have been evaluated in literature. Boonen et al. researched channelling incentives and found that negative financial incentives are more effective compared to positive ones [11]. Also, they found that quality incentives can be effective in channelling patients to preferred providers. Quality incentives they studied were extra opening hours, internet service and presence of a quality certificate [11]. Donelan et al. studied a similar method to ours; an employer offered a telephone service for advice on care provider choice [17]. However, this is different from our channelling method, since here enrolees need to call for advice about care provider choice while in our case advice on care provider choice was offered when enrolees called customer service about another question related to physiotherapy and then were offered advice. Furthermore, in the study of Donelan the service is provided by the employer instead of the health insurance company. Since health insurers suffer from a credible commitment problem, it was surprising that this was successful. The reason for this may be that the employee, who has first answered their question and later offers the enrolees advice, is more trusted than the health insurer itself. This is likely since institutional trust is different and usually lower compared to interpersonal trust [18].

In general, this thesis contributes to the knowledge on implementing selective contracting in a health care system based on managed competition. This is relevant for all countries where a health care system based on managed competition is implemented or will be implemented in the future. 


\section{Suggestions for future research}

Although this thesis has made a significant contribution to the literature on channelling enrolees to contracted or preferred care providers in a health care system based on managed competition, our research also raised further questions and therefore several recommendations for future research:

- Since we found that trust in the health insurer plays an important role in the acceptance of selective contracting, the question was raised how can health insurers work on their image so their enrolees will trust them more? Future research should focus on how enrolees' trust in health insurers is built.

- We would also recommend to study the relationship between trust in the health insurer and willingness to follow advice of the health insurer. If this relationship is strong, this would also contribute to the evidence that it is important for health insurers to build trust with their enrolees.

- We found that younger and healthier enrolees choose restrictive health plans more often compared to older enrolees and enrolees in poorer health. Although this answered our research question, it would be interesting to know how much cheaper a restrictive health plan needs to be for enrolees who use more care to choose it. Or maybe free choice health plans need to be more expensive. Determan et al. conducted such an experiment [12], and found that half of their study sample are very unlikely to choose a restrictive health plan, but the younger, healthier and less wealthy enrolees may be motivated to choose a restrictive health plan for a monthly premium discount of 15 Euros. However, in this discrete choice experiment travelling time to the nearest care provider was not included. Additionally, quality of care was not included. This can also be very important, especially to elderly and enrolees in poorer health since they use more care. Furthermore, the idea is that restrictive health plans purchase care based on price and quality and, thus, should offer better quality of care.

- From our research on what influences the acceptance of selective contracting we found that besides high trust or information, more aspects influence the acceptance of selective contracting. We discussed that autonomy may play a role in the resentment of enrolees towards selective contracting. This was not the scope of our research, since we focused on factors that are relevant for practice and autonomy is a factor that can hardly be influenced. However, it would be very interesting to test this hypothesis and to see in how far this determines the negativity of enrolees about selective contracting. 
- We showed that information on why certain care providers are not contracted can reduce the negative feeling of enrolees on selective contracting. We do expect, however, that the amount of information and the nature of the information could influence this result. In order to properly implement measures based on this result it is important to study the results if this information is more comprehensive, different information is presented or when the information is presented differently. How much information is enough and what kind of information matters most to enrolees?

- We found that channelling enrolees to preferred care providers by offering enrolees advice on provider choice when they call customer service is effective for channelling patients to preferred physiotherapists. The question was raised whether this method would also work for other types of providers. Boonen et al. found that enrolees' openness to channelling differs for type of provider [11]. Therefore, this channelling method should be studied for other types of providers as well. We expect this method could work well for choosing a hospital, however it would be difficult for choosing a GP or dentist, since most enrolees already have a regular GP and dentist.

- We found that the new channelling method was successful. However, not all enrolees are reached with this method. A lot of enrolees choose a care provider themselves without first calling their health insurer. Therefore, more soft channelling incentives should be developed and studied. Furthermore, other questions were raised. For instance, are certain channelling methods more effective in specific groups of enrolees compared to others? For instance, maybe channelling by offering advice when enrolees call customer service is more effective for older enrolees who use more care and thus have more contact with their health insurer, while younger enrolees may be more interested in quality information on care providers when they receive this through e-mail or in an App. It would be interesting to discuss these ideas with enrolees, for instance in a focus group and to test this in a questionnaire study.

- The effects of the soft channelling methods need to be studied on a larger scale in order to determine if these methods contribute to the goals of the health care system. Thus, is the health insurer able to negotiate greater discounts at preferred providers because of successful channelling to preferred providers? This is only possible when such channelling incentives are implemented on a larger scale and when care providers are aware of this. 
There are also a few hypothesis we were not able to test in the best way possible. Future research should therefore retest these hypotheses with optimized methodology:

- The new channelling method where enrolees were offered advice on care provider choice was also expected to have an effect on evaluation of service quality. We were not able to optimally study this effect. The ideal situation would be a randomised controlled trial where at least two customer service teams who are as similar as possible, get the same amount of attention and training while only half of the teams actually conducts the channelling. Proper before and after measurements of service quality need to be done and no other changes should be made during the research period.

- Most studies were conducted by using a questionnaire. As was mentioned before in the methodological reflection, this method was appropriate to test our hypotheses, however, it is unknown how enrolees will behave in a real choice situation. We would, therefore, recommend for future research to study real choice situations in lives of enrolees. This is difficult, but for instance possible when a company cancels their collective contract with a specific health plan or health insurer.

\section{Conclusion}

The research question of this thesis was: How can we explain acceptance of selective contracting and channelling enrolees to contracted care providers?

There are several aspects that explain the acceptance (or non-acceptance) of selective contracting by enrolees. Selective contracting by health insurers is a negative development in the eyes of enrolees, since it restricts their care provider choice. Restrictions in care provider choice could lead to a longer travelling time to the nearest care provider and if enrolees choose a non-contracted care provider they have to pay part of the costs themselves. One benefit for enrolees is that restrictive health plans are cheaper compared to free choice health plans. In addition, the idea of managed competition entails that health insurers select care providers based on price and quality of care. Therefore, quality of contracted care providers is supposed to be higher. Characteristics of enrolees, such as age and health status play a role in the acceptance of selective contracting, since younger people are more sensitive to price and healthier people do not expect to need care 
in the near future, which means they take a smaller risk when they choose a restrictive health plan compared to people who need care more frequently. Furthermore, results showed that trust in the health insurer plays an important role in the acceptance of selective contracting. Trust in health insurers is generally quite low, which could explain the negative attitude of enrolees towards selective contracting. Enrolees do not trust their health insurer to have their best interest at heart and to purchase good quality care for them. Providing information to enrolees on why certain care providers are not contracted was found to be important as well in the acceptance of selective contracting. However, even when enrolees trust their health insurer and even when information on why certain care providers are not contracted is provided, enrolees are still negative about financial incentives and restrictions in their freedom of choice. It is possible that factors such as loss aversion and impairment in their autonomy play a role in this. Loss aversion, since in the health insurance system before 2006 enrolees had free choice. Implementing selective contracting takes that free choice away. Autonomy is a very important value for people. When the health insurer gets involved in care provider choice people may feel their autonomy is impaired. However, these psychological aspects are hard to influence in practise. Additionally, plans to change article 13 of the Health Insurance Act in order to allow health insurers to determine the amount of reimbursement for non-contracted care providers themselves, were blocked by the First Chamber of parliament, since this would limit freedom of care provider choice too much.

Therefore, it is a logical step to look into other methods of channelling enrolees to preferred care providers without actually restricting their freedom of care provider choice. Chapter 7 of this thesis shows that it is possible to channel enrolees to preferred care providers by offering them advice on care provider choice while explaining why certain care providers are found to be of better quality compared to others. In this way, provider choice is not restricted, since enrolees choose if they follow the advice or not. If they do not, there will be no negative financial consequence for them. If this channelling is successful, care providers are still likely to compete with each other in order to be a preferred, and thus recommended, care provider since this could generate a higher income. This may still lead to reaching the goals of the managed competition health care system, which are to improve quality of care and control the costs in the health care system by encouraging competition between care providers. Although this should be evaluated in the future. However, this way of channelling does not reach all enrolees. Still, 
many enrolees visit a care provider without calling their health insurer first. In the context of a health care system where channelling could be important, more of these types of channelling methods should be developed and studied. 


\section{References}

1. Sorensen AT: Insurer-hospital bargaining: negotiated discounts in postderegulationConneticut. Journal of Industrial Economics 2003, 51(4):469-490.

2. Wu VY: Managed care's price bargaining with hospitals. Journal of Health Economics 2009, 28:350-360.

3. Schut FT, Van de Ven WPMM: Effects of purchaser competition in the Dutch health system: is the glass half full of half empty? Health Economics, Policy and Law 2011, 6:109-123.

4. Van de Ven WPMM, Schut FT: Managed competition in the Netherlands: still work-inprogress. Health Economics 2009, 18:253-255.

5. Boonen LHHM, Schut FT: Preferred providers and the credible commitment problem in health insurance: first experiences with the implementation of managed competition in the Dutch health care system. Health Economics, Policy and Law 2011, 6:219-235.

6. Greenberg J: Employee theft as a reaction to underpayment inequity: the hidden cost of pay cuts. Journal of Applied Psychology 1990, 75(5):561-568.

7. Lind EA, Tyler T: The social psychology of procedural justice. New York: Plenum Press; 1988.

8. Miller $\mathrm{NH}$ : Insurer-provider integration, credible commitment, and managed-care backlash. Journal of Health Economics 2006, 25:861-876.

9. Wendel S, de Jong JD, Curfs EC: Consumer evaluation of complaint handling in the Dutch health insurance market. BMC Health Services Research 2011, 11(doi:10.1186/1472-6963-11-310).

10. Goold SD: Trust and the ethics of health care institutions. The Hastings Center Report 2001, 31(6):26-33.

11. Boonen LHHM, Donkers B, Schut FT: Channeling consumers to preferred providers and the impact of status quo bias: does type of provider matter? Health Services Research 22011.

12. Determan D, Lambooij MS, de Bekker-Grob EW, Hayen AP, Varkevisser M, Schut FT, de Wit GA: What health plans do people prefer? The trade off between premium and provider choice. Social Science \& Medicine 2016, 165:10-18.

13. Boonen LHHM, Schut FT: Zorgverzekeraars kampen met vertrouwensprobleem (Health insurers face problems with trust). Economisch Statistische Berichten 2009, 94(4572):678-681.

14. Gawande AA, Blendon RJ, Brodie M, Benson JM, Levitt L, Hugick L: Does dissatisfaction with health plans stem from having no choices? Health Affairs 1998, 17(5):184-194. 
15. Heinemann S, Leiber S, Gress S: Managed competition in the Netherlands - A qualitative study. Health Policy 2013, 109:113-121.

16. Folger R, Bies RJ: Managerial responsibilities ans procedural justice. Employee Responsibilities and Rights Journal 1989, 2(2):79-90.

17. Donelan K, Rao SR, Rogers RS, Mailhot JR, Galvin R: Experience with health coachmediated physician referral in an employed insured population. Journal of General Internal Medicine 2010, 25(10):1071-1077.

18. Hall MA, Dugan E, Zheng B, Mishra AK: Trust in physicians and medical institutions: what is it, can it be measured, and does it matter? The Milbank Quarterly 2001, 79(4):613639. 
Chapter 8 
Samenvatting 
In een zorgstelsel gebaseerd op gereguleerde concurrentie spelen zorgverzekeraars een belangrijke rol. Van hen wordt verwacht dat zij contracten afsluiten met een selectie van zorgaanbieders, die zij kiezen op basis van prijs en kwaliteit. Het selectief contracteren van zorgaanbieders is een prikkel voor zorgaanbieders om met elkaar te concurreren en zou dus moeten leiden tot meer betaalbare en betere kwaliteit van zorg. Hiervoor is het belangrijk dat zorgverzekeraars in staat zijn om hun verzekerden te sturen naar gecontracteerde zorgaanbieders. Op deze manier verbeteren zij hun onderhandelingspositie ten opzichte van de zorgaanbieders [1, 2]. Verzekerden zijn echter heel negatief over restricties in hun keuzevrijheid. Daarom zijn zorgverzekeraars in Nederland terughoudend in het implementeren van selectief contracteren. Het doel van dit proefschrift is het identificeren van mechanismen die de acceptatie van selectief contracteren en het sturen van verzekerden naar gecontracteerde zorgaanbieders kan verklaren. De centrale onderzoeksvraag die we wilden beantwoorden is:

Hoe kunnen we de acceptatie van selectief contracteren en het sturen van verzekerden naar gecontracteerde zorgaanbieders verklaren?

\section{Antwoorden op de onderzoeksvragen}

Er zijn verschillende onderzoeksvragen geformuleerd en beantwoord. Als eerste is een scoping review uitgevoerd om deze vraag te beantwoorden:

\section{Onderzoeksvraag 1:}

Wat is bekend over selectief contracteren vanuit het perspectief van de verzekerde; wordt het gedaan en wat vinden verzekerden van de rol van de zorgverzekeraar in hun keuze voor een zorgaanbieder?

We hebben gevonden dat selectief contracteren en het sturen van verzekerden naar gecontracteerde zorgaanbieders met name in de Verenigde Staten wordt gedaan, maar ook in andere landen, zoals Zwitserland en Israël. Er zijn verschillende manieren om verzekerden naar geprefereerde of gecontracteerde zorgaanbieders te sturen. De meest effectieve manier is met negatieve financiële prikkels, zoals eigen bijdragen of het helemaal niet vergoeden van niet gecontracteerde zorgaanbieders. Verder hebben we gevonden dat er een sterke status quo bias bestaat, dit betekent dat verzekerden heel graag bij hun huidige zorgaanbieder willen blijven, zelfs als er een beter alternatief beschikbaar is. Daarnaast hebben het type zorgaanbieder, de ernst van de aandoening en aanbevelingen van anderen 
invloed op in hoeverre verzekerden gestuurd kunnen worden naar een specifieke zorgaanbieder. Verder laat de literatuur zien dat verzekerden erg negatief staan tegenover selectief contracteren en dat het toepassen hiervan kan leiden tot verminderde tevredenheid en verminderd vertrouwen in zorgaanbieders en zorgverzekeraars. Het is ook gebleken dat verzekerden meer tevreden zijn over hun zorgverzekering als ze deze zelf hebben gekozen. Dit leidt tot de vraag onder welke omstandigheden verzekerden zouden kiezen voor een selectief gecontracteerde zorgverzekering. Het is waarschijnlijk dat specifieke groepen meer geneigd zullen zijn om te kiezen voor een selectief gecontracteerde polis dan anderen. Bijvoorbeeld jongeren gebruiken maar weinig zorg, daardoor zouden ze meer gefocust kunnen zijn op het kiezen van de goedkoopste zorgverzekering. Omdat zorgverzekeringen met selectief gecontracteerde zorgaanbieders meestal het goedkoopst zijn, zouden jongeren dus vaker voor een dergelijke polis kiezen. De scoping review liet ook zien dat vertrouwen in de zorgverzekeraar een belangrijke rol zou kunnen spelen in de acceptatie van selectief contracteren. Vertrouwen zou negatief beïnvloed kunnen worden door selectief contracteren, maar het zou ook een voorwaarde kunnen zijn voor de acceptatie ervan. Omdat de scoping review laat zien dat verzekerden negatief staan tegenover selectief contracteren en negatieve financiële prikkels, zou het interessant kunnen zijn om te kijken naar zachte sturingsmethoden om verzekerden te sturen naar gecontracteerde of geprefereerde zorgaanbieders. De resultaten van de scoping review wijzen dus op een aantal kennis hiaten die wij zullen adresseren in dit proefschrift. Als eerste is onderzocht welke kenmerken mensen hebben die bereid zijn een restrictieve zorgverzekering te kiezen.

\section{Onderzoeksvraag 2:}

Wat zijn de demografische kenmerken van mensen die bereid zijn een restrictieve zorgverzekering te kiezen en waarom zijn verschillende groepen bereid om een restrictieve zorgverzekering te kiezen of niet?

Er zijn grofweg drie verschillende typen zorgverzekeringen te onderheiden in Nederland, een waar alle zorgaanbieders worden vergoed, een waar alleen gecontracteerde zorgaanbieders worden vergoed, maar waar de meeste zorgaanbieders gecontracteerd zijn (minimale restricties) en een waar alleen gecontracteerde zorgaanbieders worden vergoed, maar waar minder zorgaanbieders zijn gecontracteerd (aanzienlijke restricties). Wanneer verzekerden worden gevraagd te kiezen tussen deze verschillende typen zorgverzekeringen, vonden we dat gezondere en jongere verzekerden meer geneigd zijn te kiezen voor 
een restrictieve zorgverzekering. Dit bevestigt de hypothese die stelt dat jongeren meer prijs sensitief zijn en daarom waarschijnlijk vaker voor een restrictieve zorgverzekering zullen kiezen. Daarnaast ondersteunen de resultaten de voorspelde mechanismen dat ouderen en ongezondere mensen minder vaak zullen kiezen voor een restrictieve zorgverzekering omdat zij meer problemen hebben met hun mobiliteit en vaker al een relatie hebben met een zorgaanbieder. Het effect van gezondheid op de bereidheid een restrictieve zorgverzekering te kiezen is afhankelijk van het inkomen. Verzekerden met een hoger inkomen kunnen zich vrije keuze veroorloven en lijken daardoor hun keuze te baseren op hun vermogen om te reizen. Verzekerden met een lager inkomen hebben deze luxe niet. De resultaten laten zien dat verzekerden die meer zorg nodig hebben minder vaak kiezen voor een restrictieve zorgverzekering. Echter, in de theorie van gereguleerde concurrentie is het heel belangrijk dat ook mensen die zorg gebruiken een restrictieve zorgverzekering kiezen, omdat het de bedoeling is dat selectief contracteren leidt tot een groter marktaandeel voor de gecontracteerde zorgaanbieders en dus een betere onderhandelingspositie voor zorgverzekeraars in onderhandelingen met zorgaanbieders. Als alleen mensen die amper zorg gebruiken kiezen voor een restrictieve polis is deze prikkel voor zorgaanbieders om met elkaar te concurreren afwezig. Concurrentie tussen zorgaanbieders is echter juist belangrijk om de doelen van het zorgstelsel, namelijk verbeteren van de kwaliteit van zorg en het beheersen van de kosten van zorg, te behalen. Om deze reden is het belangrijk dat ook de mensen die veel zorg gebruiken selectief contracteren accepteren.

\section{Onderzoeksvraag 3:}

Welke rol speelt het vertrouwen van verzekerden in de zorgverzekeraar in hun acceptatie van selectief contracteren?

Omdat uit het scoping review naar voren kwam dat vertrouwen in de zorgverzekeraar wel eens een belangrijke rol zou kunnen spelen in de acceptatie van selectief contracteren, hebben we de invloed van vertrouwen in de zorgverzekeraar op acceptatie van selectief contacteren onderzocht. De resultaten van ons vragenlijstonderzoek bevestigden het verwachtte mechanisme dat vertrouwen in de zorgverzekeraar, en met name vertrouwen in de inkoop strategie van de zorgverzekeraar, een belangrijke rol speelt in de acceptatie van selectief contracteren. Deze associatie is sterker voor oudere mensen vergeleken met jongere mensen. Echter, zelfs als het vertrouwen hoog is, is de acceptatie van selectief contracteren vrij laag. Dit betekent dat ook andere factoren hierin een rol 
zullen spelen, zoals het belang van autonomie. De zelfbeschikkingstheorie geeft aan dat een gevoel van autonomie is geassocieerd met een sterker gevoel van welbevinden. Wanneer zorgverzekeraars de vrijheid van keuze voor een zorgaanbieder beperken, kunnen gevoelens van autonomie worden aangetast. Ook status quo bias zou hier een rol in kunnen spelen, aangezien verzekerden in Nederland gewend zijn om keuzevrijheid te hebben.

\section{Onderzoeksvraag 4:}

Hoe worden bronnen van kwaliteitsinformatie over ziekenhuizen gerangschikt door verzekerden?

In een zorgstelsel dat is gebaseerd op gereguleerde concurrentie is het belangrijk dat zorgverzekeraars in staat zijn om verzekerden te sturen naar geprefereerde of gecontracteerde zorgaanbieders. Informatie over kwaliteit van zorg is daarom cruciaal. Zorgverzekeraars hebben dit nodig om kritisch zorg in te kopen voor hun verzekerden en verzekerden hebben dit nodig om een zorgaanbieder en zorgverzekering te kiezen [3,4]. Zorgverzekeraars in Nederland zijn begonnen met het publiceren van kwaliteitsinformatie over zorgaanbieders op hun websites om hun verzekerden te informeren over kwaliteit van zorgaanbieders. We hebben een vragenlijst onderzoek gedaan om te kijken of zorgverzekeraars worden gezien als een belangrijke bron van kwaliteitsinformatie vergeleken met andere informatiebronnen, zoals websites die door de overheid zijn opgezet, informatie van zorgaanbieders zelf, advies van de huisarts en advies van vrienden of familie. We hebben gevonden dat kwaliteitsinformatie over zorgaanbieders die wordt aangeboden door de zorgverzekeraar niet als belangrijk wordt gezien door verzekerden wanneer ze een zorgaanbieder moeten kiezen. De reden hiervoor kan zijn dat zorgverzekeraars last hebben van een vertrouwensprobleem [5]. Dit betekent dat zorgverzekeraars in het algemeen niet erg worden vertrouwd door verzekerden. Daarnaast zijn in Nederland de verzekerden er niet aan gewend bij hun zorgverzekeraar naar dit soort informatie te zoeken. Omdat huisartsen fungeren als poortwachters naar de tweedelijnszorg, worden zij vaak als belangrijke bron van informatie over kwaliteit van zorg gezien.

\section{Onderzoeksvraag 5:}

Hoe beïnvloedt het geven van informatie over de selectie van zorgaanbieders de acceptatie van selectief contracteren, wanneer verzekerden worden geïnformeerd over de specifieke consequenties van selectief contracteren? 
In literatuur over rechtvaardigheid is gevonden dat informatie over het proces waarmee een bepaalde situatie is ontstaan belangrijk kan zijn bij de acceptatie van die situatie $[6,7]$. In de context van selectief contracteren kan dit betekenen dat wanneer aan verzekerden wordt uitgelegd warom bepaalde zorgaanbieders niet zijn gecontracteerd, hun acceptatie van selectief contracteren hoger kan zijn. We hebben een vignetstudie uitgevoerd met een $2 \times 2$ design en we hebben gevonden dat in de groep waar informatie was gegeven over hoe zorgaanbieders zijn geselecteerd, de mening van verzekerden over selectief contracteren minder negatief was dan in de groep waar geen informatie was gegeven. Dit effect is met name te zien wanneer de consequenties van selectief contracteren voor de verzekerden het meest ernstig is (dus wanneer niet alle zorgaanbieders in de regio zijn gecontracteerd en ze verder moeten reizen voor het dichtstbijzijnde ziekenhuis). Dus wanneer verzekerden geen concrete nadelen ondervinden van selectief contracteren, beïnvloedt het wel of niet geven van informatie de mening van verzekerden over selectief contracteren niet significant. Het geven van informatie over het selecteren van zorgaanbieders kan echter het negatieve gevoel over selectief contracteren niet geheel wegnemen bij de groep die negatieve gevolgen ervaart. Dus verzekerden zover krijgen dat ze selectief contracteren accepteren blijft een lastige opgave.

\section{Onderzoeksvraag 6:}

Is het mogelijk om verzekerden naar geprefereerde zorgaanbieders te sturen door ze vrijblijvend advies aan te bieden bij het kiezen van een zorgaanbieder wanneer ze bellen met de klantenservice en wat is het effect hiervan op hun tevredenheid met de klantenservice?

De scoping review heeft laten zien dat, hoewel niet zo effectief als negatieve financiële prikkels, het ook mogelijk is verzekerden te sturen met zachte prikkels. Dit zijn bijvoorbeeld kwaliteitsprikkels zoals het aanbieden van verlengde openingstijden of een gratis gezondheidscheck bij geprefereerde zorgaanbieders. Als kwaliteitsprikkels geaccepteerd zijn door verzekerden zou het belangrijk kunnen zijn dit verder te onderzoeken. De Nederlandse zorgverzekeraar coöperatie VGZ heeft een nieuwe zachte sturingsmethode uitgeprobeerd waarbij verzekerden die de klantenservice belden gratis advies werd aangeboden bij het kiezen van een zorgaanbieder. Bijvoorbeeld wanneer verzekerden de klantenservice belden over vergoeding van fysiotherapie. De medewerkers waren geïnstrueerd om aan de verzekerde te vragen of zij advies zouden willen bij het kiezen van een 
fysiotherapeut. We hebben de effectiviteit van deze sturingsmethode onderzocht. Onze studie liet zien dat deze methode effectief is, omdat $45 \%$ van de verzekerden die op deze manier een advies kreeg en ook echt een fysiotherapeut heeft bezocht na het gesprek, naar de geadviseerde fysiotherapeut is gegaan. Daarnaast hebben we verzekerden gevraagd wat zij vonden van deze methode. Verzekerden waren positief over het aanbieden van advies door de medewerker van de klantenservice en de cijfers voor de dienstverlening van de klantenservice was hoger voor het team dat deze sturingsmethode heeft toegepast ten opzichte van andere vergelijkbare teams die dit niet deden. Dit lijkt de resultaten van onderzoeksvraag 4 tegen te spreken, waar wordt gevonden dat zorgverzekeraars niet worden gezien als belangrijke bron van informatie over kwaliteit van zorg. Echter, het is mogelijk dat verzekerden niet geneigd zijn deze informatie te zoeken bij hun zorgverzekeraar, maar wanneer een medewerker van hun zorgverzekeraar deze informatie aanbiedt, zij hier wel voor open staan. Dit laat zien dat de manier waarop informatie wordt aangeboden ook belangrijk is voor de acceptatie ervan.

\section{Methodologische reflectie}

De sterke en zwakke punten van elke studie zijn al besproken. In dit deel worden alleen de belangrijkste punten genoemd.

- In drie studies hebben we een vragenlijst verstuurd naar leden van het Verzekerdenpanel. Het gebruik van een panel zorgt meestal voor een hoge respons, onder een selectie van de populatie. Leden van het Verzekerdenpanel zijn 18 jaar of ouder en verzekerd bij een van de zorgverzekeringslabels die vallen onder coöperatie VGZ. De leden van het panel zijn gemiddeld ouder dan de gemiddelde Nederlandse populatie van 18 jaar en ouder. De leden zijn in eerste instantie geworven door een uitnodiging die zij kregen via hun zorgverzekeraar. Inmiddels is de wervingsmethode veranderd en worden verzekerden uitgenodigd via een vragenlijst die zij krijgen van hun zorgverzekeraar nadat zij contact hebben gehad met de klantenservice. Het is waarschijnlijk dat verzekerden die weinig te maken hebben met hun zorgverzekeraar, bijvoorbeeld omdat zij bijna nooit zorg gebruiken, minder kans hebben om uitgenodigd te worden voor deelname aan het Verzekerdenpanel. Als zij wel uitgenodigd worden is de kans waarschijnlijk ook kleiner dat zij deelnemen, omdat zij minder affiniteit hebben met het onderwerp. Aan de andere kant zouden mensen die in heel slechte gezondheid verkeren zich waarschijnlijk ook niet willen committeren aan een panel. Hierdoor is het Verzekerdenpanel niet representatief voor de Nederlandse verzekerden- 
populatie. In de drie studies waar we leden van het Verzekerdenpanel hebben bevraagd hebben wij echter associaties onderzocht. Hierdoor verwachten wij dat de representativiteit de onderzoeksresultaten niet heeft beïnvloed.

- We hebben vragenlijsten gebruikt om data te verzamelen. Dit betekent dat respondenten met name zijn bevraagd over hypothetische situaties. Bijvoorbeeld in hoofdstuk 3 hebben we respondenten laten kiezen tussen 2 of 3 verschillende zorgverzekeringen. In werkelijkheid zijn er veel meer mogelijkheden om uit kiezen. Ook in hoofdstuk 6 worden respondenten geconfronteerd met een hypothetische situatie. Hier worden de respondenten verdeeld in 4 groepen en aan iedere groep werd een andere situatie beschreven. Deze methoden zijn zeer geschikt om onze hypotheses te testen, maar het is onbekend hoe verzekerden zich gedragen in een echte situatie, met meer keuzemogelijkheden, meer en onduidelijke informatie en een status quo bias. Om dit probleem op te lossen, zouden natuurlijke keuze situaties moeten worden bestudeerd. Bijvoorbeeld wanneer verzekerden die een collectieve zorgverzekering hebben via hun werkgever van baan wisselen. Zij moeten dan een nieuwe zorgverzekering kiezen. Dit soort situaties zouden kunnen worden bestudeerd om te ontdekken hoe deze keuzes echt worden gemaakt en of verschillende groepen op een verschillende manier kiezen.

\section{Beleidsimplicaties}

De bevindingen in dit proefschrift leiden tot verschillende implicaties voor beleid en de praktijk. Bevindingen tonen aan dat beperkingen in de vrijheid om te kiezen voor een zorgaanbieder door negatieve financiële prikkels niet wordt geaccepteerd door verzekerden. Dit bevestigt ervaringen in de Verenigde Staten, waar een managed care backlash, een collectieve boosheid tegen het zorgstelsel, ontstond [8]. Niet veel verzekerden kiezen restrictieve zorgverzekeringen en we hebben gevonden dat met name oudere mensen en mensen in slechtere gezondheid minder geneigd zijn te kiezen voor een restrictieve zorgverzekering. We vonden dat vertrouwen in de zorgverzekeraar een belangrijke rol speelt bij de acceptatie van selectief contracteren. Echter, vertrouwen in zorgverzekeraars is vrij laag. Daarom is het belangrijk dat verzekeraars investeren in het verbeteren van hun relatie met hun verzekerden. Het is bekend dat vertrouwen langzaam groeit, maar dat het positief beïnvloed kan worden door het verbeteren van elementen van functionele en technische kwaliteit [9]. Functionele kwaliteit is de manier waarop een service wordt verleend, bijvoorbeeld de vriendelijkheid van de medewerkers. Technische kwaliteit gaat meer over de uitkomst, zoals het op tijd betalen van nota's. Deze aspecten zijn 
relatief gemakkelijk te verbeteren door zorgverzekeraars. Om vertrouwen verder te verbeteren is het belangrijk dat de verzekerde weet wat de zorgverzekeraar gaat doen [10]. Zorgverzekeraars moeten hun verzekerden overtuigen van hun motieven om goede kwaliteit zorg in te kopen voor hen. Daarnaast zou het gebrek aan vertrouwen kunnen worden opgelost door het beschikbaar maken van objectieve kwaliteitsinformatie over zorgaanbieders [5]. Met deze informatie zouden zorgverzekeraars zorgaanbieders kunnen contracteren gebaseerd op kwaliteit van zorg en zouden ze hun verzekerden objectieve informatie over kwaliteit van zorg kunnen geven, wat hun geloofwaardigheid vergroot.

Verzekerden in slechte gezondheid of ouderen nemen een groter risico wanneer zij kiezen voor een restrictieve zorgverzekering, omdat zij meer kans hebben om zorg nodig te hebben in de nabije toekomst. Zij hebben daarom meer kans dat zij zouden moeten wisselen van zorgaanbieder, een langere reistijd krijgen of geconfronteerd worden met extra kosten wanneer zij een niet-gecontracteerde zorgaanbieder bezoeken. Echter, afhankelijk van waar zij precies wonen, zal de reistijd niet altijd toenemen en hun vertrouwde zorgaanbieder zou een van de gecontracteerde zorgaanbieders kunnen zijn. Daarom is het heel belangrijk dat verzekerden precies weten wat selectief contracteren inhoudt en wat de precieze consequenties voor hen zijn. Daarnaast vonden we dat als selectief contracteren negatieve gevolgen heeft voor hen, namelijk het moeten wisselen van zorgaanbieder en een langere reistijd, kan het geven van informatie over het selectieproces van zorgaanbieders de negatieve mening van verzekerden ten opzichte van selectief contracteren verminderen.

Echter, zelfs wanneer het vertrouwen in de zorgverzekeraar hoog is, is de acceptatie van selectief contracteren nog steeds relatief laag. Ook het geven van informatie over het selectieproces kan de negatieve houding van verzekerden niet tenietdoen. De vraag is dan, zouden zorgverzekeraars selectief moeten contracteren of zijn er andere manieren om concurrentie tussen zorgaanbieders te bevorderen? We hebben gevonden dat het aanwijzen van geprefereerde zorgaanbieders en het sturen van verzekerden naar deze zorgaanbieders door ze advies aan te bieden wanneer ze de klantenservice bellen effectief kan zijn. Daarnaast kan het bijdragen aan een positieve beoordeling van de klantenservice. Dit is een belangrijk resultaat omdat dit wijst op de potentie van sturingsmethoden die meer positief worden ervaren. Daarnaast wordt de keuzevrijheid van verzekerden behouden. Dit sluit aan bij het overheidsbeleid, omdat de Eerste Kamer de wijziging van artikel 13 van de 
Zorgverzekeringswet heeft tegengehouden. Deze wijziging moest ervoor zorgen dat zorgverzekeraars zelf kunnen bepalen hoeveel ze vergoeden wanneer verzekerden naar een niet-gecontracteerde zorgaanbieder gaan. De Eerste Kamer vond dat dit de keuzevrijheid van verzekerden te veel zou beperken.

De onderzochte manier van zachte zorgsturing bereikt niet alle verzekerden, omdat verzekerden eerst zelf contact moeten opnemen met de klantenservice. Daarnaast volgen niet alle verzekerden die een advies kregen dit advies op. Daarom is het belangrijk dat andere ideeën voor zachte zorgsturing worden ontwikkeld en onderzocht. Bijvoorbeeld, het is nu onderzocht voor het telefonisch aanbieden van informatie, misschien zou het ook kunnen werken om actief mensen informatie over kwaliteit van zorgaanbieders aan te bieden wanneer zij de website bezoeken of in persoonlijke nieuwsbrieven. Misschien zou dat alleen al helpen om verzekerden te laten weten dat hun zorgverzekeraar gezien kan worden als een belangrijke informatiebron over kwaliteit van zorg. Ook zou de huidige methode van aanbieden van advies over de keuze van een fysiotherapeut wanneer verzekerden de klantenservice bellen, kunnen worden uitgebreid naar meer typen zorgaanbieders. Omdat status quo bias een belangrijk obstakel is bij het sturen van verzekerden naar geprefereerde zorgaanbieders [11], is het te verwachten dat dit het best zal werken voor ziekenhuizen en het minst goed voor huisartsen en tandartsen, omdat bijna alle Nederlanders een vaste huisarts en tandarts hebben. Ook zouden chronisch zieken moeilijk te sturen kunnen zijn, omdat zij vaak ook al een vaste arts hebben bij een ziekenhuis. Dit laat zien dat de timing van zorgsturing ook erg belangrijk is voor het succes ervan.

De resultaten van dit proefschrift laten zien dat het moeilijk is om selectief contracteren te implementeren, omdat verzekerden erg negatief zijn over beperkingen in hun keuzevrijheid. Een alternatief voor zorgverzekeraars is het aanwijzen van geprefereerde zorgaanbieders en het gebruiken van zachte zorgsturingsmethoden, zoals het aanbieden van advies bij het kiezen van een zorgaanbieder. Dit soort sturingsmethoden zijn minder effectief vergeleken met negatieve financiële prikkels, bijvoorbeeld omdat niet alle verzekerden worden bereikt en omdat verzekerden vrij zijn om het advies wel of niet op te volgen. De methode die wij hebben geëvalueerd was echter wel succesvol, aangezien $45 \%$ van de mensen die een advies kregen en daarna naar een fysiotherapeut zijn gegaan, het advies hebben opgevolgd. Hierdoor is het waarschijnlijk dat zorgaanbieders nog steeds een prikkel krijgen om met elkaar te concurreren om geprefereerde, en dus 
geadviseerde, zorgaanbieder te worden, omdat dit hen meer patiënten kan opleveren. Dit zou echter nog onderzocht moeten worden.

\section{Wetenschappelijke implicaties}

Naast de beleidsimplicaties draagt dit proefschrift ook bij aan de wetenschappelijke kennis. Dit proefschrift heeft kennis gegenereerd over de implementatie van selectief contracteren in een zorgstelsel gebaseerd op gereguleerde concurrentie. We hebben specifiek gefocust op de acceptatie van selectief contracteren door verzekerden. We hebben gevonden dat specifieke groepen meer geneigd zijn een restrictieve zorgverzekering te kiezen, namelijk gezondere en jongere verzekerden. Deze bevinding is bevestigd door een onderzoek van Determan et al. die een keuze experiment hebben uitgevoerd om de keuze van verzekerden voor zorgverzekeringen te onderzoeken [12]. Onze bevinding dat vertrouwen in de zorgverzekeraar een belangrijke rol speelt in de acceptatie van selectief contracteren bevestigt suggesties uit eerder onderzoek, waar deze relatie was gesuggereerd, maar niet eerder getoetst $[8,13-15]$. We hebben laten zien dat het geven van informatie over waarom bepaalde zorgaanbieders niet gecontracteerd zijn de acceptatie van selectief contracteren verbetert. Dit bevestigt dat de theorie vanuit de rechtvaardigheidsliteratuur, die zegt dat procedurele rechtvaardigheid (het geven van informatie over procedures die hebben geleid tot een situatie) belangrijk is voor de acceptatie van een situatie, met name wanneer deze situatie ongunstig is $[6,16]$, ook toegepast kan worden in gezondheidswetenschappen. Verder heeft onze studie naar een nieuwe zachte zorgsturingsmethode, namelijk het aanbieden van advies aan verzekerden die de klantenservice bellen, een bijdrage geleverd aan de literatuur op dit gebied. Er zijn niet veel zachte zorgsturingsmethoden geëvalueerd in de literatuur. Boonen et al. hebben sturingsmethoden onderzocht en vonden dat negatieve financiële prikkels meer effectief zijn vergeleken met positieve financiële prikkels [11]. Ook vonden zij dat kwaliteitsprikkels effectief kunnen zijn om mensen naar geprefereerde zorgaanbieders te sturen. Kwaliteitsprikkels die zij onderzochten waren extra openingstijden, internet service en de aanwezigheid van een kwaliteitscertificaat [11]. Donelan et al. onderzochten een vergelijkbare methode. Een werkgever bood een telefonische service aan om mensen te helpen bij het kiezen van een zorgaanbieder [17]. Dit is echter anders dan onze sturingsmethode, omdat hier de verzekerde zelf moet bellen om te vragen om advies en bij onze methode advies vrijblijvend werd aangeboden wanneer verzekerden voor een andere vraag de klantenservice belden. Ook werd het door de werkgever aangeboden, terwijl bij onze methode de 
zorgverzekeraar deze service aanbiedt. Aangezien zorgverzekeraars last hebben van een vertrouwensprobleem, was het verrassend dat deze sturingsmethode werkte. De reden hiervoor kan zijn dat de medewerker, die eerst de vraag van de verzekerde heeft beantwoord en daarna advies aanbiedt, meer wordt vertrouwd dan de zorgverzekeraar zelf. Dit is waarschijnlijk omdat vertrouwen in een organisatie heel anders en meestal lager is dan vertrouwen in een persoon [18].

Over het algemeen draag dit proefschrift bij aan de kennis over het implementeren van selectief contracteren in een zorgstelsel dat is gebaseerd op gereguleerde concurrentie. Dit is relevant voor alle landen waar een zorgstelsel dat is gebaseerd op gereguleerde concurrentie is ingevoerd of zal worden ingevoerd in de toekomst.

\section{Suggesties voor vervolgonderzoek}

Ondanks dat dit proefschrift heeft bijgedragen aan de literatuur over het sturen van verzekerden naar gecontracteerde of geprefereerde zorgaanbieders in een zorgstelsel dat is gebaseerd op gereguleerde concurrentie, heeft ons onderzoek ook een aantal verdere vragen opgeleverd en daarmee een aantal aanbevelingen voor verder onderzoek:

- Omdat we hebben gevonden dat vertrouwen in de zorgverzekeraar een belangrijke rol speelt in de acceptatie van selectief contracteren, ontstond de vraag hoe zorgverzekeraars aan hun imago kunnen werken zodat verzekerden hen meer vertrouwen. Vervolgonderzoek zou zich moeten richten op hoe vertrouwen in zorgverzekeraars kan worden opgebouwd.

- Vervolgonderzoek zou ook moeten kijken naar de relatie tussen vertrouwen in de zorgverzekeraar en bereidheid om advies van de zorgverzekeraar op te volgen. Als deze relatie sterk is, zou dit bijdragen aan het bewijs voor het belang van het opbouwen van vertrouwen in de zorgverzekeraar.

- We hebben gevonden dat jongere en gezondere verzekerden vaker een restrictieve zorgverzekering kiezen dan ouderen en ongezondere verzekerden. Ondanks dat dit onze onderzoeksvraag heeft beantwoord, zou het daarnaast interessant zijn om te weten hoe veel goedkoper een restrictieve zorgverzekering zou moeten zijn om verzekerden die regelmatig zorg gebruiken een dergelijke zorgverzekering te laten kiezen. Of misschien zouden zorgverzekeringen met vrije keuze duurder moeten zijn. Determan et al. hebben een experiment uitgevoerd om dit te onderzoeken [12]. Zij vonden dat voor de helft van hun populatie het heel onwaarschijnlijk was dat ze een restrictieve zorgverzekering zouden kiezen, maar de jongere, gezondere en rijkere 
verzekerden zouden meer geneigd zijn een dergelijk zorgverzekering te kiezen voor een maandelijkse premiekorting van 15 Euro. Echter, in hun experiment hebben ze reistijd naar de dichtstbijzijnde zorgaanbieder niet meegenomen. Ook kwaliteit van zorg was niet opgenomen in het experiment. Dit zou heel belangrijk kunnen zijn, met name voor ouderen en ongezondere verzekerden, omdat zij meer zorg gebruiken. Daarnaast is het idee van het zorgstelsel ook dat restrictieve zorgverzekeringen betere kwaliteit van zorg leveren, omdat de zorgaanbieders zijn geselecteerd op basis van prijs en kwaliteit.

- Uit ons onderzoek over wat de acceptatie van selectief contracteren beïnvloedt bleek dat naast vertrouwen en het geven van informatie, er meer aspecten moeten zijn die dit beïnvloeden. We hebben besproken dat autonomie een rol zou kunnen spelen in de afkeer van verzekerden ten opzichte van selectief contracteren. Dit paste niet binnen het doel van ons onderzoek, omdat wij ons hebben gericht op factoren die relevant zijn voor de praktijk en autonomie is iets dat haast niet te beïnvloeden is. Het zou echter wel interessant zijn om deze hypothese te onderzoeken en om te zien in hoeverre dit de negatieve houding bepaald die verzekerden hebben ten opzichte van selectief contracteren.

- We lieten zien dat informatie over waarom bepaalde zorgaanbieders niet zijn gecontracteerd het negatieve gevoel van verzekerden over selectief contracteren deels kan wegnemen. We verwachten echter dat de hoeveelheid informatie en de inhoud van de informatie dit resultaat zouden kunnen beïnvloeden. Om maatregelen te implementeren gebaseerd op dit resultaat is het belangrijk om verder te onderzoeken wat er gebeurt met de resultaten wanneer de informatie uitgebreider is, andere informatie wordt gegeven of wanneer de informatie anders is gepresenteerd. Hoeveel informatie is genoeg en welke informatie is het meest belangrijk voor verzekerden?

- We hebben gevonden dat het sturen van verzekerden naar geprefereerde zorgaanbieders door ze advies aan te bieden wanneer ze bellen naar de klantenservice effectief is voor het sturen van verzekerden naar geprefereerde fysiotherapeuten. De vraag is of deze methode ook zal werken voor het sturen naar andere typen zorgaanbieders. Boonen et al. hebben gevonden dat de mate waarin verzekerden gestuurd kunnen worden afhangt van het type zorgaanbieder [11]. Daarom zou deze sturingsmethode ook getest moeten worden voor andere typen zorgaanbieders. We verwachten dat deze methode goed zou kunnen werken voor ziekenhuiszorg, maar het zou heel lastig kunnen zijn voor huisartsen en tandartsen, omdat de meeste verzekerden al een vaste huisarts of tandarts hebben. 
- We hebben gevonden dat de nieuwe sturingsmethode succesvol was. Echter, niet alle verzekerden worden bereikt met deze methode. Veel verzekerden kiezen zelf een zorgaanbieder zonder eerst contact op te nemen met hun zorgverzekeraar. Daarom zouden er meer zachte zorgsturingsmethoden moeten worden ontwikkeld en bestudeerd. Er zijn ook andere vragen die beantwoord zouden moeten worden. Bijvoorbeeld, zijn bepaalde zachte sturingsmethoden meer effectief in specifieke groepen? Het aanbieden van advies wanneer verzekerden bellen naar de klantenservice is wellicht meer effectief voor ouderen die meer zorg gebruiken en daardoor meer contact hebben met hun zorgverzekeraar, terwijl jongere verzekerden misschien meer geïnteresseerd zijn in kwaliteitsinformatie over zorgaanbieders wanneer zij dit ontvangen via e-mail of in een App. Het zou interessant zijn om dit soort ideeën met verzekerden zelf te bespreken, bijvoorbeeld in een focus groep en te toetsten in een vragenlijstonderzoek.

- De effecten van zachte zorgsturing zouden op grotere schaal moeten worden onderzocht om uit te zoeken of deze methoden bijdragen aan de doelen van het zorgstelsel. Is de zorgverzekeraar in staat om grotere kortingen te bedingen bij geprefereerde zorgaanbieders door het succesvol sturen van verzekerden naar deze aanbieders? Dit is alleen mogelijk wanneer deze sturingsmethoden zijn geïmplementeerd op grote schaal en wanneer zorgaanbieder zich hiervan bewust zijn.

$\mathrm{Er}$ is ook een aantal hypotheses die wij niet optimaal hebben kunnen toetsen. Vervolgonderzoek zou deze opnieuw moeten onderzoeken met geoptimaliseerde methoden:

- Van de nieuwe zachte zorgsturingsmethode waar verzekerden advies werd aangeboden wanneer ze belden met de klantenservice was ook verwacht dat het een positief effect zou hebben op de beoordeling van de kwaliteit van de klantenservice. We waren niet in staat om dit op een optimale manier te testen. In een ideale situatie zou een RCT (gerandomiseerd onderzoek met controlegroep) gedaan moeten worden, waar tenminste twee klantenservice teams, zo gelijk aan elkaar als mogelijk, dezelfde hoeveelheid aandacht en training krijgen terwijl de helft van hen de zorgsturingsmethode uitvoert en de andere helft niet. Gedegen voor- en nametingen van de kwaliteit van de service moeten worden gedaan en geen andere veranderingen moeten worden doorgevoerd tijdens de studieperiode. 
- Bij de meeste studies is gebruik gemaakt van een vragenlijst. Zoals eerder is benoemd in de methodologische reflectie, is deze methode goed om onze hypotheses te toetsen. Het is echter onduidelijk hoe verzekerden zich zouden gedragen in echte keuze situaties. Voor vervolgonderzoek zouden we daarom voorstellen om keuze situaties in het echte leven te bestuderen. Dit is moeilijk om te doen, maar zou bijvoorbeeld mogelijk zijn wanneer een werkgever het collectieve contract met een zorgverzekeraar opzegt.

\section{Conclusie}

De onderzoeksvraag in dit proefschrift was: Hoe kunnen we de acceptatie van selectief contracteren en het sturen van verzekerden naar gecontracteerde zorgaanbieders verklaren?

Er zijn verschillende aspecten die de acceptatie (of het niet accepteren) van selectief contracteren door verzekerden zouden kunnen verklaren. Selectief contracteren is een negatieve ontwikkelen in de ogen van verzekerden, omdat het hun keuzevrijheid voor zorgaanbieders beperkt. Beperkingen in keuzevrijheid voor zorgaanbieders zouden kunnen leiden tot een langere reistijd naar de dichtstbijzijnde zorgaanbieder en als verzekerden naar een niet-gecontracteerde zorgaanbieder gaan kan dit leiden tot extra kosten. Een voordeel voor verzekerden is dat restrictieve zorgverzekeringen goedkoper zijn vergeleken met zorgverzekeringen die vrije keuze bieden. Daarnaast is het ook de bedoeling dat zorgverzekeraars zorgaanbieders selecteren op basis van prijs en kwaliteit. Daarom zou kwaliteit van zorg beter moeten zijn bij de restrictieve zorgverzekeringen. Eigenschappen van verzekerden, zoals leeftijd en gezondheid spelen een rol in de acceptatie van selectief contracteren, aangezien jongeren meer gevoelig zijn voor prijs en gezondere mensen niet verwachten zorg nodig te hebben in de nabije toekomst, wat betekent dat zij een kleiner risico nemen wanneer zij een restrictieve zorgverzekering kiezen vergeleken met verzekerden die vaker zorg nodig hebben. Daarnaast lieten de resultaten zien dat vertrouwen in de zorgverzekeraar een belangrijke rol speelt bij de acceptatie van selectief contracteren. Vertrouwen in zorgverzekeraars is in het algemeen redelijk laag. Dit zou kunnen verklaren waarom verzekerden zo negatief zijn over selectief contracteren. Verzekerden vertrouwen er niet op dat hun zorgverzekeraar het beste met hen voor heeft en goede kwaliteit zorg voor hen zal inkopen. Het geven van informatie aan verzekerden over waarom 
bepaalde zorgaanbieders niet gecontracteerd zijn is ook belangrijk voor de acceptatie van selectief contracteren. Echter, zelfs wanneer verzekerden vertrouwen hebben in hun zorgverzekeraar en wanneer informatie over het contracteren van zorgaanbieders is gegeven, zijn verzekerden nog steeds negatief over financiële prikkels en beperkingen in hun keuzevrijheid. Het is mogelijk dat factoren zoals aversie tegen verlies en vermindering van de autonomie een rol spelen hierin. Aversie tegen verlies, omdat in het zorgstelsel van voor 2006 verzekerden keuzevrijheid hadden. Het implementeren van selectief contracteren neemt die keuzevrijheid weg. Autonomie is een belangrijke waarde voor mensen. Wanneer de zorgverzekeraar zich gaat bemoeien met de keuzen voor een zorgaanbieder zouden verzekerden zich beperkt kunnen voelen in hun autonomie. Deze psychologische aspecten zijn echter moeilijk te beïnvloeden in de praktijk. Daarnaast zijn beperkingen in keuzevrijheid ook niet gewenst door de overheid, aangezien de Eerste Kamer de wijziging van artikel 13 van de Zorgverzekeringswet heeft geblokkeerd die inhield dat zorgverzekeraars zelf mogen bepalen hoeveel ze vergoeden wanneer verzekerden naar een niet-gecontracteerde zorgaanbieder gaan, omdat dit de keuzevrijheid te veel zou beperken.

Daarom is het een logische stap om andere methoden te onderzoeken om verzekerden naar geprefereerde zorgaanbieders te sturen, zonder dat de keuzevrijheid van verzekerden wordt beperkt. Hoofdstuk 7 van dit proefschrift laat zien dat het mogelijk is om verzekerden naar geprefereerde zorgaanbieders te sturen door hen advies aan te bieden bij het kiezen van een zorgaanbieder. Hierbij werd ook uitgelegd waarom sommige zorgaanbieders beter werden gevonden dan anderen. Op deze manier is de keuzevrijheid niet beperkt, aangezien verzekerden zelf kunnen kiezen of ze het advies opvolgen of niet. Als ze kiezen het advies niet op te volgen zit daar geen negatieve financiële consequentie aan vast. Als dit type zorgsturing effectief is zullen zorgaanbieders waarschijnlijk nog steeds een prikkel krijgen om met elkaar te concurreren om een geprefereerde, en dus geadviseerde, zorgaanbieder te zijn, aangezien dit leidt tot een hoger inkomen. Op deze manier zouden alsnog de doelen van het huidige zorgstelsel, namelijk verbeteren van kwaliteit van zorg terwijl de kosten worden beheerst, kunnen worden behaald. Dit zou echter moeten worden geëvalueerd in de toekomst. Deze manier van sturen bereikt echter niet alle verzekerden. Veel verzekerden kiezen een zorgaanbieder zonder dat ze eerst contact opnemen met hun zorgverzekeraar. Daarom is het, in het kader van een zorgstelsel gebaseerd op gereguleerde concurrentie, belangrijk dat meer van dit soort zachte sturingsmethoden worden ontwikkeld en bestudeerd. 


\section{Referenties}

1. Sorensen AT: Insurer-hospital bargaining: negotiated discounts in post-deregulation Conneticut. Journal of Industrial Economics 2003, 51(4):469-490.

2. Wu VY: Managed care's price bargaining with hospitals. Journal of Health Economics 2009, 28:350-360. Fig. 1: Questionnaire scheme.

3. Schut FT, Van de Ven WPMM: Effects of purchaser competition in the Dutch health system: is the glass half full of half empty? Health Economics, Policy and Law 2011, 6:109-123.

4. Van de Ven WPMM, Schut FT: Managed competition in the Netherlands: still work-inprogress. Health Economics 2009, 18:253-255.

5. Boonen LHHM, Schut FT: Preferred providers and the credible commitment problem in health insurance: first experiences with the implementation of managed competition in the Dutch health care system. Health Economics, Policy and Law 2011, 6:219-235.

6. Greenberg J: Employee theft as a reaction to underpayment inequity: the hidden cost of pay cuts. Journal of Applied Psychology 1990, 75(5):561-568.

7. Lind EA, Tyler T: The social psychology of procedural justice. New York: Plenum Press; 1988.

8. Miller $\mathrm{NH}$ : Insurer-provider integration, credible commitment, and managed-care acklash. Journal of Health Economics 2006, 25:861-876.

9. Wendel S, de Jong JD, Curfs EC: Consumer evaluation of complaint handling in the Dutch health insurance market. BMC Health Services Research 2011, 11(doi:10.1186/1472-6963-11-310).

10. Goold SD: Trust and the ethics of health care institutions. The Hastings Center Report 2001, 31(6):26-33.

11. Boonen LHHM, Donkers B, Schut FT: Channeling consumers to preferred providers and the impact of status quo bias: does type of provider matter? Health Services Research 2011.

12. Determan D, Lambooij MS, de Bekker-Grob EW, Hayen AP, Varkevisser M, Schut FT, de Wit GA: What health plans do people prefer? The trade off between premium and provider choice. Social Science \& Medicine 2016, 165:10-18.

13. Boonen LHHM, Schut FT: Zorgverzekeraars kampen met vertrouwensprobleem (Health insurers face problems with trust). Economisch Statistische Berichten 2009, 94(4572):678-681.

14. Gawande AA, Blendon RJ, Brodie M, Benson JM, Levitt L, Hugick L: Does dissatisfaction with health plans stem from having no choices? Health Affairs 1998, 17(5):184-194. 
15. Heinemann S, Leiber S, Gress S: Managed competition in the Netherlands - A qualitative study. Health Policy 2013, 109:113-121.

16. Folger R, Bies RJ: Managerial responsibilities ans procedural justice. Employee Responsibilities and Rights Journal 1989, 2(2):79-90.

17. Donelan K, Rao SR, Rogers RS, Mailhot JR, Galvin R: Experience with health coachmediated physician referral in an employed insured population. Journal of General Internal Medicine 2010, 25(10):1071-1077.

18. Hall MA, Dugan E, Zheng B, Mishra AK: Trust in physicians and medical institutions: what is it, can it be measured, and does it matter? The Milbank Quarterly 2001, 79(4):613639. 
Valorisation 
This thesis explains why enrolees are very negative about selective contracting in a health care system based on managed competition and how this may be overcome. This is important for a successful implementation of managed competition and to reach the intended goals of the health care system, because selective contracting and channelling enrolees to contracted care providers is supposed to contribute to increasing quality of care and containing the costs in the health care system by promoting competition between care providers. The results of this thesis are very relevant for health care policy and practice in the Netherlands, but also for other countries where a system of managed competition is implemented or will be implemented in the future. Results of this thesis are also relevant for health insurance companies as well as for enrolees.

For health care policy it is important that in this thesis we showed that some enrolees are more open to selective contracting than others. However, enrolees who use most care, the elderly and enrolees in poorer health are least likely to choose a restrictive health plan. Furthermore, we found that acceptance of selective contracting is higher if enrolees have more trust in their health insurer and when they are informed about the reasons why certain care providers are not contracted or preferred over others. Results were sent to the Ministry of Health, Welfare and Sport and have also been presented to and discussed with policy makers at the Ministry. Results have also been presented to and discussed with an international audience at several international conferences and have been published in international and national journals.

For health insurers concrete recommendations were made, for instance that health insurers should be clear to enrolees about the consequences of selective contracting and they should give information to enrolees about why certain care providers are not contracted or why certain care providers are preferred over others. This reduces the feeling of taking a risk for enrolees when they choose a restrictive health plan and the negative attitude enrolees have about selective contracting. Furthermore, health insurers should focus on increasing trust in their relationship with their enrolees, since trust plays an important role in the acceptance of selective contracting. Another important recommendation for health insurers is to focus more on positive or soft channelling methods to channel their enrolees to preferred care providers. We found that channelling enrolees to preferred providers by offering them advice on care provider choice when they call customer service can be successful. In addition, this channelling method may potentially lead to higher 
service quality scores from enrolees. In our study, this method was only applied for channelling enrolees to preferred physiotherapists. Therefore, this method should be further tested for other care provider types. Also, not all enrolees are reached with this method, since enrolees are only offered advice when they call customer service and not all enrolees first call their health insurer before they see a care provider. Thus, it is important for health insurers to find other ways to get the advice on quality of care providers to enrolees in a way enrolees appreciate. The latter method was applied by Dutch health insurance cooperative VGZ and the researcher was involved in the development of the method. The results of the evaluation performed for this thesis were presented and discussed at the health insurer. As a result, VGZ is working on a strategy to expand this channelling strategy to the other customer service teams and to expand it to other care provider types.

The research for this $\mathrm{PhD}$-thesis was conducted within the $\mathrm{AOZ}$, the Academic Workplace for Health insurers, a cooperation between VGZ, NIVEL and the Open University. In the AOZ co-creating knowledge by conducting practice based scientific research is a central element. Through continuous cooperation between the different parties throughout the research process, knowledge can be better applied. During her PhD track, the researcher has been employed at VGZ for two months. This was very helpful for the study, since it helped to see what kind of issues are currently important for health insurers in order to make the research even more relevant for practice.

For enrolees the results are important, since health insurers use these results to contribute to improve quality of care and reduce costs in health care in a way that is acceptable to enrolees. Members of the Insurance Panel were informed through newsletters about the results and how the health insurer changed its policy based on the results.

So far, no research had been conducted to explain the acceptance of selective contracting of enrolees. Literature did point at trust as an important predictor for acceptance of selective contracting, however, this was not yet tested [1-5]. Furthermore, in justice literature it was found that procedural justice, (i.e. providing information on procedures that led to a situation) is important for acceptance of a situation, especially when this situation is unfavourable $[6,7]$. Our study confirmed this and showed that this mechanism is also applicable in health sciences. Ways to channel enrolees to contracted care providers were researched before, however, 
the method of offering enrolees advice on care provider choice when they call customer service is new. A study by Donelan et al. is similar, however, they study a telephone service of the employer that offers advice on care provider choice [8]. This is different from the method we evaluated, since in our case, the health insurer provided the advice and the advice was offered to enrolees who initially did not call for advice, but for an other question related to physiotherapy. Therefore, this is an important contribution to the literature. Furthermore, we are not aware of any other health insurers in the Netherlands who have tried this method of channelling enrolees to preferred providers before.

Studies in this thesis were conducted in cooperation with Dutch health insurance cooperative VGZ. They, as well as other health insurance companies, can use the results of this thesis for determining their policy on contracting care providers and their channelling strategies. Implementing successful channelling strategies that enrolees accept can yield money, because they improve the bargaining position of health insurers in negotiations with care providers. Furthermore, they are likely to be able to purchase larger volumes of care at preferred care providers which could also lead to greater discounts [9]. In addition, by channelling enrolees to care providers that deliver care sensibly and effectively, waste in health care can be minimized and, thus, costs can be saved. Additionally, this contributes to improving quality of care, since health insurers need to explain to their enrolees why certain care providers are preferred, which is an important incentive for them to make quality of care a priority in purchasing health care.

Furthermore, results of this thesis are relevant for the Dutch Ministry of Health, Welfare and Sport, since the government has implemented managed competition in order to create competition between care providers to reach the goals of reducing costs while improving quality of care. This thesis contributes to the knowledge on successful implementation of selective contracting in a health care system based on managed competition and, therefore, contributes to reaching the goals of the health care system. 


\section{References}

1. Boonen LHHM, Schut FT: Zorgverzekeraars kampen met vertrouwensprobleem (Health insurers face problems with trust). Economisch Statistische Berichten 2009, 94(4572):678-681.

2. Boonen LHHM, Schut FT: Preferred providers and the credible commitment problem in health insurance: first experiences with the implementation of managed competition in the Dutch health care system. Health Economics, Policy and Law 2011, 6:219-235.

3. Gawande AA, Blendon RJ, Brodie M, Benson JM, Levitt L, Hugick L: Does dissatisfaction with health plans stem from having no choices? Health Affairs 1998, 17(5):184-194.

4. Heinemann S, Leiber S, Gress S: Managed competition in the Netherlands - A qualitative study. Health Policy 2013, 109:113-121.

5. Miller $\mathrm{NH}$ : Insurer-provider integration, credible commitment, and managed-care backlash. Journal of Health Economics 2006, 25:861-876.

6. Folger R, Bies RJ: Managerial responsibilities ans procedural justice. Employee Responsibilities and Rights Journal 1989, 2(2):79-90.

7. Greenberg J: Employee theft as a reaction to underpayment inequity: the hidden cost of pay cuts. Journal of Applied Psychology 1990, 75(5):561-568.

8. Donelan K, Rao SR, Rogers RS, Mailhot JR, Galvin R: Experience with health coachmediated physician referral in an employed insured population. Journal of General Internal Medicine 2010, 25(10):1071-1077.

9. Sorensen AT: Insurer-hospital bargaining: negotiated discounts in post-deregulation Conneticut. Journal of Industrial Economics 2003, 51(4):469-490. 


\section{Dankwoord}


Als mij een jaar of zeven geleden was verteld dat ik een proefschrift zou schrijven, had ik het waarschijnlijk niet geloofd. Toch is het nu zover en ben ik heel blij dat ik het heb gedaan. Ik had dit niet kunnen doen zonder de hulp van een heleboel mensen die ik op deze plaats wil bedanken.

Allereerst wil ik mijn promotoren Judith de Jong, Peter Groenewegen en Emile Curfs bedanken. Judith, doordat jij geloofde dat ik dit kon, ging ik het zelf ook een beetje geloven. Bedankt voor je vertrouwen en je altijd scherpe en heldere commentaar. Ik heb heel veel van je geleerd. Peter, bedankt voor je hulp en altijd nuttige commentaar. Emile, Hartelijk dank voor je bijdrage aan mijn proefschrift. Ik vond het heel erg leuk door jou meer de praktijk kant van zorgverzekeraars te zien.

Daarnaast wil ik ook de leden van de leescommissie - Dirk Ruwaard, Hans Maarse, Wim Groot, Patrick Jeurissen en Ab Klink - hartelijk bedanken voor het kritisch beoordelen van mijn proefschrift en het opponeren tijdens de verdediging ervan.

Verder wil graag mijn collega's van het NIVEL die hebben bijgedragen aan de onderzoeken, analyses en de lay-out van mijn proefschrift bedanken voor de goede samenwerking en de leuke tijd die ik heb gehad. Ria, bedankt dat je altijd voor me klaarstond. Carlijn, Leanne, Dominique en Channa, bedankt voor de ondersteuning bij het versturen en verwerken van de vragenlijsten en databestanden. Lucas, bedankt voor je hulp bij de analyses. Ik wil ook graag mijn co-auteurs Sonja, Kim en Bernard bedanken voor de prettige samenwerking en hun waardevolle bijdragen aan mijn artikelen. Ria en Christel, hartelijk dank voor het opmaken van mijn proefschrift. Daarnaast wil ik ook graag de leden van het Verzekerdenpanel bedanken voor het altijd trouw invullen van alle vragenlijsten. De medewerkers van VGZ waar ik nauw mee heb samengewerkt om deze onderzoeken en met name het experiment beschreven in Hoofdstuk 7 te kunnen uitvoeren, wil ik ook hartelijk bedanken.

Verder wil ik ook graag mijn directe collega's en ex-collega's bedanken voor de leuke tijd die ik heb gehad op het NIVEL. Aafke, Lieke, Janneke, Renée, Dagmar, Anne, Kim, Sonja, mijn (ex-)kamergenootjes Daphne, Evelien en Marcia, jullie hebben mijn tijd bij het NIVEL allemaal een beetje leuker, gezelliger en leerzamer gemaakt!

Marcia en mijn zusje Leontien wil ik graag nog in het bijzonder bedanken. Super lief dat jullie mijn paranimfen willen zijn! 
Ten slotte wil ik graag mijn familie en partner Nathaniël bedanken dat zij altijd in mij hebben geloofd en mij het vertrouwen hebben gegeven dat ik nodig had om dit proefschrift af te ronden. 
Dankwoord 


\section{Curriculum Vitae}


Curriculum Vitae 
Romy Bes, born on 24-07-1987 in Beverwijk, the Netherlands, studied General Health Sciences at the Free University in Amsterdam. In 2009 she obtained a Master of Science in Policy and Organisation of Health Care. After her graduation Romy started working at the Netherlands Institute for Health Services Research (NIVEL). She worked on the project called VGZ Insurance Panel which was later called 'Choice insured - Research in cooperation between NIVEL and VGZ'. Within this project Romy worked on many different studies related to health care and health insurance. Main themes were switching health insurers, service quality of the health insurer, health care purchasing and policy, all from the perspective of enrolees. From 2013 to 2017 Romy also worked as a PhD student at the NIVEL. During this period she worked on her thesis and published several articles in scientific journals. Additionally, she presented her work at several international conferences. 


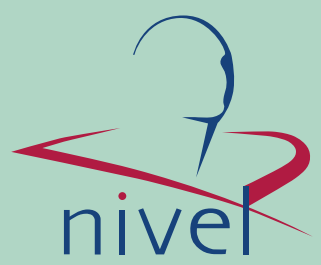

